\title{
Surveillance or surgery? A description of the factors that influence high risk premenopausal women's decisions about prophylactic oophorectomy
}

\author{
Nina Hallowell, Ian Jacobs, Martin Richards, James Mackay, Martin Gore
}

EDITOR-Approximately 5\% of cases of epithelial ovarian cancer result from an inherited susceptibility. ${ }^{1}$ Some of the genetic mutations responsible have recently been identified..$^{2-5} \mathrm{It}$ is estimated that BRCA1 carriers have a $28 \%$ lifetime risk of developing ovarian cancer, ${ }^{6}$ while $B R C A 2$ carriers have a risk of $0.4 \%$ of developing ovarian cancer at the age of 50 , which rises to $27 \%$ by the age of $70 .^{7}$ The recommended management of high risk women is either annual ovarian screening (transvaginal ultrasound) with serum CA125 measurement or bilateral prophylactic oophorectomy from the age of 35 onwards, or once childbearing is completed. ${ }^{8-11}$ As there is no evidence that ovarian screening is effective in reducing mortality, it is currently assumed that prophylactic surgery is the best form of risk management, ${ }^{12-14}$ although data suggest that intra-abdominal carcinomas may still arise following this procedure..$^{15-17}$

There is little published research on the uptake of preventative surgery in at risk women ${ }^{18}$ or mutation carriers. ${ }^{19}{ }^{20}$ However, it is generally assumed that there will be an increase in demand for prophylactic surgery, as direct mutation testing becomes more widely available. Epidemiological studies suggest that prophylactic oophorectomy may play a role in the prevention of breast cancer in high risk populations. ${ }^{21}{ }^{22}$ Therefore, there may be a case for informing women at risk of breast cancer about this option. If health professionals are to facilitate informed decision making about ovarian cancer risk management, then they need to be aware of the factors that influence women's decisions about prophylactic surgery.

There are few published data that describe the factors that influence women's decisions to undergo prophylactic surgery because of their inherited risk of developing cancer. Studies of high risk women who have undergone prophylactic mastectomy to manage their risk of breast cancer suggest that surgical decisions are influenced by subjective risk perception and cancer worry ${ }^{23}{ }^{24}$ and the death of other family members from breast cancer. ${ }^{24}$ Similarly, research involving at risk women following attendance at genetic counselling for hereditary breast/ovarian cancer suggests that attitudes to prophylactic oophorectomy are influenced by subjective risk perception, cancer worry, attitudes about the menopause, and social obligations. ${ }^{2526}$ While this research is informative, it can also be seen as problematical because (1) prophylactic surgery was a hypothetical option for some of the women in these studies, in the sense that there was no indication that they were seriously considering this form of risk management, and (2) the menopausal status of participants was not reported. With regard to the latter point, it can be speculated that, because oophorectomy results in menopause, surgical decisions may be influenced by current menopausal status. The present study of surgical decision making has tried to overcome the shortcomings of previous research on prophylactic oophorectomy, by interviewing high risk women who have previously undergone prophylactic surgery before the menopause, together with premenopausal women who have rejected this option for the present.

\section{Methods}

RECRUITMENT

The participants were recruited from the United Kingdom Cancer Coordinating Committee's Familial Ovarian Cancer Register, the Risk Advisory Clinic at St Bartholomew's Hospital, London, and the Cancer Family History Clinic at the Royal Marsden Hospital, following LREC approval for the study. Information about menopausal status before surgery or at the time of interview was available for women recruited from the UKCCCR register; for the remainder of the sample, whose menopausal status was unknown, 45 years of age was used as an arbitrary cut off point for recruitment. With the exception of one affected woman, only women who had at least two first or second degree relatives affected with ovarian (or breast) cancer were approached to participate. All women in the surgery group were recruited from the UKCCCR register, and therefore had two relatives with ovarian cancer. With the exception of two women who had no affected first degree relatives, one of whom had a paternal family history, all had a $50 \%$ chance of carrying a mutation. Sixteen women in the screening group were recruited from the register and the remaining women were recruited from the clinics mentioned above. In the case of women recruited from the clinics, only those 
Box 1

At the start of the interview the participants were asked to provide a narrative account of their experiences of cancer in their family and to describe their risk management behaviour. Thus, the structure and content of the interviews was dictated by participants' initial responses. In addition, a series of questions was also used to guide the interviews. These explored: women's decision making, attitudes about the different risk management options, knowledge of ovarian function and menopause, their understanding and recall of the information they received pre- and post-surgery, the sources of this information, and what further information they wanted or needed.

with a family history consistent with HBOC were recruited, which meant that they had at least one relative with ovarian cancer and other relatives with breast cancer. Eight women in the screening group had no affected first degree relatives, although one of these had been treated for breast cancer. Thus, 19 women in the screening group had a $50 \%$ chance of carrying a mutation and seven were at $25 \%$ risk of carrying a mutation. Of these seven women, three had a paternal family history and four a maternal history. In three of the latter cases their mother had undergone therapeutic or prophylactic oophorectomy because of the family history of ovarian cancer.

DATA COLLECTION AND ANALYSIS

In depth interviews (one to three hours) were carried out in a location of the participant's choice (see box 1). All interviews were tape recorded with consent and transcribed. Consent to analyse the tapes was also obtained at the end of the interview. A thematic analysis of the interview transcripts was undertaken using Atlas- $t i^{27}$ to manage the data. The data were initially indexed on a case by case basis, which allowed patterns and relationships between the codes to emerge within the data set. ${ }^{28}$ Between interview comparisons were also made and this enabled deviant cases to be taken into consideration. ${ }^{29}$ The resulting themes provided an all inclusive description of participants' accounts of surgical decision making. The frequencies with which some responses occurred are noted in the presentation of the results. While this should not be interpreted as indicating the relative importance of the different responses, it does provide an indication of their representativeness within this data set.

\section{Results}

The surgery group, who were invited to participate, included 33 women from the Familial Ovarian Cancer Register who had undergone surgery and met the study criteria. Ten failed to reply and $23(70 \%)$ women from 17 families were finally recruited. The screening group, who were contacted by letter, included 34 women who were currently undergoing screening and/or had attended genetic counselling. Three refused to take part and five did not respond; 26 (76\%) women from 24 families were recruited. The demographic and cancer family history variables of the participants are summarised in table 1.

Table 1 Participants' characteristics

\begin{tabular}{|c|c|c|c|c|c|c|}
\hline & \multicolumn{3}{|l|}{ Surgery } & \multicolumn{3}{|c|}{ Screening } \\
\hline & $(n=23)$ & Range & $\%$ & $(n=26)$ & Range & $\%$ \\
\hline \multicolumn{7}{|l|}{ Demographic characteristics } \\
\hline Mean age & 44.4 & $32-62$ & - & 36.5 & $28-50$ & - \\
\hline Mean age at surgery & 38.8 & $31-45$ & - & - & - & - \\
\hline Mean time since surgery $(y)$ & 5.5 & $0.5-25$ & - & - & - & - \\
\hline Single & 0 & - & - & 4 & - & 15 \\
\hline Married/living as married & 21 & - & 91 & 14 & - & 54 \\
\hline Divorced/separated & 2 & - & 9 & 8 & - & 31 \\
\hline Women with children & 23 & - & 100 & 19 & - & 73 \\
\hline Pregnant & 0 & - & - & 1 & - & 4 \\
\hline \multicolumn{7}{|l|}{ Family history of ovarian and breast cancer } \\
\hline Maternal family history & 20 & - & 87 & 20 & - & 77 \\
\hline Paternal family history & 1 & - & 4 & 5 & - & 19 \\
\hline Maternal + paternal family history & 2 & - & 9 & 1 & - & 4 \\
\hline Total number of affected relatives & 98 & $2-8$ & - & 97 & $1-9^{\star}$ & - \\
\hline Mean number of affected relatives & 4.3 & - & - & 4.0 & - & - \\
\hline Women with affected 1 st degree relatives & 21 & - & 91 & 18 & - & 69 \\
\hline Women with affected 2 nd degree relatives & 19 & - & 83 & 23 & - & 88 \\
\hline Personal history of breast cancer & - & - & - & 4 & - & 15 \\
\hline \multicolumn{7}{|l|}{ Cancer risk management history } \\
\hline Cancer genetic counselling pre-surgery & 6 & - & 26 & 19 & - & 73 \\
\hline Cancer genetic counselling post-surgery & 5 & - & 22 & - & - & - \\
\hline Ovarian screening pre-surgery & 16 & - & 70 & $26+$ & - & 96 \\
\hline Ovarian screening post-surgery & 3 & - & 13 & - & - & - \\
\hline \multicolumn{7}{|l|}{ Surgical procedures $\ddagger$} \\
\hline $\mathrm{BSO}+$ hysterectomy & 16 & - & 70 & - & - & - \\
\hline BSO only & $7 \S$ & - & 30 & - & - & - \\
\hline \multicolumn{7}{|l|}{ BRCA1/2 mutation status } \\
\hline Mutation search initiated in family & 3 & - & 13 & 12 & - & 44 \\
\hline Mutation positive & 1 & - & 4 & 1 & - & 4 \\
\hline Mutation negative & 1 & - & 4 & - & - & - \\
\hline
\end{tabular}

*Women with only one affected relative were themselves affected with breast cancer

†One woman had ceased screening and another was about to start screening.

$\neq$ In five cases, oophorectomy was performed following abnormal screening results/during an exploratory operation.

$\S$ Four women had previously undergone therapeutic hysterectomy. 
The analysis of the interviews with women in both the screening and surgery groups suggested that there are five main factors that influence surgical decisions. These can be summarised as: (1) risk perception and the risk of cancer, (2) witnessing a relative's experience of ovarian cancer, (3) family and social obligations, (4) fertility and menopause, and (5) fear of surgical procedures in general. Where appropriate, the following discussion will compare the responses of those who had undergone or rejected surgery (for the present) to highlight points of continuity and difference between the two groups.

(1) RISK PERCEPTION AND THE RISK OF CANCER Others have observed that risk perception and cancer worry may influence the decision to undergo surgery. ${ }^{23-26}$ Similar observations were made in the present study, for with one exception, all of the women in the surgery group reported experiencing a great deal of anxiety about their ovarian cancer risk before the removal of their ovaries. Eight women said they had previously viewed their risk in absolute terms and had undergone oophorectomy because they had believed that they would definitely develop ovarian cancer in the future. (To maintain the participants' confidentiality all the names used in this paper are self-chosen pseudonyms.)

Fulie: "My own personal reason was, I had the operation because I didn't want to die. That's how I looked at it. And I was really, really concerned that because of the history that we've got, that I would get ovarian cancer, even though I was being screened regularly ... And I would honestly say that I was so concerned that I would get the cancer. . . .. I thought, no, I've got to have it done. I don't want to die. That's how I ended up. I don't want to die. I thought, I'm not going to die, I'm going to have this operation no matter what."

Ten women claimed to have viewed their risk probabilistically, and said they used to think of themselves as having a higher risk of developing cancer than other women because of their family history. Seventeen women reported that their fear of developing cancer had been an influential factor in the decision to undergo surgery, and all the women in the surgery group reported feeling an overwhelming sense of relief following oophorectomy. They said they no longer perceived themselves to be at risk and no longer felt afraid or worried about developing ovarian cancer.

Sue: "Certainly the worry taken away is worth everything else because ... it was a big worry especially since my sister died. I mean when it was just my mum it was one of them things, then it was my aunties ... .and then when it starts on your sister you think... that worry taken away just made such a difference."

Five women in the screening group perceived their risk in absolute terms and were convinced they would develop ovarian cancer in the future (three of these planned to undergo prophylactic surgery), while 16 women said they perceived themselves as at increased risk compared with the general population. Fourteen women said they needed more information about their risk of developing ovarian cancer before they would seriously consider prophylactic surgery. More specifically, they suggested that confirmation of their mutation status would help them to make a decision about surgery, as Nicola said: "If I knew that I had the defective gene I would have surgery without a doubt." This contrasts with women in the surgery group, who, with one exception, had undergone surgery without verification of their mutation status. However, it must be noted that in many cases this option was not available at that time.

Other women in the screening group indicated that, even if they were confirmed as mutation carriers, they would not proceed with surgery on the basis of increased cancer risk alone.

Carol: "It's like sort of - I don't know, cutting your arm off for a scratch on your finger . . . even if they identify me as having the gene, they say you may or may not get cancer from it. You may still not get cancer from it all your life. I just think it just seems - to cut out healthy organs as a preventative measure seems drastic, unless you've got one hell of a case for doing that."

Susan: "On - on the whole - you know? I mean you can have the test, you can have the gene, but you still might not get the cancer. You might not have the gene, and you could still get cancer. Um... you know? So the - I mean I don't know. Obviously they're not going to know how many people who've got the gene go on to develop the cancer, are they?"

Some women in the screening group also expressed scepticism about the efficacy of prophylactic surgery in containing/lessening the risk of ovarian cancer. They reported receiving confusing messages either from their doctors or the media about whether surgery would prevent cancer occurring.

Katrina: "Well, nobody seems to know really if it [surgery] is beneficial or not. I get sort of not conclusive answers, really. It's almost as if, um, well, give it a try. We think it may be beneficial. And some consultants do it, some don't. And it's this conflict of opinion that - it confuses you really .... I think if I conclusively knew that there was a big reduction in the risk, I would probably opt for it. But as it's still up in the air at the moment, I'm just going to stick with screening for the moment."

Moreover, 10 women said they did not perceive surgery as a viable option because of the residual risk of developing peritoneal cancers.

Carol: "If they could say, you've inherited the gene - but they can't tell me that either. It's a gamble, I know. And my sister was told at X by the consultant there, even having your ovaries removed wouldn't really make the risk because there's still ovarian cells in the rest of your body from um when you're in the embryo stage. Apparently there's ovarian cells still in your body that could turn cancerous. Just a very, very remote chance, but there is a chance." 
Some of these women were uncertain about where these cancers might develop and worried that they might be potentially "less detectable" with screening.

Sarah: "Oh, one of the things I would worry about is the risk of this little bit of ovary being left behind, and if that did happen - she said, oh, it was very, very minimal, but if that did happen, and some cancer started growing there, where would it start growing next? What sort of direction? Like I say, they may not know, but where would it go? So what - if it started growing on another organ, what would the consequences of that be?"

As far as some women in the screening group were concerned, it was important to keep their ovaries because they constituted a target organ for cancer to develop in/on. Indeed, because these women believed in the efficacy of ovarian screening, they felt their risk of cancer would be better managed, at least for the present, by keeping their ovaries and having them monitored.

In contrast, only one woman in the surgery group reported that she was aware of the risk of peritoneal carcinomas following surgery, while another recalled being told that her risk of breast cancer was increased because she had undergone ovarian surgery. With these exceptions, there was no evidence that women in the surgery group had taken the residual risk of developing peritoneal cancer into account when making their decisions. This line of questioning was not pursued during the interview for ethical reasons.

Finally, two women in the screening group said that they would like more information about the symptoms of ovarian cancer and the efficacy of screening, particularly the prognosis of cancers detected during screening.

Vicky: "I mean I think, you know, the implications of if you do get it, how quickly it - and how deadly it is, actually. It's pretty horrible, isn't it?"

(2) WITNESSING A RELATIVE'S EXPERIENCE OF OVARIAN CANCER

Cancer risk management decisions were frequently described as influenced by people's former experiences of ovarian cancer, particularly nursing a dying relative. Many women talked at great length and very emotionally about their mother's or sister's illness. Indeed, many of those in the surgery group said that the death of their mother or sister or a relative in their generation (for example, a cousin) had been the one of the most influential factors in their decision to have their ovaries removed.

Linda: "I suppose I might have been luckier than some, with actually having seen a lot of what goes on, with my mother, as well. I'm you know? - I'm aware of what happened. Some people don't ever see that. They don't ever see that side, you see. So um when I saw that, then that's another fact that made me you know, that helped towards me making my mind up."

Pam: "No, I think knowing that - how my mum looked, and what she suffered, or what she must have suffered, I thought, there's no way I'm going to do that. I mean the poor lady, I mean they drained 19 litres of fluid off of her, and it still came back. She was like a beached whale. And I thought, how can anybody suffer like that? And how long had this been going on? And they say it's one of the fast-growing ones, because it's hormonal. And I thought, well, there's no way. Because I wouldn't want my children to see me go through that agony."

Similarly, some women in the screening group acknowledged that their past experiences with ovarian cancer were an important influence on both their risk perception and attitudes about future cancer risk management.

Mary: "I think the biggest influence for me is seeing personally at first hand people dying of it. There's no doubt that that brings it home to you, and I'd prefer not to go down that route ... I mean I don't want to end up in the pitiful state that my mother was in. I've seen that, and I remember her suffering. I can see her crawling across the floor on her hands and knees, because she was in so much pain. And after seeing something like that, if hysterectomy is the answer, then I'll go for it. . . . I think it might be a harder decision for somebody to make who hasn't seen anybody with the illness, who's never come into contact with cancer of any form, because it's the nasty word, people don't - well, they talk about it more than they used to, but a lot of people don't come into contact with it. And having seen people with it, and just what it does to them, and the family round them, I don't want to go - I've no intention of going through that, if I can help it. So if they said, you've got to have your right arm off at the same time, I'd do it. I'd do it."

While others were aware that their lack of first hand experiences of others' suffering had influenced their risk perception and attitudes about prophylactic surgery, they felt at less risk and were less inclined to opt for this risk management option.

Susan: "I think they've [cousins] got a very negative - I mean obviously it's hard for them, because they - I don't know, I think their mother died possibly, or, um - whereas, you know, my mum's still alive. I suppose if she had died, I would perhaps feel differently. But I do think they put across a negative attitude, that if you've got this gene, you're going to get it and you're going to die unless you - you know, unless you take this drastic - have this drastic surgery . . Unless I had a cancer, I don't think I would take it as a preventative medicine, because you have to keep cutting bits out, you know. That's how I feel. But um, you know, obviously I haven't had - I haven't seen somebody die from it."

The importance of witnessing a relative's experience of ovarian cancer may account for the fact that $87 \%$ of the women who had undergone surgery had first degree relatives who had died from ovarian cancer, compared with only $41 \%$ of women in the screening group. Indeed, the women in the surgery group, and those currently considering surgery in the screening group, also reported experiencing high levels of anxiety about developing 
ovarian cancer before surgery, which many acknowledged had been explicitly influenced by their experiences of cancer in the family. This observation suggests that those who have not witnessed ovarian cancer in a close relative, for example, women with a paternal family history, may be less inclined to opt for surgical risk management. There was some evidence of this in the present study, as the screening group contained a larger proportion $(19 \%)$ of women with a paternal history than the surgery group $(4 \%)$.

\section{(3) FAMILY OBLIGATIONS}

As has been noted elsewhere, high risk women frequently describe themselves as having an obligation to their family to manage their cancer risks. ${ }^{30}$ Similarly, in this study, none of the women in the surgery group described their decision to undergo surgery as a decision they made just for themselves; indeed, nearly all the women said that they had a responsibility to their family to prevent ovarian cancer occurring. They described themselves as having had a responsibility to undergo surgery to ensure they remained healthy so that they could raise their family.

I: "What was the most important reason for you having the operation?"

Linda: "My son, my husband, I think deep down, my son more than anything... I wanted to be around for him you know I didn't want like my mum lost her mum at age 10 and my sister was 19 no 20 something... but I wanted my son to have me here as long as possible, and to be around for him and my husband... having said that if I'd been on my own I would still have probably gone ahead with the operation because I want to live."

As noted above, they also saw themselves as under an obligation to prevent their family from seeing them suffer or having to care for them as they had cared for their relatives.

Victoria: "I mean I knew I had to. Once the [mutation] test was positive, I knew I had to have it [surgery], because of the chances. But I never felt that I would actually get it. I couldn't take that chance, and my husband didn't want me to. And if it did happen, I didn't want my children to suffer how I suffered with my mum and even more so with my sister ... If I'd been on, a single person on my own, I might not have. I don't know. I just didn't want my children to go through what I'd been through with my sister and with my mother."

Familial obligations also influenced decisions about the timing of surgery. All the women acknowledged that social support during convalescence was important. Some in the surgery group had postponed surgery until the summer holidays so their children could help out, others timed their admission to hospital so that their in laws or partners could look after the children. For one woman with very young children, the option of surgery only became a possibility once she found out that she was entitled to a home help supplied by social services.

However, familial obligations not only influenced decisions to accept surgery, but also to reject it. Seven women in the screening group said their decision to continue screening, rather than undergo surgery, was affected by the long period of convalescence needed following surgery, and the effect that it would have on their ability to provide practical and economic support for their family.

Katrina: "I'd want to know the recovery time, and the time out I'd have to take from work, which is very important for me because I'm a single parent now, so I haven't got a husband ready to take over. Which also is a personal reason for me not opting for it. . . .I mean it's social reasons are one of the reasons why not, as far as I'm concerned. If I was married and had a husband at home earning a wage, I could quite possibly consider it. But as I'm the only - you know? - wage earner and stuff like that, I have to consider that as well. I suppose we could live on [unclear] for six months [unclear, laughter]."

Others rejected the idea of prophylactic surgery on the grounds that their admission to hospital would potentially cause emotional upset within the family. In particular, the women who had previously undergone therapeutic surgery for breast cancer talked about the effect of their cancer treatment upon family dynamics, and were very keen to avoid causing their family any further anxiety by seeing them hospitalised again.

I: "Are there any other reasons that put you off having surgery?"

Barbara: "No, nothing else. It's just that I just don't want to go through all that again. Really don't want to go through it again. It was just traumatic last time. Not the actual surgery as such, but the trauma thing of leaving here to go and have it done. You can imagine, leaving your children and thinking, oh, I've got to go back in there again. Oh, I can't go through that. And I keep thinking, you know, I keep thinking I'd be really unlucky to get breast cancer and ovarian cancer. You know? But I'm prepared to take the chance."

\section{(2) OVARIAN FUNCTION: FERTILITY AND}

MENOPAUSE

All the women knew that ovaries have a reproductive function and infertility following oophorectomy was seen as a major influence on risk management decisions. All those in the surgery group said they had taken this into account when making the decision. In most cases when their doctor first mentioned surgery, they had already completed their families. However, two women said they had postponed the operation for a few years because they were not sure about having more children.

Nine women in the screening group also described their decision to continue screening as specifically influenced by the need to maintain their fertility for the present, although one woman said that if surgery were necessary she would consider adoption.

I: "What do you think would happen to women who had their ovaries out at 26?"

Abby: "I just think they'd be extremely depressed. Definitely. The thought of you not 
being able to choose to have any more children yourself - I don't - I didn't then, I didn't want that decision taken away from me. That was my decision, nobody else's, and I didn't want that taken away from me."

Sandra: "But all the time I'm 37 and under forty especially and I've only got the one child, that is the reason, because it would take all my options away, and er you just don't know. That is the main reason. It would completely take my options away."

Six women in the screening group and five in the surgery group were not aware of the hormonal functions of the ovaries at the time of the interview or before their operation, respectively. These women said they did not know, or had not known, that the removal of their ovaries would result in immediate menopause or that they would need hormone replacement therapy (HRT) after surgery. The remaining women in the surgery group said they had been aware they would be menopausal following the operation, and some said they had been worried about the effects of menopause before surgery.

Fulie: "And I had visions of me having hairy legs and beard and broken bones and - you know, like an old person."

On the other-hand, 14 of these women said they had been unaware of the specific menopausal symptoms that they could, or did, experience postoperatively.

Fifteen women in the screening group said their attitudes to prophylactic surgery were influenced by their concerns about the physical and psychological sequelae of surgical menopause.

Emma: "I suppose I think in a way, er, the effects, hormonal effects, on your body."

I: "I mean what sort of - apart from the bones [laughter] what other effects do you think there would be? What side effects?"

Emma: "I suppose being less feminine. I don't know if that's a mental thing as well."

I: "Yes. And what do you sort of mean? In what sort of a way?"

Emma: "Um... I don't know. I suppose you think of like growing facial hair, and - I don't know, perhaps does it alter your figure or - you know? Do you start losing your hair? You know? It's that kind of a thing, I suppose."

Four women in the screening group, who were aware of other potential health risks associated with a surgical menopause (for example, the increased risks of osteoporosis and cardiovascular disease) said they would like more information about the most appropriate age to undergo ovarian surgery.

fenny: "But it's being in the limbo and not knowing when's the appropriate age to have it done."

Although 17 women in the surgery group recalled being told that they would have to take HRT following surgery, many said this was the only information they received. Most reported that they had felt less anxious about the menopausal side effects of oophorectomy when they were told, before their operation, that they could take HRT, although one women described how she had worried that the HRT might make her more emotionally labile.

Eve: "I know one of the things I did say to him [gynaecologist] about HRT was I didn't want it to make me a Jeckyll and Hyde character, because even with my periods before hand I was very very even, I didn't peak and trough through the month um .. and I didn't want that."

The data suggest that women want and need much more information about HRT both before and after surgery. Seven women in the screening group expressed concerns about the history of breast cancer in their family and had interpreted press coverage of breast cancer and HRT as meaning they would be unable to take HRT following an operation. Women in the surgery group voiced similar concerns. They said that they worried about HRT increasing their risk of breast cancer and had received conflicting information from their doctors and/or the media. The most frequent types of questions about HRT asked by women in both groups were summarised by Jenny as follows.

"I'm going to need HRT. Can I get away without HRT? How am I going to increase my personal risk of CA breast if I go on HRT, given the family history? There's a new hormone-free HRT. Is that going to be banned before I can get my hands on it? Er, and what's the minimum-maximum period that I would stay on the HRT?"

(5) FEAR OF SURGICAL PROCEDURES

Seven women in the surgery group said that the decision to undergo surgery had been influenced by their fear of surgical procedures in general. In every case their anxiety about surgical procedures had meant that they had postponed making the decision for a few months.

Sue: "It never - it - apart from the surgery itself, which I was terrified of, actually having your ovaries taken away never, never bothered me ... I'm so frightened of hospitals...I wanted one [oophorectomy], out of fear, but I didn't want one out of fear of hospitals! [laughs]"

Fear of surgery similarly influenced the risk management choices of some of the women in the screening group. Eight women said their decision to continue ovarian screening was influenced by their fear of surgical procedures in general, for example, anaesthesia, pain, and postoperative complications.

Fane: "Surgery is a bit sort of frightening."

I: "What sort of things frighten you about surgery?"

Fane: "Well it is just the thought of them cutting you up, and if anything went wrong, and you didn't wake up again ...."

Fanet: "And I'm also concerned with keyhole surgery...I've had laparoscopies, and I know it moves things around, because they blow your stomach up and things don't go back in the right place."

The women who had previously undergone surgery for breast cancer also talked about their fear of surgical procedures. They were less likely to want to undergo further surgery for 
prophylactic reasons, even if DNA testing showed they carried a mutation.

Barbara: "He [consultant gynaecologist] said, 'I strongly suggest you have them out'. And I thought about it and I thought, I just don't want another operation. So I opted for the screening as opposed to the operation. And he did explain that the screening isn't one hundred per cent. But that's a chance I'll take. . . . quite honestly I don't want another operation. I am so scared of going under, and thinking, will I wake up again? You know? I just - being in hospital again, with all that business of the having the things aspirated,... Oh, no thanks. No, I'll take the chance."

\section{Discussion}

The present study used qualitative methods to determine the factors that influence high risk premenopausal women's decisions about prophylactic ovarian surgery. As others have noted, surgical decision making involves the weighing up of both positive and negative expectancies concerning the outcome of surgery. ${ }^{31}$ In the present study, this involved women balancing the gains of risk reduction, the relief of anxiety, and fulfilling one's familial obligations to remain healthy against the potential costs of surgery, such as infertility and the onset of menopause, the continuing risk of developing what is perceived as a "less detectable" peritoneal carcinoma, and one's inability to care for the family during convalescence. While it is difficult to draw firm conclusions from this study, because of the small number of women involved, the data raise some interesting questions for further research.

The interviews showed that decision making about cancer risk management is a complex process, involving the consideration of both individual and social factors, individual perceptions of cancer risk and the recognition of the effects of undergoing surgery upon the family. Furthermore, surgical decision making emerged as a dynamic process, as shown by the fact that none of the women in the screening group had absolutely ruled out the possibility of prophylactic surgery at some future date. All the women who were currently undergoing ovarian screening acknowledged that they could change their minds about surgery, if their circumstances changed. This observation suggests that to divide these women into two distinct groups is to make a somewhat artificial distinction. However, as has been shown above, subtle differences were also apparent between the responses of the two groups.

As a recent study of decision making about prophylactic mastectomy has shown, risk perception and attitudes to breast cancer risk management appear to be affected by previous experiences of cancer in the family. ${ }^{24}$ The present study similarly found that the experience of witnessing ovarian cancer in a close relative was a very influential factor in surgical decision making. Many women in the surgery group reported experiencing high levels of anxiety about developing ovarian cancer before surgery, which most acknowledged had been influenced by their experiences of cancer in the family; similarly, some in the screening group hypothesised that they were less anxious because they had not had this experience. This observation may explain the recent finding that the consideration of prophylactic oophorectomy is positively associated with subjective risk perception and cancer worry rather than objective risk estimates. ${ }^{26}$ Indeed, the fact that a larger proportion of women in the surgery group had witnessed the death of a close relative from ovarian cancer may explain the fact that more women in the surgery group expressed the view that their risk of cancer was absolute than those in the screening group.

It was suggested that women who have a paternal family history of these cancers, and are therefore less likely to have witnessed ovarian cancer in a close relative, may be less inclined to opt for surgical risk management. However, research suggests that women with a paternal family history may opt for screening rather than surgery for other reasons. A recent study of at risk women and breast cancer patients indicates that they regard men as less likely to pass on the genetic mutation for breast cancer susceptibility than women. ${ }^{32}$ Thus, it is possible that women with a paternal history consider themselves to be at less risk of carrying a mutation and developing ovarian cancer than those with a maternal history, which indeed they are if they do not have an affected first degree relative. While there were not enough women in this sample with a paternal family history to substantiate these claims, what must be noted is that of the four women in the screening group with a paternal history, who had a $25 \%$ risk of inheriting a mutation, only one had attended genetic counselling and received this information. These observations suggest that there is a need for research that specifically focuses upon the attitudes and risk management practices of women who have a paternal family history of breast/ovarian cancer.

One of the main differences between the groups' responses was the importance they placed upon establishing their mutation status before prophylactic surgery. It was observed that many of those currently undergoing screening said they would consider surgery if they were confirmed as a mutation carrier, in contrast to the majority of women in the surgery group who had undergone surgery without previous confirmation of their mutation status. This difference may be explained by the fact that most women in the surgery group had not been offered mutation testing before surgery; indeed, in some cases this was not an available option as the gene had not been identified at the time they were making the decision to undergo surgery. Given these observations, it can be argued that the responses of women in the screening group may provide a more accurate picture of the influence of mutation testing on surgical decisions. Indeed, the responses of the screening group concur with the findings of recent research which suggest that many women undergo $B R C A 1 / 2$ testing to facilitate decisions about prophylactic surgery. ${ }^{34}$ Thus, it can be 
hypothesised that as the availability of mutation testing increases, we may see more women postponing prophylactic surgery until they have received information about their mutation status. ${ }^{19}$ Clearly, there is scope for a prospective study that looks at the impact of mutation testing on risk management decision making.

Similarly, between group differences were observed with regard to women's attitudes about the risks of peritoneal carcinomas. A large proportion of the screening group said that these risks had influenced their decision to reject surgery, whereas only one woman in the surgery group specifically mentioned these risks. As was noted above, it was thought unethical to pursue this topic with women who had already undergone surgery, on the grounds that if they were unaware of this risk, then providing them with this information could cause them anxiety. Therefore, as there is no evidence that the women in the surgery group had been told of this risk before surgery, it is impossible to say whether the risk of peritoneal cancer had any effect upon their decisions. However, the responses of the screening group suggest that providing women with this information does influence their risk management decisions. What was apparent from these women's responses was that the smaller risk of a less detectable cancer developing following surgery was seen as a negative outcome of oophorectomy and this, when combined with other perceived costs of surgery, was used as a justification for rejecting the surgical option for the present.

Finally, this study can be seen as having implications for clinical practice. It suggests that if medical professionals are to facilitate women's decisions about their cancer risk management, then they need to ensure that they receive clear information about the risk reducing benefits of prophylactic oophorectomy and the potential physical and emotional consequences of undergoing gynaecological surgery. Furthermore, medical professionals need to take into account the weight given to familial responsibilities in the decision making process. In addition to providing emotional care, women also provide practical care for their families and, particularly in families where they are the main or only wage earner, surgery may not be perceived as a practical risk management option. Medical professionals need to be aware of these practical and/or economic constraints on women's cancer risk management choices and, if appropriate, provide information about agencies that can provide support.

In conclusion, it must be noted that the information needs of high risk women who consider prophylactic mastectomy are well provided for; in many centres within the UK they have access to breast care nurses and/or high risk women who have undergone prophylactic surgery. At present, similar support does not appear to be available for those undergoing prophylactic gynaecological surgery. This study suggests that an information and support network should be put in place for premenopausal women who are considering prophylactic oophorectomy. This could either involve the establishment of self-help groups in regional centres, the provision of gynaecological nurses, pre- and post-surgery, or, at the very least, providing women with written information about prophylactic ovarian surgery and its potential after effects. ${ }^{35}$

We would like to thank all the women who took part in this research, the Steering Committee of the UKCCCR Familial Ovarian Cancer Register, Carole Pye, and Amy Storffer-Isser, the staff at St Bartholomew's and the Royal Marsden Hospitals the staff at St Bartholomew's and the Royal Marsden Hospitals particularly, Laura Hitchcock, Karen Cook, Karen Sibley,
Audrey Ardern-Jones, Ros Eeles, and Chris Haracopus. Thanks Audrey Ardern-Jones, Ros Eeles, and Chris Haracopus. Thanks
are also due to Julia Lawton for her very helpful comments on an are also due to Julia Lawton for her very helpful comments on an
earlier draft of this paper. This research was supported by a earlier draft of this paper. This research was support
grant from WellBeing (grant No HI/97) to the authors.

1 Stratton JF, Gayther SA, Russell P, Dearden J, Gore M, Blake P, Easton D, Ponder BA. Contribution of BRCA1 mutations to ovarian cancer. N Engl f Med 1997;336:112530 .

2 Leach FS, Nicolaides NC, Papadopoulos N, Liu B, Jen J, Parsons R, Peltomaki P, Sistonen P, Aaltonen LA, Nystrom-Lahti M, Meltzer PS, Yu JW, Kao FT, Chen DJ, Cerosaletti KM, Fournier REK, Todd S, Lewis T, Leach RJ, Naylor SL, Weissenbach J, Mecklin JP, Jarvinen H, Petersen GM, Hamilton SR, Green J, Jass J, Watson P, Lynch HT, Trent JM, De la Chapelle A, Kinzler KW, Vogelstein B. Mutations of a MutS homolog in hereditary nonpolyposis colorectal cancer. Cell 1993;75:1215-25.

3 Bronner CE, Baker SM, Morrison PT, Warren G, Smith LG, Lescoe MK, Kane M, Earabino C, Lipford J, Lindblom A, Godwin AR, Ward DC, Nordenskjold M, Fishel R, Kolodner R, Liskay RM. Mutation in the DNA mismatch repair gene homologue $\mathrm{hMLH} 1$ is associate with hereditary non-polyposis colon cancer. Nature 1994;368: 258-61.

4 Miki J, Swensen J, Shattuck-Eidens D, Futreal PA, Harshman K, Tavigian S, Liu QY, Cochran C, Bennett LM, Ding W, Bell R, Rosenthal J, Hussey C, Tran T, McClure M, Frye C, Hattier T, Phelps R, Haugenstrano A, Katcher H, Yakumo K, Gholami Z, Shaffer D, Stone S, Bayer S, Wray C, Bogden R, Dayananth P, Ward J, Tonin P, Narod S, Bristow PK, Norris FH, Helvering L, Morrison P, Narod S, Bristow PK, Norris FH, Helvering L, Morrison P,
Rosteck P, Lai M, Barrett JC, Lewis C, Neuhausen S,
Cannonalbright L, Goldgar D, Wiseman R, Kamb A, Cannonalbright L, Goldgar D, Wiseman R, Kamb A,
Skolnick MH. A strong candidate for the breast ovarian cancer susceptibility gene BRCA1. Science 1994;266:6671

5 Wooster R, Bignell G, Lancaster J, Swift S, Seal S, Mangion , Collins N, Gregory S, Gumbs C, Micklem G. Identification of the breast cancer susceptibility gene BRCA2. Nature 1995;378:789-91.

6 Whittemore AS, Gong G, Itnyre J. Prevalence and contribution of BRCA1 mutations in breast and ovarian cancer: results from three US population-based case-control studies of ovarian cancer. Am f Hum Genet 1998;60:496-504.

7 Ford D, Easton DF, Stratton M, Narod S, Goldgar D, Devilee P, and the Breast Cancer Linkage Consortium. Genetic heterogeneity and penetrance analysis of the BRCA1 and BRCA2 genes in breast cancer families. Am f Hum Genet BRCA2 genes in

8 Kerlowske K, Brown JS, Grady DG. Should women with familial ovarian cancer undergo prophylactic oophorectomy? Obstet Gynecol 1992;80:700-7.

9 van Eijkeren MA, de Graaff J, van Etten FH. Familial ovarian cancer. Eur $\mathcal{F}$ Obstet Gynecol Reprod Biol 1992;47:263-6.

10 Amos CI, Shaw GL, Tucker MA, Hartge P. Age at onset for familial epithelial ovarian cancer. FAMA 1992;268:1896-9.

11 National Institute of Health Consensus Conference Statement. Ovarian cancer: screening, treatment, and follow-up. Gynecol Oncol 1994;55:S4-14.

12 Burke W, Daly M, Garber J, Botkin J, Kahn MJ, Lynch P, McTiernan A, Offit K, Perlman J, Petersen G, Thomson E, Varricchio C. Recommendations for follow-up care of indivarricchio $\mathrm{C}$. Recommendations for follow-up care of indi-
viduals with an inherited predisposition to cancer II. viduals with an inherited predisposition to cance

13 Andolf $E$. Ultrasound screening for women at risk of ovarian cancer. Clin Obstet Gynecol 1993;36:423-32.

14 Droegemueller W. Screening for ovarian cancer: hopeful and wishful thinking. Am F Obstet Gynecol 1994;170:10958.

15 Tobacman JK, Greene MH, Tucker MA, Costa J, Kase R, Fraumeni JF Jr. Intra-abdominal carcinomatosis after prophylactic oophorectomy in ovarian-cancer-prone families. Lancet 1982;ii: 195-9.

16 Weber AM, Hewett WJ, Gajewski WH, Curry SL. Serous carcinoma of the peritoneum after oophorectomy. Obstet Gynecol 1992;80:558-60.

17 Piver MS, Jishi MF, Tsukada Y, Nava G. Primary peritoneal carcinoma after prophylactic oophorectomy in women with a family history of ovarian cancer. A report of the Gilda a family history of ovarian cancer. A report of the Gilda 2751-5. 
18 Evans DG, Ribiero G, Warrell D, Donnai D. Ovarian cancer family and prophylactic choices. 7 Med Genet 1992;29:41618 .

19 Lerman C, Hughes C, Croyle RT, Main D, Durham C, Snyder CA, Lynch JF, Narod SA, Lynch HT. Prophylactic surgery decisions and surveillance practices a year following BRCA1/2 testing. Prev Med 2000;31:75-80.

20 Meijers-Heijboer EJ, Verhoog LC, Brekelmans CT, Seynaeve C, Tilanus-Linthorst MM Wagner A, Dukel L, Devilee P, van Geel AN, Klijn JG. Presymptomatic DNA testing and prophylactic surgery in families with BRCA1 or BRCA2 mutations. Lancet 2000;355:2015-20.

21 Meijer WJ, van Lindert AC. Prophylactic oophorectomy. Eur 7 Obstet Gynecol Reprod Biol 1992;47:59-65.

22 Rebbeck TR, Levin AM, Eisen A, Snyder C, Watson P, Cannon-Albright L, Isaacs C, Olofunmilayo O, Garber JE, Godwin AK, Daly MB, Narod SA, Neuhausen ST Godwin AK, Daly MB, Narod SA, Neuhausen SL, Lynch HT, Weber BL. Breast cancer risk after bilateral prophylactic oophorectomy in BRCA

23 Stephanek ME, Helzlsouer KJ, Wilcox PM, Houn F. Predictors of and satisfaction with bilateral prophylactic mastectomy. Prev Med 1995;24:412-19.

24 Hatcher M, Fallowfield L. Psychosocial implications of bilateral prophylactic mastectomy. Paper presented at the British Psychological Society Health Psychology Conference, Leeds University, 1999

25 Hallowell N. "You don't want to lose your ovaries because you think 'I might become a man'.”: women's perceptions of prophylactic surgery as a cancer risk management option. Psycho-Oncology 1998;7:263-75.
26 Meiser B, Butow P, Barratt A, Friedlander M, Gattas M, Kirk J, Suthers G, Walpole I, Tucker K. Attitudes toward prophylactic oophorectomy and screening utilization in women at increased risk of developing hereditary breast/ women at increased risk of developing here ovarian cancer. Gynecol Oncol
Muhr T. Atlas-ti. Berlin, 1994.

27 Pope C, Mays N. Reaching the parts that other methods cannot reach: an introduction to qualitative methods in health and health services research. BMF1995;311:42-5.

29 Silverman D. Interpreting qualitative data: methods for analysing talk, text and interaction. London: Sage, 1993.

30 Hallowell N. Doing the right thing: genetic risk and responsibility Soc Health Illness 1999;21:597-621.

31 Miller SM, Fang CY, Manne SL, Engstrom PF, Daly MB. Decision-making about prophylactic oophorectomy among at-risk women: Psychological influences and implications. Gynecol Oncol 1999;75:406-12.

32 Wonderlick AL, Fine B. Knowledge of breast cancer genetics among breast cancer patients and first-degree relatives ics among breast cancer patients and first-degree relativ

33 Meisser B, Butow P, Barratt A, Suthers G, Smith M, Colley A, Thompson E, Tucker K. Attitudes to genetic testing for breast cancer susceptibility in women at increased risk of developing hereditary breast cancer. F Med Genet 2000;37: 472-76.

34 Lerman C, Daly M, Masny A, Balshem A, Audrain J. Attitude about genetic testing for breast-ovarian cancer susceptibility. F Clin Oncol 1994;12:843-50.

35 Hallowell N. A qualitative study of the information needs of high-risk women undergoing prophylactic oophorectomy. Psycho-Oncology 2000;9:486-95.

\title{
Oncology nurse training in cancer genetics
}

\author{
Clara Gaff, Kristiina Aittomäki, Robert Williamson
}

f Med Genet

2001;38:691-695

Victorian Clinical

Genetics Services,

Royal Children's

Hospital, Flemington

Road, Parkville,

Melbourne, Victoria

3052, Australia

C Gaff

K Aittomäki

Murdoch Children's

Research Institute,

Melbourne, Australia

C Gaff

$\mathrm{R}$ Williamson

Department of Clinical Genetics, HUS,

Finland

K Aittomäki

Correspondence to: Dr Gaff, clara.gaff@mh.org.au
EDITOR - The rapid increase in understanding of cancer genetics in recent years means that few oncology nurses have sufficient knowledge to address the issues of patients concerned about inherited predisposition to cancer. ${ }^{1-3}$ While some nursing curricula have recently incorporated cancer genetics, this does not assist the large body of oncology nurses already in practice. The need for an educational programme in cancer genetics was highlighted locally by a focus group of senior level nurses and social workers practising in oncology (unpublished data). All felt inadequately equipped to deal with enquiries regarding family history and cancer risk from patients and staff. Nobody in the focus group was aware of the Australian protocols for referral to familial cancer clinics within their employing organisations and family history was not routinely collected.

The Australian guidelines categorise families according to their level of cancer risk ("high", "moderate", or "low") based on family history and/or the presence of a germline mutation known to predispose to cancer. ${ }^{4}$ In Australia, multidisciplinary Familial Cancer Centres provide genetic counselling, genetic testing, and risk management advice to those families judged to be at "high risk".

Those categorised at low or moderate inherited risk of cancer may also benefit from informed counselling but may not meet the criteria for referral to the Familial Cancer Centres. As cancers are common, a significant number of people in the community with a family history of cancer will be in these categories. Many will not have a single gene mutation, but are at somewhat increased risk of developing cancer and require surveillance advice. ${ }^{5-7}$ The person's perception of this risk may not reflect reality. People at moderate risk for breast cancer often overestimate their level of risk..$^{8-10}$ After receiving counselling and a personal risk estimate, most report feeling less worried and their perception of risk is more accurate. ${ }^{8}$ These issues may be addressed by services focusing predominantly on surveillance and management issues rather than inheritance.

The Australian model requires relevant health professionals to incorporate family history assessment into their practice. Oncology nurses are in an ideal situation to distinguish families at high risk from those who are concerned about their personal inherited risk but are in a low or moderate risk category. Ongoing involvement with patients and their families during the course of the treatment, post-diagnosis support, and palliative care leads to a trusting relationship between the patient and nurse and consequently the opportunity to discuss referral of family members. Some oncology nurses see genetics as an important facet of nursing practice ${ }^{11} 12$ and a role for oncology nurses in family history collection and assessment has been proposed..$^{11} 1314$

Cancer genetics requires a shift in focus from the traditional nursing role. Oncology nurses have a patient centred approach and well developed skills with respect to care of the patient; genetics requires the consideration of the whole family. Not only is information about the extended family required for assessment, but information given to patients may be directly relevant to, or impact on, other family 
Table 1 Syllabus and learning goals for "Counselling” module

\begin{tabular}{lll}
\hline Topic & $\begin{array}{l}\text { Time } \\
\text { allocated } \\
(h)^{\star}\end{array}$ & Learning goals \\
\hline $\begin{array}{l}\text { Revision of } \\
\text { counselling skills }\end{array}$ & 5 & $\begin{array}{l}\text { Review the skills of attending, listening, empathy, probing } \\
\text { Practise these skills and developing rapport }\end{array}$ \\
Self-awareness & 4 & $\begin{array}{l}\text { To understand the need for self-awareness in counselling } \\
\text { To practise monitoring one's owns feelings and responses } \\
\text { To understand "parallel process" }\end{array}$ \\
Crisis & 4 & $\begin{array}{l}\text { To understand the nature and stages of crisis } \\
\text { To be aware of the physical and emotional reactions to crisis } \\
\text { To develop and practise counselling skills in relation to crisis }\end{array}$ \\
Grief & 4 & $\begin{array}{l}\text { To review grief responses } \\
\text { To be aware of the impact of grief over time } \\
\text { To practise counselling skills in relation to grief }\end{array}$ \\
Psychiatric illness & 1 & $\begin{array}{l}\text { To be aware of potential psychiatric presentations } \\
\text { To be aware of appropriate referrals }\end{array}$
\end{tabular}

^Time allocations are somewhat arbitrary as there was overlap between all topics.

members. Consequently, issues of confidentiality, disclosure, and autonomy are complex, and discussion needs to be based upon sound genetic knowledge and principles.

We developed a 16 week (60 hour) course entitled "Cancer Genetics Resource training course" designed to enable oncology nurses to assess a person's category of inherited cancer risk, facilitate appropriate referral, and identify psychosocial issues.

\section{Course development}

The philosophical basis of the course was that dissemination of information and development of skills throughout the health sector would increase accessibility of appropriate services to families. Specifically, educating health professionals about cancer genetics will assist in identification of high risk families and facilitate risk management of those in the low and moderate risk categories. The graduates will be able to assess a family's inherited risk category, facilitate referral to the relevant services, explore expectations of services, and provide brief counselling for issues such as anxiety and/or grief which may serve as a barrier to acceptance of a referral by the family members.

The course syllabus was developed based on feedback from a focus group comprising oncology nurses and in conjunction with the Anti-Cancer Council of Victoria. It was publicised through the local Oncology Nurses Society, major hospital oncology day centres, and focus group participants. The number of participants was limited to allow effective counselling skills training. Participants were all working in oncology and able to apply the course content in their work. After interview, 10 were accepted from various areas of oncology (education (1), palliative care (1), breast care support (2), cancer help line (2), research/ registry (1), wards (3)). Six participants were subsidised by their employing hospital, indicating institutional support and recognition of the course.

\section{Syllabus}

Our experience in running workshops in cancer genetics emphasised a diversity of experience and a lack of familiarity with basic genetic concepts. Consequently, participants in the Cancer Genetics Resource training course were expected to complete a basic genetics workshop (12 hours) at the beginning of the course to ensure all had sufficient understanding of key genetic terms and concepts, including ethical issues.

In developing the core syllabus, we focused on skills that nurses could incorporate into their work. Graduates of the course would undertake counselling low and moderate risk families regarding their inherited risk and refer high risk families for specialised counselling. Detailed information about specific cancer predisposition genes, such as the mismatch repair genes, was therefore considered less important than a general understanding of the role of genes in cancer predisposition.

A syllabus was structured in three modules: Counselling Skills (six sessions), Science and Genetics of Cancer (six sessions), and Practice and Perspective (four sessions). Each session was of three hours' duration.

\section{COUNSELLING SKILLS}

The ability to explore issues underlying a person's concern about their history is essential in determining the services best able to meet a family's information and psychosocial needs. Questions by family members are often triggered by a recent critical event (for example, diagnosis, death, or an anniversary) and the emotions engendered by these events may affect the family member's acceptance of appropriate services.

Areas covered are outlined in table 1. Skills and issues were explored through discussion and role play. The nurses felt comfortable with the "task based" approach necessitated by their usual work and showed a desire to "fix it". The ability to live with uncertainty, necessary in so many areas of genetics, created problems for participants and was explored further in tutorials by a psychologist with extensive experience in education and supervision.

\section{CANCER: SCIENCE AND GENETICS}

This module was designed to enable participants to elicit and distinguish information relevant to family history assessment, to establish the inherited risk category, and identify people whose surveillance was insufficient. The course outline is presented in table 2 . The majority of the tutorials focused on risk assessment for the common cancers (breast, bowel, gynaecological, and melanoma). Each was divided into two parts, the first being an overview covering incidence, benign and malignant conditions, inherited conditions, and surveillance. The second part was skill based, with participants assessing case studies. The tutorials relating to fundamental principles of cancer genetics were designed to provide participants with sufficient information to correct common misconceptions, but not to provide detailed genetic information to a patient. Tutors were medical specialists in the field associated with Familial Cancer Clinics. This had the additional benefit of increasing the familiarity and accessibility of participants to key practitioners in the area. 
Table 2 Syllabus and learning goals for "Cancer: Science and Genetics" module

\begin{tabular}{|c|c|c|}
\hline Topic & $\begin{array}{l}\text { Time } \\
\text { allocated } \\
\text { (h) }\end{array}$ & Learning goals \\
\hline Epidemiology of cancer and risk factors & 1 & $\begin{array}{l}\text { Understanding of the population risk of cancer } \\
\text { Appreciation of the risk factors for common cancers } \\
\text { Awareness that the incidence of a cancer can fluctuate } \\
\text { Awareness that different countries and racial backgrounds have different } \\
\text { cancer risks }\end{array}$ \\
\hline Cancer genes and genetic testing & 5 & $\begin{array}{l}\text { Understanding of the two hit model (revision) } \\
\text { Ability to distinguish tests that indicate a genetic predisposition from those } \\
\text { that detect gene mutations (eg, microsatellite instability testing) } \\
\text { Understanding of the practicalities of gene testing } \\
\text { Understanding of "normal" and "abnormal" gene test results } \\
\text { Awareness of rare familial cancer syndromes }\end{array}$ \\
\hline Breast cancer & 3 & Knowledge of the population incidence \\
\hline Gynaecological and prostate cancer & 3 & Recognition of risk factors \\
\hline Colorectal cancer & 3 & Knowledge of risk prevention measures \\
\hline Skin cancer and melanoma & 3 & $\begin{array}{l}\text { Recognition of insufficient surveillance for a person's risk category } \\
\text { Ability to ask appropriate questions to elicit relevant family history } \\
\text { Recognition of medical events that are relevant to assessment of the family history } \\
\text { Assessment of the inherited risk category of a family (low, moderate, high) } \\
\text { Knowledge of cancer predisposition genes }\end{array}$ \\
\hline
\end{tabular}

PRACTICE AND PERSPECTIVE

This focused on incorporation of the previous modules into routine work (table 3), including discussion about the participants' individual workplace situations and challenges. Three common themes emerged. The participants had particular concerns about (1) raising the issue of familial cancer with people who were at high risk but had not indicated any interest in their genetic status, (2) raising the issue of referral with the clinician responsible for care, and (3) the potential increase in workload and need to document the work performed in this area.

\section{Assessment of participants}

A criterion referenced approach to assessment was adopted. ${ }^{15}$ Participants were expected to show the required level of competency by completing set assessment tasks. If the necessary standard was not achieved, further study was required and competence reassessed until proven.

In the Cancer Genetic Resource course, the ability to determine inherited risk category accurately and competency in deciding the appropriate course of action were assessed. Three assessment strategies were used. The tutor for the counselling module evaluated the involvement and ability shown by the participants during the counselling tutorials. The other modules were assessed by a written examination comprising case studies, family history assessment, and construction of an accurate family tree. This examination was open book, as participants would be expected to access relevant information and resources in their own workplaces rather than rely on memorised information. Each participant was informed of areas of weakness identified by the examination and was then expected to show sufficient skill in that area. Finally, all participants conducted an "in service" training session at their workplace to educate their colleagues about application of their skills.

\section{Evaluation of the Cancer Genetic \\ Resource course}

The course was evaluated by the students at the conclusion of each module, at the conclusion of the course, and six months after completion. The participants evaluated a number of parameters, including module content, teaching quality, applicability, expectations fulfilled, and practice of skills. Some parameters were assessed by open questions, but the majority were assessed by Likert scales. Those scores assessed by Likert

Table 3 Syllabus and learning goals for "Practice and Perspective" module

\begin{tabular}{|c|c|c|}
\hline Topic & $\begin{array}{l}\text { Time } \\
\text { allocated } \\
\text { (h) }\end{array}$ & Learning goals \\
\hline Family history collection & 3 & $\begin{array}{l}\text { Knowledge of the information required to collate a family tree } \\
\text { Collection of a clear, informative, and accurate family tree } \\
\text { Awareness that family history is evolving } \\
\text { Appreciation of the cultural and social factors that affect collection of information } \\
\text { Understanding of issues of ethics and confidentiality } \\
\text { Awareness of verification and consent }\end{array}$ \\
\hline Referral process & 3 & $\begin{array}{l}\text { Understanding of Familial Cancer Clinic function } \\
\text { Ability to arrange a referral to a Familial Cancer Clinic locally and interstate } \\
\text { Ability to arrange a referral of a low or moderate risk person to appropriate services } \\
\text { Some knowledge of the community resources available to families } \\
\text { Some knowledge of current familial cancer research projects occurring locally }\end{array}$ \\
\hline Incorporating cancer genetics & 3 & $\begin{array}{l}\text { Improve and consolidate skills through role plays } \\
\text { Appreciation of the influence of "family myths" on understanding of genetics } \\
\text { Development of a plan for implementing cancer genetic skills into work practice } \\
\text { Awareness of work place issues and boundaries }\end{array}$ \\
\hline Review and assessment task & 3 & \\
\hline
\end{tabular}



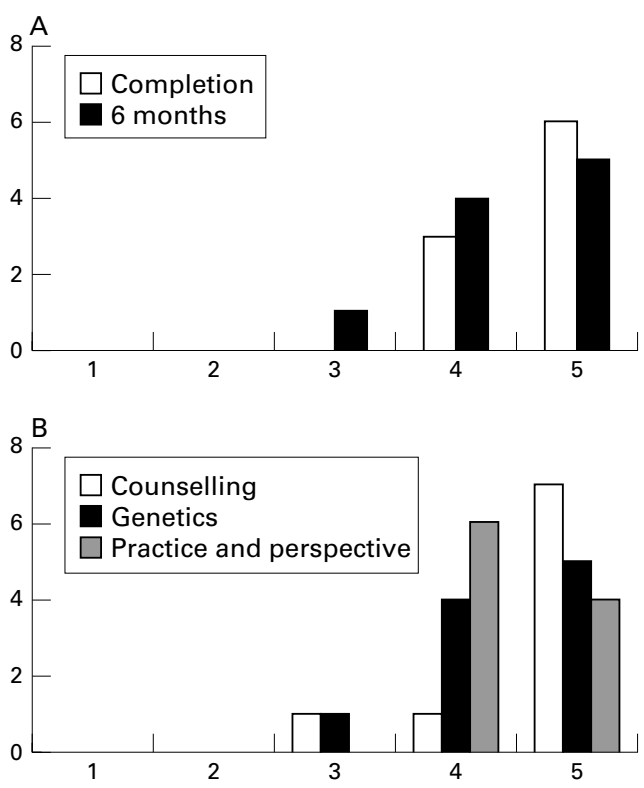

Figure 1 Participants' assessment of course usefulness. (A) Usefulness assessed at completion of the course and six months afterwards. (B) Relevance of modules assessed at completion of the module.

scales (1-5, with 5 being the highest rating) were averaged for each module separately.

The Counselling Module scored 4.5 (range 3.8-4.7), the Cancer: Science and Genetics Module scored 4.2 (range 3.9-5), and the Practice and Perspective module rated 4.4 (range 3.7-4.7). In particular, the teaching style rated highly for all units and tutorials were considered stimulating.

Overall satisfaction was high both immediately after the course and six months after completion, with participants indicating that the course overall was useful (fig 1A) and each module relevant to their work (fig 1B). Many participants felt before the course that their counselling skills were sufficient, but reported gaining additional skills during the course. Most commonly these were listening skills, self-awareness, and dealing with their own "fix it" mentality. The assessment of risk category and construction of family trees were regarded as the most helpful skills learnt overall and the participants commented on the supportive learning environment.

To assess the effectiveness of the Cancer Genetics Resource Course as a whole, the graduates were asked about their work practice six months after completion of the course. Nine of the graduates had patient contact in oncology and all had been asked about family history by patients or raised the issue of cancer genetics with patients. Three always asked patients about their family history, three asked only if the patient mentioned other affected relatives or asked directly, and three asked if time and the patient relationship permitted. All graduates reported receiving questions from other staff and applying the skills learnt. All had either facilitated a referral (6/9) to a familial cancer service or suggested to medical staff that a referral may be appropriate (6/9), compared with $11 \%(1 / 9)$ before the course.
A questionnaire was completed by supervisors six months after the course ended. One person had changed jobs during the six month period. Of the remaining nine, eight supervisors indicated that the graduates had incorporated new skills in their work and would recommend the course to other nurses. The remaining one had not observed any change, although the participant herself felt that she had been able to apply her new skills.

\section{Future directions}

The success of the course in meeting its aims was indicated by (1) the accuracy of the participants' family history assessment, (2) the sixfold increase in the number of participants facilitating referral, and (3) the assessment by participants and supervisors of the applicability of the skills learnt. We conclude that completing a skills based course improves assessment and appropriate referral of those who may be at risk of familial cancer.

Further evaluation is required to assess the extent to which learned skills have been applied and the effectiveness and appropriateness of counselling provided by the graduates. The possibility of holding a full time, intensive, two week course, enabling easier access for nonmetropolitan nurses, has been considered. This benefit needs to be weighed against the reduced opportunities for the nurses to apply skills and reflect on their practice between tutorials.

Our course focuses on recognising and meeting the needs of families at low and moderate risk, which constitute the majority of patients and families encountered by oncology nurses. In contrast many training programmes appear to focus on high risk families. ${ }^{16}$ Diverse roles for oncology nurses in cancer genetics have been proposed $^{1117}$ and it is reasonable to expect that different programmes will be required to meet the varying educational needs of these roles.

In time the role of a "Cancer Genetics Resource Nurse" may evolve into a dedicated position, distinct from, but complementary to, the role of Genetic Counsellors working with high risk families in Familial Cancer Centres. This role need not be confined to oncology nurses. With this form of training, social workers would be well placed to elicit concern regarding family history and counsel accordingly. The Cancer Genetic Resource course can be readily adapted for allied health staff or medical professionals.

The Cancer Genetic Resource course was funded by the Victorian Department of Human Services. Mary-Anne Young and Margaret Sahhar were instrumental in convening the course and Margaret Sahhar were instrumental in convening the course and
the Anti-Cancer Council of Victoria, in particular Amanda Howden and Doreen Ackerman, provided support and valuable Howden and Doreen Ackerman, provided support and valuable
suggestions. We thank Drs Mac Gardner and John Rogers for comments on the paper.

1 Jenkins J. Educational issues relating to cancer genetics. Semin Oncol Nurs 1997;13:141-4.

2 Chorley W, MacDermot K. Who should talk to patients with cancer about genetics? BMF 1997;314:441.

3 Peterson SK, Rieger PT, Marani SK, deMoor C, Gritz ER. Oncology nurses' knowledge, practice, and educational needs regarding cancer genetics. Am f Hum Genet 2001;98: 3-12.

4 Australian Cancer Network. Familial aspects of cancer: a guide to clinical practice 2000; http://www.health.gov.au/ nhmrc/publicat/synopses/cp67syn.htm 
5 Claus EB, Risch N, Thompson WD. Genetic analysis of breast cancer in the cancer and steroid hormone study. $A m$ 7 Hum Genet 1991;48:232-42.

6 St John DJB, McDermott FT, Hopper JL, Debney EA, Johnson WR, Hughes ES. Cancer risk in relatives of patients with common colorectal cancer. Ann Intern Med 1993;118:785-90

7 Ford D, Bliss JM, Swerdlow AJ, Armstrong BK, Franceschi S, Green A, Holly EA, Mack T, MacKie RM, Osterlind A, Walter SD, Peto J, Easton DF. Risk of cutaneous melanoma associated with a family history of the disease. Int $\mathcal{f}$ Cancer 1995;62:377-81.

8 Burke W, Culver JO, Bowen D, Lowry D Durfy S, McTiernan A, Anderson MR. Genetic counselling for women with an intermediate family history of breast cancer. Am ₹ Med Genet 2000;90:361-8.

9 Evans DG, Burnell LD, Hopwood P, Howell A. Perception of risk in women with a family history of breast cancer. $\mathrm{BrF}$ Cancer 1993;67:612-14.

10 Meiser B, Butow P, Barrat A, Gattas M Gaff C, Haan E, Gleeson M, Dudding T, Tucker K, and the Psychological
Impact Collaborative Group. Risk perceptions and knowledge of breast cancer genetics in women at increased risk of developing hereditary breast cancer. Psychol Health (in press).

1 Dimond E, Calzone K, Davis J, Jenkins J. The role of the nurse in cancer genetics. Cancer Nurs 1998;21:57-70.

12 Calzone K, MacDonald D, Tranin AS. Readers comment on the nursing role of cancer genetics. Oncol Nurs Forum 1995;22:887-8.

13 Loescher L. Genetics in cancer prediction, screening and counselling. Part II. The nurse's role in genetic counselling. Oncol Nurses Forum 1995;22:16-19.

14 MacDonald DJ. The oncology nurse's role in cancer risk assessment and counseling. Semin Oncol Nurs 1997;13: 123-8.

15 Guskey T. Implementing mastery learning. Belmont, USA: Wadsworth, 1985

16 Board of Censors in Genetic Counselling. Training guidelines. Human Genetics Society of Australasia, 1999.

17 Stoll BA. Specialist breast and ovarian cancer clinics should be staffed by oncology nurses. BMF 1996;312:913.

\title{
Participation in preconceptional carrier couple screening: characteristics, attitudes, and knowledge of both partners
}

\author{
L Henneman, I Bramsen, H M van der Ploeg, H J Adèr, H E van der Horst, J J P Gille, \\ L P ten Kate
}

7 Med Genet

2001;38:695-703

Department of Clinical Genetics and Human Genetics, Vrije

Universiteit Medical

Centre, Van der

Boechorststraat 7,

NL-1081 BT

Amsterdam, The

Netherlands

L Henneman

J J P Gille

L P ten Kate

Department of

Medical Psychology,

Vrije Universiteit

Medical Centre,

Amsterdam, The

Netherlands

I Bramsen

H M van der Ploeg

Department of Clinical

Epidemiology and

Biostatistics, Vrije

Universiteit Medical

Centre, Amsterdam,

The Netherlands

$\mathrm{H} J$ Adèr

Department of

General Practice,

Nursing Home and

Social Medicine, Vrije

Universiteit Medical

Centre, Amsterdam,

The Netherlands

$\mathrm{H}$ E van der Horst

Correspondence to:

L Henneman,

1.henneman.humgen $a$

med.vu.nl
EDITOR-Couples in which both partners are carriers for a particular autosomal recessive disease, such as cystic fibrosis, Tay-Sachs disease, or thalassaemia, have a 1 in 4 risk for each child to have this disorder. Population carrier screening programmes aimed at the identification of carrier couples make it possible to inform these couples about their risk and about the reproductive options that are available. Before beginning any genetic screening programme, it is important to assess community interest in screening. ${ }^{1}$

It is well known that the way in which carrier screening is offered and the timing, for example, during or outside pregnancy, determine participation in screening and the reasons for participation. Screening offered face to face with the possibility of immediate testing gives high uptake rates, whereas offers made by mailed invitation or poster announcements attract little interest. ${ }^{2-6}$

Most of the data on motives for participation have been obtained from programmes offering carrier screening during pregnancy. ${ }^{7-15}$ In these studies, a high interest in screening was reported, although it has been argued that testing during pregnancy is often accepted just because it is offered. ${ }^{16}$ The decision to participate was mostly made by women, who were often initially tested without discussing it with their partner. Anxiety has been reported among those who are tested positive, while waiting for their partner's results. ${ }^{10} 18$ It can also cause distress when the partner is not available or does not want to be tested. ${ }^{19}$ Furthermore, prenatal screening leaves limited reproductive options for a carrier couple and might impose time constraints when decisions about a prenatal diagnosis have to be made. ${ }^{20}$
Offering carrier screening outside pregnancy shows low participation rates when no pregnancy is planned, but interest is higher when there are plans for having children (preconceptional)..$^{421}$

This study focused on the preconception period as the time for screening and considered couples as the screening unit. Determining why some couples participate in a preconceptional carrier screening programme while others decline provides insight into the desirability of screening. It may also give some indications of how to improve accessibility to screening for those who are interested. To investigate this, couples can be directly asked for reasons why they decided (not) to participate. In addition, determining differences in individual variables and attitudes between participants and nonparticipants can be used to explain participation. Early theories on health related behaviour suggest that intention to take a preventive health action is likely when people (1) view themselves as susceptible to the condition, (2) consider the disease to be serious, (3) perceive high benefits of the health action, and (4) perceive few disadvantages in undertaking it. ${ }^{22}$ These four components are the earliest constructs of the Health Belief Model (HBM), which has been considerably expanded, as was reviewed by Janz and Becker. ${ }^{23}$ The present study focused on a select group of variables derived from the HBM. This model was chosen because of its applicability to predicting behaviour towards voluntary action, such as carrier screening.

In this study, the determinants of participation in preconceptional cystic fibrosis (CF) carrier couple screening was investigated, focusing on the characteristics and attitudes of 
both partners. The study was carried out within the framework of a large project on the feasibility and desirability of CF carrier screening in The Netherlands. It was designed to address the following research questions. What is the main reason why couples choose to participate or choose not to participate in carrier couple screening? Are there HBM related factors associated with participation among eligible couples invited for screening?

\section{Subjects and methods}

PROCEDURES

Participating and non-participating couples were recruited from a feasibility study of preconceptional CF carrier couples screening in The Netherlands. Screening was offered to couples who were considering a pregnancy in the future, by five general practices, between May 1997 and June 1998. In total, 5414 people, aged 20 to 35 years, received a letter of invitation signed by their general practitioner (GP). GPs were asked to exclude patients with fertility problems or psychosocial problems from the mailing list to avoid any possible emotional disturbance of these people by the invitation. The letter invited couples, interested in screening, to attend a 45 minute educational session at a nearby location on two evenings in one week. The letters were non-directive, did not encourage couples to participate, and mentioned that this was a scientific study on interest in participation. Both partners were asked to be present. Enclosed with the letter was an information leaflet. The leaflet described the clinical and genetic aspects of CF, carrier prevalence in the population, the implications for the couple of a positive carrier screening test, and how testing is conducted, including information about the imperfect sensitivity of the test (the test sensitivity in this study was approximately $87 \%$ ). A member of the research group (LH) organised the educational sessions. At the session, attendees were given more detailed information, and an outline of possible advantages and disadvantages of screening was presented. At the end of the session, couples were offered the carrier test, which would be performed by mutation analysis on a mouthwash sample. All of this was offered free of charge. Exclusion criteria for the participation of couples were: pregnancy, a positive family history of $\mathrm{CF}$, and age younger than 18 years. Both partners of participating couples provided a mouthwash sample. If only one partner was able to attend the session, a kit was provided in which the mouthwash sample of the other partner could be collected at home. After the educational session, couples were given an informed consent form to take home and were asked to return it by mail within one week. The Medical Ethical Committee of the academic hospital Vrije Universiteit in Amsterdam approved the study protocol.

UPTAKE

To determine the uptake of screening, a non-response survey by telephone was performed to estimate the percentage of eligible persons in the invited population. Eligibility was defined as having a steady relationship and planning to have one or more children with the partner. A random, age stratified sample of those who did not respond to the initial invitation for screening, that is, did not attend the educational session, was contacted by telephone on different evenings during the week. Other random subjects replaced those who did not answer the telephone after three calls until samples of approximately $10 \%(n=387)$ in every practice were reached. Respondents were asked whether they had received the letter of invitation from their GP, whether they were interested in screening, and whether their situation conformed to that of the target population. The non-response telephone survey showed that $19.6 \%(76 / 387)$ of these invited subjects were eligible for participation. In the calculation of uptake rates, the responses of subjects to the invitation were considered, and not the responses of couples, since invitations were sent to individual people and some partners did not receive an invitation because their age group was not included or because they had a different GP. Subjects whose mail was returned by the post office as undeliverable $(n=99)$ were excluded from the study. In total, 108 subjects (related to 79 couples) responded to the invitation for screening. The response therefore was $2 \%$ of the total population (108/ 5315 ) and $10.4 \%$ of the eligible (target) population (108/1042). Seventy eight couples consented to participate in the test $(78 / 79,98.7 \%$ participation) after the educational session.

COMPARISON OF PARTICIPANTS AND

NON-PARTICIPANTS

To determine factors influencing the decision to accept the test, differences between consenting couples (participants) and a sample (see below) of eligible couples who did not attend the screening session, identified through the non-response telephone survey (nonparticipants), were investigated. Data were gathered by means of questionnaires that were identical for both partners and both groups. Questionnaires were administered to all attendants at the beginning of the educational session. Each partner in a couple was asked to complete the questionnaire individually without consulting the other partner. Of the 78 participating couples, 76 completed the questionnaire.

Non-participants who confirmed during the non-response telephone survey a desire to have children with their partner, that is, they were eligible for participation $(n=76)$, were asked whether they and their partner would be willing to complete the questionnaire and return it by mail. Of these 76 non-participants, six did not wish to take part in the study. In total, $76 \%$ (53/70) of the non-attending eligible couples returned the questionnaire. Those who did not return the questionnaire $(n=17)$ had previously reported by telephone that their main reason for non-participation was lack of time. Eventually, 76 participating and 53 eligible non-participating couples could be compared. 
QUESTIONNAIRE DESIGN

The questionnaire was developed and tested for homogeneity specifically for this study. Subjects were asked, in an open ended question, to indicate the single most important reason for participating or not participating in the screening. In addition, they were asked to report which partner (both partners, man, or woman) had influenced the decision most, and their agreement over the final decision (both agree, partner disagrees, or I disagree). Furthermore, the questionnaire assessed certain components of the Health Belief Model (HBM) including the following:

\section{(1) Sociodemographics}

Subjects provided information on age, gender, marital status, highest level of education, number of children, and religiousness. Couples were also asked to indicate whether a pregnancy was planned in the short term (within the next two years) or in the long term (after the next two years).

(2) Familiarity with the disease

Familiarity with the disease was derived from the response to the question: had you heard about the disease cystic fibrosis before receiving the invitation for screening?

\section{(3) Knowledge of the disease}

This consisted of seven multiple choice questions, assessing the level of understanding of the medical and genetic aspect of CF and carrier testing. A response of "don't know" was scored as an incorrect answer. The number of questions answered correctly was calculated as a sum score. The answers to the separate questions were also considered.

\section{(4) Health locus of control}

The validated subscale of the Multidimensional Health Locus of Control scale with the locus dimension "internal control" was used to indicate the extent to which subjects perceived their behaviour as responsible for their own health (IHLC) ${ }^{24}$ According to this model, a person is more likely to engage in healthy behaviour if he or she has a strong internal locus of control. The subscale consists of six items, and the answering format was a six point Likert-type scale (completely agree (1) to completely disagree (6)). A total sum score was computed for each subject, with high scores indicating a higher likelihood of engaging in healthy behaviour. Cronbach's $\alpha$ for IHLC on the data was 0.76

\section{(5) Perceived discomfort}

The respondents were asked to indicate the extent to which they agreed that screening requires too much of their time and effort (completely disagree (1) to completely agree (5)).

\section{(6) Constructs of HBM}

The questionnaire included 14 items specifically addressing carrier screening, to measure perceptions concerning carrier testing (see Appendix). The newly developed constructs were derived from the four basic HBM dimensions ${ }^{22}$ : (1) perceived risk of being a carrier (couple) and having a child with CF ("Perceived susceptibility", three items), (2) perceived severity of the disease and the burden of treatment of a child with CF ("Perceived seriousness", three items), (3) benefits of testing ("Perceived benefits", five items), and (4) perceived barriers related to screening, such as worries about testing, the perceived impact of carrier status, and the perception that other people will look differently at them when they are identified as carrier ("Perceived impact barriers", three items). For "Perceived susceptibility", respondents were asked to indicate the estimated likelihood of their risk on a six point scale (very unlikely (1) to very likely (6)). For all other items, the respondents were asked to indicate the extent to which they agreed with each statement on a five point Likert scale (completely disagree (1) to completely agree (5)). Principal axis factor analysis with varimax rotation was performed to verify that the items loaded on the four factors of the HBM. Subsequently, a reliability analysis was performed on each scale to determine whether all items contributed to the internal consistency of the scale. Summing up items results in a single measure for three subscales with good reliability: "Perceived susceptibility" (Cronbach's $\alpha=0.83$ ), "Perceived benefits" (Cronbach's $\alpha=0.90$ ), and "Perceived impact barriers" (Cronbach's $\alpha=0.64)$. For "Perceived seriousness", the items $(n=3)$ were considered separately, owing to the low internal consistency of the total scale.

\section{DATA ANALYSES}

To answer the first research question, the answers of couples to the open ended question about the main reason for participating or not participating in screening were coded into general categories. Before trying to answer the second research question, it was necessary to determine whether the data of both partners should be included as a pair, because both the man and the woman of each couple completed a questionnaire. To investigate this, the responses to questionnaires of both partners were compared, using McNemar non-parametric tests for categorical data and paired $t$ tests for continuous data. Since the sociodemographic status was highly correlated between the partners within a couple, data of only one randomly selected partner were included in the bivariate analyses comparing participants and non-participants. For all the other variables (2) to (6), at first the median split of the sum scores was taken, which resulted in subjects with low scores and subjects with high scores (knowledge low (0-3), high (4-7); IHLC low (6-23), high (24-36); susceptibility low (3-9), high (10-18); benefits low (5-19), high (20-25); impact barriers low (3-6), high (7-14), and separate items (discomfort and seriousness) low (1-3), high (4-5)). Paired data analyses showed that in the responses to these variables, there were moderate to low associations between partners in a couple, indicating that both partners provide different information. Therefore, it was not possible randomly to select one partner of the couple for the analyses. In addition, since the attendance of a couple at the 
educational session and participation in screening requires a joint decision, it was assumed that the association between a given variable and participation in screening would be stronger when partners have similar attitudes. To quantify the association between the scores of both partners of a couple, a concordance score was formed on a three point scale: $2=$ "High-High" (both partners in a couple scoring high on the variable), 1="High-Low" (one partner scoring high (male or female) and one partner scoring low (male or female), and 0="Low-Low" (both partners in a couple scoring low on the variable). Subsequently, bivariate analyses were performed to examine the association between participation in screening and the concordance variables (2) to (6). Chi-square analysis and Fisher's exact tests were used to compare responses between participating and non-participating couples. Finally, all variables (1) to (6) that showed statistical significance in bivariate analyses were entered into one multiple logistic regression model simultaneously. All analyses were performed using SPSS for Windows. ${ }^{25} \mathrm{~A} p$ value of $<0.05$ was considered to indicate statistical significance.

\section{Results}

MAIN REASON GIVEN FOR PARTICIPATION AND NON-PARTICIPATION

Among the 76 couples who decided to attend the educational session and consented to $\mathrm{CF}$ carrier testing, the decision was taken jointly in $85 \%$, while $15 \%$ reported that the woman had more influence on the decision to participate. Nevertheless, none of the couples reported disagreement on the final decision. The main reason given by couples for taking the test was that they wanted to know whether they were a carrier couple with a high risk of having a child with CF $(97 \%)$. The other couples (3\%) gave no specific reasons for taking the test. The reasons nonparticipants gave (in their own words) for not responding to the invitation for screening varied, but the most commonly stated reason for not attending the educational session was "lack of time" or "forgot to attend the educational

Table 1 Sociodemographic characteristics of participants and non-participants in a preconceptional CF carrier screening programme*

\begin{tabular}{|c|c|c|c|c|}
\hline & \multicolumn{2}{|c|}{ Participants ( 76 couples) } & \multicolumn{2}{|c|}{ Non-participants (53 couples) } \\
\hline & $\begin{array}{l}\text { Women } \\
(n=76)\end{array}$ & $\operatorname{Men}(n=74)$ & $\begin{array}{l}\text { Women } \\
(n=53)\end{array}$ & $\operatorname{Men}(n=52)$ \\
\hline Age (mean (range)) & $28.5(20-44)$ & $30.9(20-45) \S$ & $27.6(20-37)$ & $30.4(23-41)$ \\
\hline Marital status (\% married) & 45 & 45 & 45 & 46 \\
\hline \multicolumn{5}{|l|}{ Level of education $\dagger(\%)$} \\
\hline Low & 13 & 16 & 19 & 23 \\
\hline Medium & 42 & 42 & 51 & 40 \\
\hline High & 45 & 42 & 30 & 37 \\
\hline Children (\% having children) & 26 & 27 & 42 & 42 \\
\hline $\begin{array}{l}\text { Planning children (\% within } 2 \\
\text { years) }\end{array}$ & 55 & 49 & 62 & 58 \\
\hline \multicolumn{5}{|l|}{ Religion $\ddagger(\%)$} \\
\hline No religion & 47 & 52 & 53 & 59 \\
\hline Religion, irregular practice & 49 & 43 & 34 & 31 \\
\hline Religion, regular practice & 4 & 5 & 13 & 10 \\
\hline
\end{tabular}

For three couples, sociodemographic data for the man were missing.

*Age was evaluated by $t$ test; all other characteristics were evaluated by chi-square.

†Low: primary school, lower level of secondary school, lower vocational training. Medium: higher level of secondary school, intermediate vocational training. High: higher vocational training, university.

$\ddagger$ Irregular practice: church attendance $<1$ month. Regular practice: church attendance $\geqslant 1$ month \Significant at $\mathrm{p}<0.05$ for comparison of men and women within the couples. session" $(53 \%, \mathrm{n}=28)$. Other reasons given were that "the test results would not influence our attitudes towards family planning" (21\%, $\mathrm{n}=11$ ). Furthermore, $15 \%$ of the couples were not interested in testing because they "were not concerned" $(n=6)$ or they had "never heard of CF" $(n=2)$. Five percent reported "testing would make us too anxious". The answers of most partners in a couple could be placed in the same category. However, in three couples (6\%), the partners showed disagreement; the women reported that they were interested in screening but they declined the test because their partners were reluctant to participate.

FACTORS ASSOCIATED WITH PARTICIPATION

Sociodemographics of participants and nonparticipants, both men and women, are shown in table 1. Within the couples included in the study, no statistically significant differences were found between men and women with regard to educational level, time period in which children were planned, and religiousness. The men were significantly older than the women in both participating and nonparticipating couples. In general, within a relationship, men are older than women in The Netherlands. ${ }^{26}$ In bivariate analyses, no associations could be shown between participation and the variables age, marital status, level of education, number of children, the time period for planning children, or religiousness.

While the sociodemographics for both men and women within the couples were highly comparable, paired data analyses showed that in the responses to the other variables, such as familiarity with CF, knowledge of $\mathrm{CF}$, and perceptions with regard to carrier screening, there were differences between partners. Therefore, data of both partners were included in the subsequent analyses. Table 2 shows the bivariate associations between components of the Health Belief Model and participation in screening for the three different concordance groups ("High-High", "High-Low", "LowLow"). Participating couples scored higher than non-participating couples on the knowledge questionnaire, and higher on the internal health locus of control (IHLC) scale and perceived higher benefits of testing. In addition, participating couples were more likely than non-participating couples to perceive low discomfort of screening and low impact barriers to screening. No associations were found between participation in screening and familiarity with $\mathrm{CF}$, perceived susceptibility, or the items on perceived seriousness. Furthermore, no differences in responses were found between the five general practices that participated in offering the screening.

The relevant components found in the bivariate analyses were entered into one multiple logistic model simultaneously. Coefficients, odds ratios (OR), 95\% confidence intervals (95\% CI), and $\mathrm{p}$ values for this model are presented in table 3. Perceived discomfort and perceived benefits appeared to be the strongest predictors for participation in screening. Couples in which both partners perceived low discomfort of screening were more likely to 
Table 2 Bivariate associations of components of the Health Belief Model and concordance variables ${ }^{\star}$ of participating and non-participating couples

\begin{tabular}{|c|c|c|}
\hline & $\begin{array}{l}\text { Participants } \\
n=76 \text { couples (\%) }\end{array}$ & $\begin{array}{l}\text { Non-participants } \\
n=53 \text { couples (\%) }\end{array}$ \\
\hline \multicolumn{3}{|c|}{ Familiarity with the disease } \\
\hline Yes-Yes & 34 & 28 \\
\hline Yes-No & 36 & 30 \\
\hline No-No & 30 & 42 \\
\hline \multicolumn{3}{|c|}{ Knowledge of the disease } \\
\hline High-High & 62 & $34^{\star \star \star \star}$ \\
\hline High-Low & 26 & $25^{\star \star \star}$ \\
\hline Low-Low & 12 & $41^{\star \star \star}$ \\
\hline \multicolumn{3}{|l|}{ IHLC† } \\
\hline High-High & 33 & $23^{\star \star}$ \\
\hline High-Low & 40 & $24^{\star \star}$ \\
\hline Low-Low & 27 & $53^{\star \star}$ \\
\hline \multicolumn{3}{|c|}{ Perceived discomfort } \\
\hline High-High & 0 & $11^{\star \star \star}$ \\
\hline High-Low & 3 & $23^{\star \star \star \star}$ \\
\hline Low-Low & 97 & $66^{\star \star \star}$ \\
\hline \multicolumn{3}{|c|}{ Perceived susceptibility } \\
\hline High-High & 1 & 4 \\
\hline High-Low & 13 & 8 \\
\hline Low-Low & 86 & 88 \\
\hline \multicolumn{3}{|c|}{ Perceived benefits } \\
\hline High-High & 77 & $34^{\star \star \star}$ \\
\hline High-Low & 18 & $26^{\star \star \star}$ \\
\hline Low-Low & 5 & $40^{\star \star \star}$ \\
\hline \multicolumn{3}{|c|}{ Perceived impact barriers } \\
\hline High-High & 5 & $38^{\star \star \star}$ \\
\hline High-Low & 32 & $38^{\star \star \star}$ \\
\hline Low-Low & 63 & $24^{\star \star \star}$ \\
\hline \multicolumn{3}{|c|}{ Burden of disease } \\
\hline High-High & 67 & 55 \\
\hline High-Low & 17 & 24 \\
\hline Low-Low & 16 & 21 \\
\hline \multicolumn{3}{|c|}{ Burden of child with disease } \\
\hline High-High & 75 & 64 \\
\hline High-Low & 18 & 25 \\
\hline Low-Low & 7 & 11 \\
\hline \multicolumn{3}{|c|}{ Burden of treatment } \\
\hline High-High & 22 & 19 \\
\hline High-Low & 38 & 26 \\
\hline Low-Low & 40 & 55 \\
\hline
\end{tabular}

For five couples, data for only one partner were available. In the analyses, data of the available partner were used for the missing data of the other partner. Analyses without these five couples showed the same results.

${ }^{\star}$ High-High/Yes-Yes (both partners of a couple scoring $\mathrm{High} / Y e s$ on the variable). High-Low/Yes-No (one partner scoring High/Yes (male or female) and one partner scoring Low/No (male or female)). Low-Low/No-No (both partners of a couple scoring Low/No on the variable).

tInternal health locus of control scale.

Chi-square tests for comparison of participating and nonparticipating couples, ${ }^{\star \star} \mathrm{p}<0.01,{ }^{\star \star \star} \mathrm{p}<0.001$.

participate than couples in which at least one partner perceived high discomfort of screening. Compared to couples perceiving low benefits from screening, couples in which one or both partners perceived high benefits were more likely to participate. Couples in which both partners perceived low impact barriers were more likely to have the test than couples in which both partners perceived high barriers. Couples with high knowledge scores were more likely than couples with low knowledge scores to participate in screening. Finally, couples with one partner scoring high on the internal health locus of control scale were more likely to participate than couples with low scores.

ATTITUDES OF COUPLES WITH DIFFERENT

REASONS FOR NON-PARTICIPATION

Over half of the couples who did not attend the educational session $(53 \%)$ reported that the main reason for non-participation was that they had no time or had forgotten to attend the educational sessions. These couples may differ in their attitude towards testing from the other non-participating couples. To analyse this, couples who did not attend were divided into two subgroups: (1) those who reported that they had no time or had forgotten to attend, but were possibly interested in screening ("lack of time", $n=28$ ), and (2) those who did not attend for other reasons ("other reasons", $\mathrm{n}=25$ ). Bivariate analyses of the variables (1) to (6) showed that only one variable was associated with reporting "lack of time". In nonparticipating couples reporting "lack of time", it was more likely that both partners perceived high benefits of screening than in nonparticipating couples reporting "other reasons" $(50 \%$ v 16\%) (OR=8.7 (2.0-37.7)). In addition, two-thirds of these couples perceiving high benefits and reporting "lack of time" had high knowledge scores.

Of all non-participants, $76 \%$ supported the view that genetic carrier testing for CF should be offered to all couples planning to have children, $15 \%$ did not favour this opinion, and 9\% were not sure. Among those who reported "lack of time", only two respondents were opposed to offering screening in the general population.

\section{PARTICIPANT AND NON-PARTICIPANT \\ KNOWLEDGE}

With regard to more detailed knowledge of $\mathrm{CF}$, a comparison was made of correct answers of participants (before the educational session) and non-participants to five multiple choice questions on the knowledge questionnaire. The answers to these questions could all have been found in the information leaflet, which was sent with the letter of invitation for screening. Participants were significantly more likely than non-participants to be aware of the most important symptoms of CF (64\% v 32\%), to know that carriers do not need to have a family history of CF ( $83 \% v 69 \%)$, to recall the risk of being a CF carrier (61\% v 39\%), and to

Table 3 Multiple logistic regression model: odds of participation of couples in CF carrier screening

\begin{tabular}{ll}
\hline Predictor & Odds ratio $(95 \%$ CI) \\
\hline $\begin{array}{l}\text { Knowledge of disease } \\
\text { High-High }\end{array}$ & $6.1(1.5-24.9)^{\star \star}$ \\
High-Low & $3.2(0.8-13.5)$ \\
Low-Low & Ref \\
IHLC & \\
High-High & $2.3(0.7-8.1)$ \\
High-Low & $5.2(1.4-19.4)^{\star \star}$ \\
Low-Low & Ref \\
Perceived discomfort $\dagger$ & \\
High-High/High-Low & Ref \\
Low-Low & $19.2(2.9-125.5)^{\star \star \star}$ \\
Perceived benefits & \\
High-High & $16.2(3.8-69.1)^{\star \star \star}$ \\
High-Low & $7.9(1.6-39.4)^{\star \star}$ \\
Low-Low & Ref \\
Perceived impact barriers & \\
High-High & Ref \\
High-Low & $3.7(0.8-17.5)$ \\
Low-Low & $7.0(1.5-32.2)^{\star \star}$ \\
\end{tabular}

Ref $=$ reference category.

${ }^{\star}$ Internal health locus of control scale.

$\dagger$ In the analyses, the subgroups High-High and High-Low were added together, to account for empty cells in the subgroup High-High.

${ }^{\star \star} \mathrm{p}<0.05,{ }^{\star \star \star} \mathrm{p}<0.01$. 
understand that carriers of $\mathrm{CF}$ would not develop CF related health problems $(66 \%$ v $41 \%)$. There was no association between knowledge scores and level of education. In both groups, women scored higher on the knowledge questionnaire than men. In addition, more women than men had previously heard of CF.

\section{Discussion}

In this study, factors associated with participation in preconceptional carrier couple screening were assessed. The results suggest that couples who participated in the CF carrier screening programme, as opposed to those who did not, perceived lower discomfort from screening, perceived higher benefits, perceived lower impact of the consequences of screening, knew more about CF, and perceived their own behaviour to be responsible for their health. Overall, the results were more pronounced when partners had similar perceptions. The main reason given for not participating in screening was lack of time to attend the educational session. The results showed that couples who lacked the time to attend perceived more benefits from screening than couples reporting "other reasons" for nonparticipation.

As expected, higher perceived benefits of the test were associated with more participation in screening. Benefits from testing reflect the importance couples attach to knowing their chances of having a child with $\mathrm{CF}$, which was also found to be the most frequently reported reason for participation in screening. It also reflects the expectations of the couples that they will have more reassurance and that the test results will help them to make decisions about having children. Higher awareness of the benefits of screening may increase the acceptance and participation of couples in screening. In $34 \%$ of the non-participating couples, the perception of the discomfort of screening was high for at least one partner. These couples will probably only participate if screening takes less of their time and does not require an extra visit. The results also suggest that those who perceive low impact barriers, such as the impact of carriership on their general health status and the perception that other people will look differently at them, are more likely to accept screening. Only $41 \%$ of all nonparticipants stated correctly that carriers of CF would not develop health problems resulting from their carrier status. These results suggest that anxiety about screening and the burden of carrier status are partly based on misconceptions owing to lack of knowledge.

Knowledge of CF was also a predictor for participation in screening, although this is probably more a reflection of the interest couples have in screening and reading the leaflet before attending the educational session than knowing about CF before the invitation for screening. Nevertheless, inadequate understanding could lead to increased anxiety, and therefore result in non-participation. Bernhardt $e t a l^{7}$ stated that better baseline understanding of human genetics in the public might provide a basis for understanding genetic screening tests and increase interest in learning about screening tests.

The percentage of respondents who were familiar with CF is comparable with the percentages in the Dutch population in general, in which $60 \%$ know about the disease and $15 \%$ know somebody with $\mathrm{CF}^{28}$ Familiarity with the disease was not associated with participation. This could be explained by the fact that people may have heard about CF, but do not know the clinical implications or the hereditary pattern of the disease. Possibly therefore, this variable was not a motivating factor in participation.

Studies have shown that people are more likely to participate in screening if they consider themselves susceptible to being a carrier or to having an affected child. ${ }^{412}{ }^{29}{ }^{30}$ This is in contrast with the finding of the present study, in which no association was found between perceived risk and participation. Most respondents thought it very unlikely that they would be a carrier or that they would have a child with CF. The percentage of respondents knowing the carrier risk was $61 \%$ in the participants and 39\% in the non-participants. Again, this might imply that non-participation is partly based on lack of knowledge and the assumption that $\mathrm{CF}$ is not very common. The question remains as to whether a more accurate understanding of actual risk might have led to a different perception of risk, which would influence participation. A previous study has shown that perceived risk, rather than actual risk, influences the participation of women in prenatal screening tests. ${ }^{31}$ Presumably, couples participate because they want to be reassured that their risk is low, and not because there is a chance of their being carriers or having a child with CF. This is supported by the findings of Loader $e t a l^{12}$ that the desire for reassurance of a low risk of having a child with CF was mentioned twice as often $(50.6 \%)$ as the intention to avoid having such a child $(27.8 \%)$.

Other studies ${ }^{49}$ have also reported the lack of an association between perceived seriousness of the disease itself and participation in screening. In the present study, the burden of the disease and the burden of a child with CF was perceived as high for most respondents, whereas the impact of treatment was perceived as moderate to low. This suggests that respondents perceive $\mathrm{CF}$ as a very serious disease, but think they can cope with a sick child in practice. In the present study, no influence of the level of education on participation was found, which is in contrast with the findings of other studies. ${ }^{412132129}$ Furthermore, already having children was not found to be a reason to decline screening, suggesting that the couples understood this aspect of inheriting CF. Overall, $45 \%$ of the couples were married, as expected from this age group in the Dutch population..$^{25}$

The effect of factors predicting participation in screening was more pronounced when couples shared their views. To our knowledge, only one other study ${ }^{29}$ described the agreement of 
husband and wife in predicting participation in a carrier screening programme. In this study, it was found that the combined beliefs of couples increased precision in the prediction of who will participate in screening for Tay-Sachs disease.

In the present study it was stressed that both partners should attend the educational session to receive the same information, on which subsequent decision making could be based. Of all participating couples, $15 \%$ reported that the decision to accept screening was merely the woman's decision, whereas $6 \%$ declined because the male partner did not wish to participate. The results also showed that women had heard about CF more often than men and knew more about the disease. Overall, these results are consistent with the findings of other studies, ${ }^{3}{ }^{5-7} 2132$ that is, that interest in testing is greater among women than among men. This may reflect the greater concern and responsibility in reproductive decisions felt by women. Future analyses of additional data will be performed to determine whether gender differences in the response to the test results can be found, as has been reported in other studies. $^{33} 34$

Lack of time was the most frequently reported reason for non-participation. The invitation to attend the educational session on two evenings in one week was sent 14 days in advance. This might have been too short for people who already had other appointments on these evenings. Moreover, it has been found that when screening is offered a second time, on more evenings, or when people can make their own appointment, for example with their own GP, participation increases (Henneman et $a l$, in preparation). Although not reported, another reason for non-participation might be that couples prefer personal counselling instead of attending a general educational session with other couples. In a study carried out by Clayton et $a l,{ }^{6}$ non-pregnant couples showed lack of interest in carrier screening. Reluctance to participate was ascribed to worries about factors such as insurability, being at risk, what they would need to learn, abortion, and religious beliefs. However, the authors believe that lack of interest in that study might also be explained by the mode of invitation, letters placed in pockets on signs and not personally addressed to those who were offered screening. Mode of invitation has been found to be the most important factor influencing acceptance. ${ }^{2-4}$ Invitations that were more personal might have increased interest in that specific screening programme. In prenatal carrier screening, unwillingness to terminate an affected pregnancy was mainly found to be the most frequently reported reason to decline screening, ${ }^{9} 1235$ although lack of time has also been reported. ${ }^{14}$

The uptake of the pre-educational screening session of couples who planned to have children was $10.4 \%$ in the present study. This uptake is not high, compared with other screening programmes offered before pregnancy ${ }^{235}$ and during pregnancy. ${ }^{910} 1336$ However, the authors are of the opinion that uptake rate is not the most important determinant, if not for economic reasons, of the desirability of screening. Yet, knowledge about motives and barriers for participation is important. As Marteau ${ }^{37}$ also emphasised, one of the key research questions for the next 10 years should be to find the best way of offering tests to achieve informed choice. In the present study, the main reason couples gave for participation in the screening was to find out whether they were at high risk of having a child with CF. None of the couples reported that they participated in the screening because they were told to do so by their GP or that they felt that they could not refuse. These results suggest that because of the time and effort needed for participation, couples were stimulated to make a decision based on the conviction that screening is important, and not just because it is offered or strongly recommended, as was argued for opportunistic screening programmes with high uptake rates. $^{36} 38$

For this study, new scales based on the Health Belief Model (HBM) were developed to evaluate the response of couples to $\mathrm{CF}$ carrier screening. Several other components of the HBM, that were not addressed in the present study for practical reasons, may also be important, such as interpersonal interactions and mass media communications, ${ }^{22}$ and the influence of psychological defence mechanisms, such as avoidance behaviour. ${ }^{30}$ There has also been more general criticism of the model, like other rational choice theories, that is, that it provides an idealised view of how decisions should be made and that it gives insufficient attention to emotion in decision making and the role of cultural standards and values. ${ }^{39}$ However, the HBM provided more insight into the motives and barriers reported by couples who were offered carrier screening. In addition to $\mathrm{HBM}$ related variables, other variables are also considered to be important in affecting participation in carrier screening, such as tolerance of test uncertainty. ${ }^{4}$

This article specifically addressed the participation in preconceptional CF carrier screening in The Netherlands. Differences between other screening programmes and other countries will exist, but many similarities are evident, and the results of this study can be used in the development of other programmes. Preconceptional screening was chosen because it provides a maximum number of reproductive options for identified carrier couples and involves a minimum of (time) constraint. Furthermore, there are three other reasons why preconceptional screening is highly applicable in The Netherlands. Firstly, prenatal screening is difficult for practical reasons, because many pregnant women visit a clinic late in their pregnancy. Secondly, preconceptional screening meets the requirements formulated by the Committee for Genetic Screening of the Dutch Health Council, whereas prenatal screening does not. ${ }^{40}$ Thirdly, there are a large number of planned pregnancies in The Netherlands (85-90\%), creating an ideal situation for contacting couples before conception. These reasons may also be valid for other countries. In 


\section{Appendix}

Constructs of the Health Belief Model: subscales and items with good reliability and associated $\alpha(n=3)$ and separate items of subscales with low reliability $(n=1)$

\begin{tabular}{|c|c|}
\hline Subscales: & $\begin{array}{l}\text { Perceived susceptibility (Cronbach's a 0.90) } \\
\text { - Estimated likelihood of being a CF carrier } \\
\text { - Estimated likelihood of being a CF carrier } \\
\text { couple } \\
\text { - Estimated likelihood of having a child with CF } \\
\text { Perceived benefits (Cronbach's a 0.83) } \\
\text { - Carrier testing gives me more reassurance } \\
\text { - It is important for me to know if I am a carrier } \\
\text { - It is important for me to know my risk of } \\
\text { having a child with CF } \\
\text { - The test results will help me to make } \\
\text { childbearing decisions } \\
\text { - Carrier testing should be offered to all couples } \\
\text { who are planning to have children } \\
\text { Perceived impact barriers (Cronbach's a 0.64) } \\
\text { - If I had carrier testing, I would feel worried } \\
\text { - If I were a carrier, I would feel less healthy } \\
\text { - If I were a carrier, people would look } \\
\text { differently at me }\end{array}$ \\
\hline Separate items: & $\begin{array}{l}\text { Perceived seriousness of disease } \\
\text { - CF is one of the worst diseases there is } \\
\text { (burden of disease) } \\
\text { - I would find it hard if my child had CF } \\
\text { (burden of child with disease) } \\
\text { - I would find it hard to give my child the } \\
\text { treatment (burden of treatment) }\end{array}$ \\
\hline
\end{tabular}

${ }^{\star}$ Cronbach's $\alpha$ less than 0.40 .

addition, preconceptional screening can be considered for a number of other reasons, as has recently been suggested for Tay-Sachs disease $^{41}$ and haemoglobin disorders. ${ }^{43}$ For example, in the UK, prenatal screening for haemoglobin disorders is recommended as a routine practice, ${ }^{44}$ although it has been shown that the present practice does not always meet the needs for early information and leads to the late recognition of risk. ${ }^{45}$ Moreover, at the beginning of a thalassaemia screening programme $^{43}$ in Sardinia in the mid 1970s, the largest category of participants consisted of pregnant women, whereas the number of couples without a pregnancy is currently increasing. In other countries, however, cultural differences influence the approach to carrier screening. ${ }^{47}$ For example, screening is offered premaritally to communities of Orthodox Jews, to prevent the marriage of two carriers of recessive disorders. ${ }^{48}$

In this study, interest in preconceptional CF carrier screening, requiring time and effort to participate, is shown, both by the actual participation of couples and by the perceived benefits of screening of couples who did not participate. The results of the study could be used as a model for other screening programmes. Lack of time to attend the educational session was found to be the main influence on participation in carrier screening by non-pregnant couples. However, the results suggest that these couples have positive attitudes towards screening and will attend when screening is offered more conveniently. The results also indicate that participation is influenced by "psychological" barriers, possibly caused by an inadequate understanding of the consequences of carrier testing. These barriers could be removed by providing more clear information about the meaning of carrier status and by increasing public awareness. In addition to participation in screening, the psychological and cognitive consequences of screening are being investigated.

The authors thank the participating general practitioners for their cooperation in this project, and especially Henk de Vries. This project was supported by the Vrije Universiteit Medical Centre Amsterdam and by grant No 2827030 from The Netherlands Health Research and Development Council.

1 Wilfond BS, Thomson EJ. Models of public health genetic policy development. In: Khoury MJ, Burke W, Thomson EJ, eds. Genetics and public health in the 21st century. Using genetic information to improve health and prevent disease. Oxford: Oxford University Press, 2000:61-81.

2 Watson EK, Mayall E, Chapple J, Dalziel M, Harrington K, Williams C, Williamson R. Screening for carriers of cystic fibrosis through primary health care services. BMF 1991;303:504-7.

3 Bekker H, Modell M, Denniss G, Silver A, Mathew C, Bobrow M, Marteau T. Uptake of cystic fibrosis testing in Bobrow M, Marteau T. Uptake of cystic fibrosis testing in
primary care: supply push or demand pull? BMF 1993;306: primary

4 Tambor ES, Bernhardt BA, Chase GA, Faden RR, Geller G, Hofman KJ, Holtzman NA. Offering cystic fibrosis carrier screening to an HMO population: factors associated with utilization. Am f Hum Genet 1994;55:626-37.

5 Payne Y, Williams M, Cheadle J, Stott NC, Rowlands M, Shickle D, West G, Meredith L, Goodchild M, Harper PS, Clarke A. Carrier screening for cystic fibrosis in primary care: evaluation of a project in South Wales. The South Wales Cystic Fibrosis Carrier Screening Research Team. Clin Genet 1997;51:153-63.

6 Clayton EW, Hannig VL, Pfotenhauer JP, Parker RA, Campbell PW, Phillips JA. Lack of interest by nonpregnant couples in population-based cystic fibrosis carrier screening. Am f Hum Genet 1996;58:617-27.

7 Kaback MM, Becker MH, Ruth MV. Sociologic studies in human genetics. I. Compliance factors in a voluntary heterozygote screening program. Birth Defects 1974;10: 145-63.

8 Rowley PT, Loader S, Sutera CJ, Walden M, Kozyra A. Prenatal screening for hemoglobinopathies. III. Applicability of the health belief model. Am f Hum Genet 1991;48:452-9.

9 Mennie ME, Gilfillan A, Compton ME, Liston WA, Brock DJ. Prenatal cystic fibrosis carrier screening: factors in a woman's decision to decline testing. Prenat Diagn 1993;13: 807-14

10 Miedzybrodzka ZH, Hall MH, Mollison J, Templeton A, Russell IT, Dean JCS, Kelly KF, Marteau TM, Haites NE. Antenatal screening for carriers of cystic fibrosis: randomised trial of stepwise $\mathrm{v}$ couple screening. BMF 1995;310:353-7.

11 Harris HJ, Scotcher D, Hartley NE, Wallace A, Craufurd D, Harris R. Pilot study of the acceptability of cystic fibrosis carrier testing during routine antenatal consultations in general practice. Br f Gen Pract 1996;46:225-7.

12 Loader S, Caldwell P, Kozyra A, Levenkron JC, Boehm CD, Kazazian HH, Rowley PT. Cystic fibrosis carrier populaKazazian HH, Rowley PT. Cystic fibrosis carrier popula-
tion screening in the primary care setting. Am f Hum Genet 1996;59:234-47.

13 Witt DR, Schaefer C, Hallam P, Wi S, Blumberg B, Fishbach A, Holtzman J, Kornfeld S, Lee R, Nemzer L, Palmer R. Cystic fibrosis heterozygote screening in 5,161 pregnant women. Am f Hum Genet 1996;58:823-35.

14 Grody WW, Dunkel-Schetter C, Tatsugawa ZH, Fox MA, Fang CY, Cantor RM, Novak JM, Bass HN, Crandall BF. PCR-based screening for cystic fibrosis carrier mutations in an ethnically diverse pregnant population. Am f Hum Genet 1997;60:935-47

15 Modell B, Harris R, Lane B, Khan M, Darlison M, Petrou $\mathrm{M}$, Old J, Layton M, Varnavides L. Informed choice in genetic screening for thalassaemia during pregnancy: audit from a national confidential inquiry. BMF 2000;320:33741.

16 Hartley NE, Scotcher D, Harris H, Williamson P, Wallace A, Craufurd D, Harris R. The uptake and acceptability to patients of cystic fibrosis carrier testing offered in patients of cystic fibrosis carrier testing offe
pregnancy by the GP. f Med Genet 1997;34:459-64.

17 Mennie ME, Gilfillan A, Compton M, Curtis L, Liston WA, Pullen I, Whyte DA, Brock DJH. Prenatal screening for Pullen I, Whyte DA, Brock DJH. Prentic fibrosis. Lancet 1992;340:214-16.

18 Clausen H, Brandt NJ, Schwartz M, Skovby F. Psychological and social impact of carrier screening for cystic fibrosis among pregnant woman - a pilot study. Clin Genet 1996;49: 200-5.

19 Wald NJ, George LM, Wald NM, Mackenzie I. Couple screening for cystic fibrosis. Lancet 1993;342:1307-8.

20 Raeburn JA. Screening for carriers of cystic fibrosis. Screening before pregnancy is needed. BMF 1994;309:1428-9.

21 Honnor M, Zubrick SR, Walpole I, Bower C, Goldblatt J. Population screening for cystic fibrosis in Western Australia: community response. Am 7 Med Genet 2000; 93:198-204.

22 Rosenstock IM. Why people use health services. Milbank Mem Fund $Q 1966 ; 44: 94-127$.

23 Janz NK, Becker MH. The Health Belief Model: a decade later. Health Educ $Q$ 1984;11:1-47.

24 Wallston KA, Wallston BS, DeVellis R. Development of the Multidimensional Health Locus of Control (MHLC) Scales. Health Educ Monogr 1978;6:160-0. 
25 SPSS Inc. SPSS release 7.5.2. Chicago, 1997

26 Statistics Netherlands. Statistical yearbook (in Dutch). The Hague: Sdu/publishers, 1998 .

27 Bernhardt BA, Chase GA, Faden RR, Geller G, Hofman KJ, Tambor ES, Holtzman NA. Educating patients about cystic fibrosis carrier screening in a primary care setting. Arch Fam Med 1996;5:336-40.

28 Healthcare Marketing and Research. Cystic fibrosis. Omnibusonderzoek onder de Nederlandse bevolking en een telefonisch onderzoek onder huisartsen en kinderartsen (in Dutch). Bussum: Jan Schipper Compagnie, 1998

29 Becker MH, Kaback MM, Rosenstock IM, Ruth MV. Some influences on public participation in a genetic screening program. 7 Commun Health 1975;1:3-14.

30 Fang CY, Dunkel-Schetter C, Tatsugawa ZH, Fox MA, Bass HN, Crandall BF, Grody WW. Attitudes toward genetic carrier screming for cystic fibrosis among pregnant camen: the role of Womens Health 1997;3:31-51.

31 Marteau TM, Kidd J, Cook R, Michie S, Johnston M, Slack J, Shaw RW. Perceived risk not actual risk predicts uptake for amniocentesis. Br f Obstet Gynaecol 1991;98:282-6.

32 Wake SA, Rogers CJ, Colley PW, Hieatt EA, Jenner CF, Turner GM. Cystic fibrosis carrier screening in two New South Wales country towns. Med f Aust 1996;164:471-4.

33 Marteau TM, Dundas R, Axworthy D. Long-term cognitive and emotional impact of genetic testing for carriers of cystic fibrosis: the effects of test result and gender. Health Psychol 1997;16:51-62.

34 Evers-Kiebooms G, Denayer L, Welkenhuysen M, Cassiman JJ, Van den Berghe H. A stigmatizing effect of the carrier status for cystic fibrosis? Clin Genet 1994;46:336-43.

35 Livingstone J, Axton RA, Mennie M, Gilfillan A, Brock DJ. A preliminary trial of couple screening for cystic fibrosis: designing an appropriate information leaflet. Clin Genet $1993 ; 43 \cdot 57-62$

36 Schwartz M, Brandt NJ, Skovby F. Screening for carriers of cystic fibrosis among pregnant women: a pilot study. Eur $\mathcal{F}$ cystic fibrosis among pregnan Genet 1993;1:239-44.
Hum

37 Marteau TM. Population screening for cystic fibrosis: a research agenda for the next 10 years. Am $\mathcal{F}$ Med Genet 2000;93:205-6.
38 Schmidtke J. Proceed with much more caution. Hum Genet 1994;94:25-7.

39 Kessler RC, House JS, Anspach RR, Williams DR. Social psychology and health. In: Cook KS, Fine GA, House JS, eds. Sociological perspectives on social psychology. Boston: Allyn and Bacon, 1995:548-70.

40 Van de Laar J, Ten Kate LP. Preconception screening for carrier state in cystic fibrosis; testing against Health Council's criteria for genetic screening (in Dutch). Ned Tijdschr Geneeskd 1996;140:487-91.

41 Kaplan F. Tay-Sachs disease carrier screening: a model for prevention of genetic disease. Genet Test 1998;2:271-92.

42 Modell M, Wonke B, Anionwu E, Khan M, Tai SS, Lloyd $\mathrm{M}$, Modell B. A multidisciplinary approach for improving services in primary care: randomised controlled trial of screening for haemoglobin disorders. BMF 1998;317:78891

43 Cao A, Saba L, Galanello R, Rosatelli MC. Molecular diagnosis and carrier screening for $\beta$ thalassemia. FAMA 1997; 278:1273-7.

44 Standing Medical Advisory Committee. Report of a working party of the Standing Medical Advisory Committee on Sickle Cell, Thalassemia and Other Hemoglobinopathies. London: Her Majesty's Stationary Office, 1994.

45 Modell B, Petrou M, Layton M, Varnavides L, Slater C, Ward RHT, Rodeck C, Nicolaides K, Gibbons S, Fitches A, Old J. Audit of prenatal diagnosis for haemoglobin disorders in the United Kingdom: the first 20 years. BMF orders in the United

46 Neuenschwander H, Modell B. Audit of process of antenatal screening for sickle cell disorders at a north London hospital. BMF 1997;315:784-5.

47 Burnett L, Proos AL, Chesher D, Howell VM, Longo L, Tedeschi V, Yang VA, Siafakas N, Turner G. The Tay-Sachs disease prevention program in Australia: Sydney pilot study. Med F Aust 1995;163:298-300.

48 Abeliovich D, Quint A, Weinberg N, Verchezon G, Lerer I, Ekstein J, Rubinstein E. Cystic fibrosis heterozygote screening in the Orthodox Community of Ashkenazi Jews: the Dor Yesharim approach and heterozygote frequency. Eur F Hum Genet 1996;4:338-41.
7 Med Genet 2001;38:703-705

Department of Neurology, Aichi Medical University

School of Medicine, 21 Karimata, Yazako, Nagakute, Aichi 480-1195, Japan

K Sahashi

T Ibi

Department of Internal Medicine II, Fukui Medical University, Fukui 910-1193, Japan

M Yoneda

Department of Neurology, Mayo Clinic, Rochester, MN 55905, USA

K Ohno

Department of Gene Therapy, Gifu International Institute of Biotechnology, Gifu 505-0116, Japan M Tanaka

Department of Neurology, Nagoya

First Red Cross Hospital, Aichi 453-8511, Japan

K Sahashi

Correspondence to: Dr Sahashi,

sahashi@aichi-med-u.ac.jp

\title{
Functional characterisation of mitochondrial
} $\mathrm{tRNA}^{\mathrm{Tyr}}$ mutation $(5877 \mathrm{G} \rightarrow \mathrm{A})$ associated with familial chronic progressive external ophthalmoplegia

\author{
Ko Sahashi, Makoto Yoneda, Kinji Ohno, Masashi Tanaka, Tohru Ibi, Kentaro Sahashi
}

EDITOR-Chronic progressive external ophthalmoplegia (CPEO) is a common clinical manifestation of mitochondrial cytopathies characterised by ophthalmoplegia and ptosis. ${ }^{1}$ Approximately two-thirds of CPEO patients harbour a large, heteroplasmic, mitochondrial DNA (mtDNA) deletion. ${ }^{2}$ Some other CPEO patients carry a point mutation in the mitochondrial tRNA genes. Twelve point mutations in six mitochondrial tRNA genes have been reported to date in association with CPEO (Mitomap at http://www.gen.emory.edu/ mitomap.html). Among the 12 mutations, $5703 \mathrm{C} \rightarrow \mathrm{T}$ in the $\mathrm{tRNA}^{\mathrm{Asn}}$ gene has been functionally characterised. ${ }^{3}$ Here we report functional analysis of $5877 \mathrm{G} \rightarrow \mathrm{A}$ in tRNA ${ }^{\mathrm{Tyr}}$ identified in a patient with $\mathrm{CPEO}^{4}$ using $\rho^{0}$ cells that lack mtDNA.

A 45 year old woman had moderate degrees of ptosis, external ophthalmoplegia, and proximal muscle weakness from the age of 28 . She had no sensorineural hearing loss, ataxia, pigmentary retinopathy, hypogonadism, or mental retardation. She had episodic diarrhoea of unknown aetiology. An ECG showed atrioventricular conduction block, while EEG, brain CT, and brain
MRI showed no abnormalities. An exercise loading test of 15 watts for 15 minutes on a bicycle ergometer ${ }^{5}$ raised her serum lactate from $6.9 \mathrm{mg} / \mathrm{dl}$ to $24.0 \mathrm{mg} / \mathrm{dl}$ (normal, less than 18.0 $\mathrm{mg} / \mathrm{dl}$ ), and her serum pyruvate from $0.6 \mathrm{mg} / \mathrm{dl}$ to $1.4 \mathrm{mg} / \mathrm{dl}$ (normal, less than $1.3 \mathrm{mg} / \mathrm{dl}$ ), thereby increasing the lactate to pyruvate ratio from 10.7 to 17.1 (normal, less than 13.8). A biopsy specimen obtained from the biceps brachii showed $4.0 \%$ ragged red fibres and $0.7 \%$ cytochrome $c$ oxidase negative fibres.

Mutation analysis of muscle mtDNA was briefly described previously (patient 2 in Ozawa et $a l^{4}$ ). Determination of the entire mtDNA sequence showed 34 nucleotide changes; 33 were homoplasmic and were observed in 274 controls with variable frequencies. A $5877 \mathrm{G} \rightarrow \mathrm{A}$ transition in the $\mathrm{tRNA}^{\mathrm{Tyr}}$ gene was heteroplasmic and unique to the patient. The ratios of mutant to wild type mtDNA were $73 \%$ in skeletal muscle and $0.7 \%$ in blood (fig $1 \mathrm{~B}$ ). The $5877 \mathrm{G} \rightarrow \mathrm{A}$ mutation is located in the DHU loop of the tRNA ${ }^{\text {Tyr }}$ gene (fig $1 \mathrm{~A}$ ). The $5877 \mathrm{G}$ base pairs with $5905 \mathrm{C}$ in the variable loop (circle in fig $1 \mathrm{~A}$ ) to form the L shaped tertiary structure of the tRNA 
A

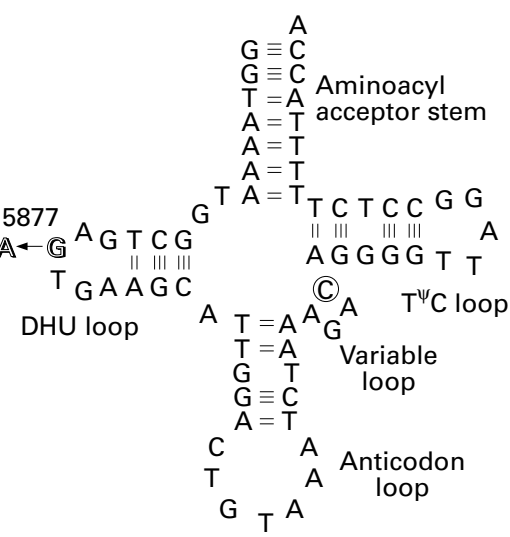

B

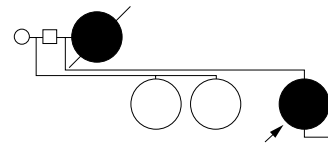

BS PB PB $\overline{P B} \quad S M \overline{P B ~ U C ~} \overline{P B \quad U C}$

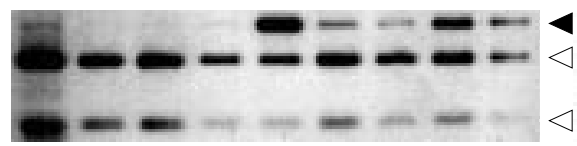

Figure 1 (A) Secondary structure of $t R N A^{\mathrm{Tir} r}$ and $5877 G \rightarrow A$ mutation. A circled $C$ nucleotide in the variable loop (5905C) indicates a residue that base pairs with

$5877 G$ to make the $L$ shaped tertiary structure. ${ }^{6}$ Short lines in the stems indicate hydrogen bonds linking the paired nucleotides. (B) DdeI restriction analysis of $5877 G \rightarrow A$ in family members. PCR amplified mtDNA fragments from nucleotides 5681 to 5960 were digested with DdeI, which only cleaves at the wild type $5877 \mathrm{G}$. Closed arrowhead points to a mutant $261 \mathrm{bp}$ fragment. Open arrowheads indicate wild type 178 and $83 \mathrm{bp}$ fragments. A mutant fragment in the patient's blood is scarcely visible in the figure. Arrow indicates the patient. Closed symbols show affected family members. BS, blood spot in the hospital archives from deceased mother, $P B$, peripheral blood, $S M$, skeletal muscle, UC, archived umbilical cords of patient's children which had been saved as mementos of birth.

molecule. ${ }^{6}$ The $5877 \mathrm{G}$ is conserved in 29 of 43 species or in 25 of 28 vertebrates (alignment not shown). The $5877 \mathrm{G} \rightarrow \mathrm{A}$ mutation has not been reported in other patients with mitochondrial cytopathies (Mitomap).

Restriction enzyme analysis of blood and umbilical cord DNA of family members showed that the deceased mother, who had ptosis, carried $5877 \mathrm{G} \rightarrow \mathrm{A}$ and that two asymptomatic children (a 21 year old son and 19 year old daughter) harbour $5877 \mathrm{G} \rightarrow \mathrm{A}$ in peripheral blood and umbilical cord (fig 1B). The patient developed ptosis at the age of 28 and the children may be too young to show any symptoms. Alternatively, the ratio of mutant mtDNA in muscle may be less in the children than in the patient. The children had no increase in resting serum lactate. Two asymptomatic paternal half sisters (aged 60 and 59 years) do not carry $5877 \mathrm{G} \rightarrow \mathrm{A}$ (fig 1B). Photographs showed that the maternal grandmother also had ptosis, but her DNA was not available.

To characterise the functional consequences of $5877 \mathrm{G} \rightarrow \mathrm{A}$, we transformed $\rho^{0}$ cells with
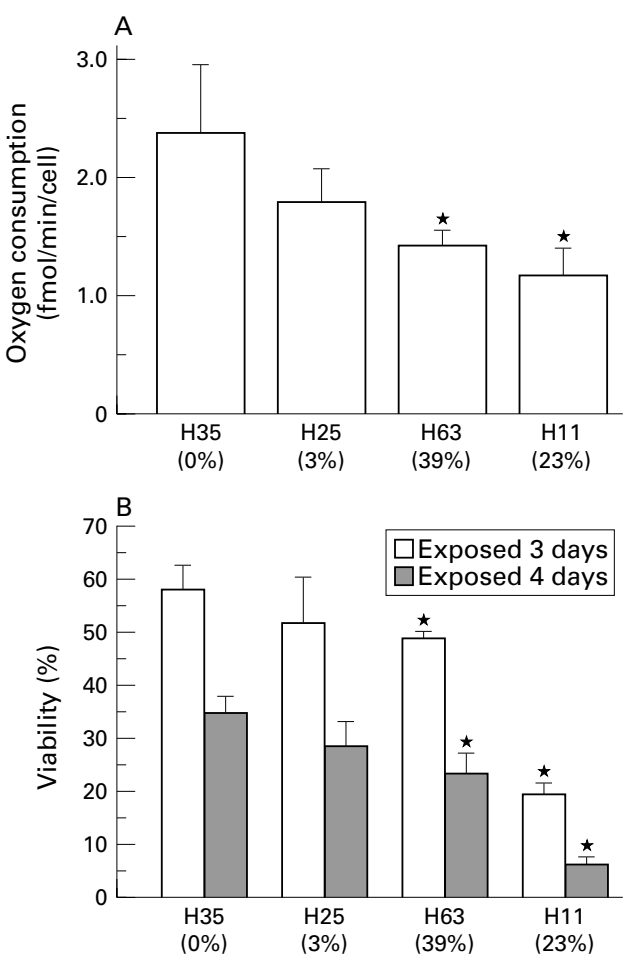

Figure 2 (A) Oxygen consumption rate and (B) cell viability rate of transmitochondrial cybrid cell lines after exposure to $95 \%$ oxygen. Clones H35, H25, H63, and H11 carry $0,3,39$, and $23 \%$, respectively, of mutant mtDNA carrying $5877 G \rightarrow A .{ }^{\star} p<0.05$ compared to wild type H35.

patient's skin fibroblasts as described elsewhere. ${ }^{7}$ We obtained four distinct cybrid clones, $\mathrm{H} 35, \mathrm{H} 25$, H63, and H11, harbouring 0, 3, 39, and $23 \%$ of mutant mtDNA, respectively. We measured the oxygen consumption as an indicator for the mitochondrial respiratory chain functions, using a Clark type oxygen electrode. The H35 clone showed the highest oxygen consumption and the $\mathrm{H} 11$ clone the lowest (fig 2A). We next measured the viability of cybrids under $95 \%$ oxygen on days 3 and 4 by staining cells with $0.15 \%$ trypan blue, because we assumed that mutant mtDNA increases the leakage of reactive oxygen species, which in turn exerts cytotoxic effects leading to cell death. ${ }^{8}$ Even normal mitochondria convert approximately $1-5 \%$ of oxygen into the reactive oxygen species, which results in degeneration of proteins, lipids, and nucleic acids. ' Similar to the oxygen consumption analysis, H35 showed the highest viability rate and $\mathrm{H} 11$ the lowest (fig 2B). Although H63 harboured a higher ratio of mutant mtDNA than H11, H63 showed higher oxygen consumption and higher viability rate than H11. This may be because of the difference in the intracellular distribution of mutant mtDNA or in the total number of transformed mtDNA.

A previously characterised $5703 \mathrm{C} \rightarrow \mathrm{T}$ mutation at the anticodon stem of tRNA ${ }^{\text {Asn }}$ destabilises the tRNA secondary or tertiary structure and decreases steady state levels of $\mathrm{tRNA}^{\mathrm{Asn}}$. $^{3}$ The present $5877 \mathrm{G} \rightarrow \mathrm{A}^{\mathrm{m}}$ mutation in $\mathrm{tRNA}^{\text {Tyr }}$ alters an essential residue to form the $\mathrm{L}$ shaped tertiary structure of tRNA. ${ }^{6}$ Similarly, seven out of the 11 other CPEO associated point mutations (Mitomap) are at the tRNA stems 
and probably destabilise the tRNA structure. However, four other mutations are at the tRNA loops and their effects on the tRNA structure remain unknown.

The $5877 \mathrm{G} \rightarrow \mathrm{A}$ mutation exerts deleterious effects even at $23 \%$ of mutant mtDNA, whereas more than $90 \%$ of mutant mtDNA is required to show pathogenicity of $3243 \mathrm{~A} \rightarrow \mathrm{G}$ in tRNA Leu(UUR),${ }^{10}$ which is primarily associated with MELAS. ${ }^{11}$ Hao and Moraes ${ }^{3}$ proposed that null or near null mtDNA mutations are associated with muscle pathologies, as exemplified in $5703 \mathrm{C} \rightarrow \mathrm{T}$ in $\mathrm{tRNA}^{\mathrm{Asn}}$ and in $\mathrm{mtDNA}$ deletions. On the other hand, less severe mtDNA mutations are associated with central nervous system symptoms, as in the MELAS and MERRF associated mutations. ${ }^{10}$ That low levels of mutant mtDNA decrease oxygen consumption and compromise cell viability under 95\% oxygen in the current studies further supports their hypothesis on phenotype-genotype correlation of mtDNA mutations.

This work was supported in part by the Grants in Aid for General Scientific Research (62570128) to MT from the Ministry of Education, Science, and Culture of Japan, and the Research Grant (11B-1) for Nervous and Mental Disorders to KS from the Ministry of Health and Welfare of Japan. We presented part of the present study in a review article (Nippon Rinsho $1997 ; 55: 3265-9)$
1 DiMauro S, Bonilla E, Zeviani $M$, Nakagawa $M$, DeVivo DC. Mitochondrial myopathies. Ann Neurol 1985;17:521DC.

2 Zeviani M, DiDonato S. Neurological disorders due to mutations of the mitochondrial genome. Neuromusc Disord 1991;1:165-72.

3 Hao H, Moraes CT. A disease-associated G5703A mutation in human mitochondrial DNA causes a conformational change and a marked decrease in steady-state levels of mitochondrial tRNA(Asn). Mol Cell Biol 1997;17:6831-7.

4 Ozawa T, Sahashi K, Nakase Y, Chance B. Extensive tissue oxygenation associated with mitochondrial DNA mutations. Biochem Biophys Res Commun 1995:213:432-8.

5 Ogasahara S, Yorifuji S, Nishikawa Y, Takahashi M, Wada K, Hazama T, Nakamura Y, Hashimoto S, Kono N, Tarui S. Improvement of abnormal pyruvate metabolism and cardiac conduction defect with coenzyme $\mathrm{Q}_{10}$ in KearnsSayre syndrome. Neurology 1985;35:372-7

6 Kim SH, Suddath FL, Quigley GJ, McPherson A, Sussman JL, Wang AH, Seeman NC, Rich A. Three-dimensional tertiary structure of yeast phenylalanine transfer RNA. Science 1974;185:435-40

7 Yoneda M, Chomyn A, Martinuzzi A, Hurko O, Attardi G. Marked replicative advantage of human $\mathrm{mtDNA}$ carrying a point mutation that causes the MELAS encephalomyopathy. Proc Natl Acad Sci USA 1992;89:11164-8.

8 Zhang J, Yoneda M, Naruse K, Borgeld HJ, Gong JS, Obata S, Tanaka M, Yagi K. Peroxide production and apoptosis in cultured cells carrying mtDNA mutation causing encephacultured cells carrying mtDNA mutation causing
lomyopathy. Biochem Mol Biol Int 1998;46:71-9.

9 Halliwell B. Free radicals and antioxidants: a personal view. 9 Halliwell B. Free radicals and

10 Chomyn A, Martinuzzi A, Yoneda M, Daga A, Hurko O, Johns D, Lai ST, Nonaka I, Angelini C, Attardi G. MELAS mutation in mtDNA binding site for transcription termination factor causes defects in protein synthesis and in respiration but no change in levels of upstream and downstream mature transcripts. Proc Natl Acad Sci USA 1992;89:4221-5.

11 Goto Y, Nonaka I, Horai S. A mutation in the tRNA ${ }^{\mathrm{Leu}(\mathrm{UUR})}$ gene associated with the MELAS subgroup of mitochondrial encephalomyopathy. Nature 1990;348:651-3.

\title{
Mutation detection in long QT syndrome: a comprehensive set of primers and PCR conditions
}

\author{
P Syrris, A Murray, N D Carter, W M McKenna, S Jeffery
}

EDITOR-Long QT syndrome (LQTS) is an inherited disorder which produces arrhythmia and sudden death. The only presymptomatic indication of the disorder is an extended QT interval, in excess of $460 \mathrm{~ms}^{1}{ }^{1}$ However, those with LQTS do not always show this prolongation of QT. There are dominantly and recessively inherited forms of the disease, Romano-Ward syndrome and Jervell LangeNielsen syndrome, respectively, the latter also exhibiting severe sensorineural deafness. ${ }^{2-4}$ About half the familial cases of LQT are known to be caused by mutations in five ion channel or channel associated genes, with over $90 \%$ being accounted for by KCNQ1 and HERG, both of which code for potassium channels. ${ }^{5}$ The sodium channel gene $S C N 5 A$ is responsible for about $8 \%$ of cases with a known gene mutation, while KCNE1 and KCNE2, which code for proteins that associate with $K C N Q 1$ and $H E R G$ respectively, are mutated in $1-2 \% .{ }^{5}$ Mutations in KCNQ1 can produce both dominant and recessive forms of the disease, depending on the nature of the mutation. ${ }^{6-12}$ HERG and SCN5A mutations are dominant, while those in KCNE1 and KCNE2 are recessive. ${ }^{13-16}$ There are, however, exceptions to these rules. ${ }^{17} 18$
Mutations have been identified throughout the genes, ${ }^{19} 20$ although analysis of both HERG and $S C N 5 A$ has tended to be concentrated on the pore regions owing to the substantial number of exons in both genes. The initial publications on KCNQ1 (formerly KVLQT1) also analysed the pore and surrounding regions, although several groups have now produced primers that cover the entire gene. ${ }^{1921}$ The mutation analysis has been by PCR followed by SSCP, and although laborious, this is still the most commonly used method. Investigation of all the genes has not been possible, mainly because the exact sequence of the PCR fragments amplified by the existing primer sets was not available for SCN5 $\mathrm{A}^{22}$ and the published primers for SCN5A, HERG, and KCNQ1 amplified fragments outside the optimum size for SSCP or proved difficult to use. ${ }^{21-23}$ Larsen et $a l^{24}$ have reported a robust analysis of KCNQ1 and $H E R G$, but this uses an automated capillary SSCP analysis on an ABI 310 with an in house cooling system, which is not available in most laboratories, and SCN5A was not included in this report. To allow extensive investigation of populations potentially at high risk for mutations in genes known to cause LQTS, we have put together primer sets for all five genes, using 
published sequences where appropriate, but redesigning where necessary. These primer sets, with their specific PCR conditions that are effective on all thermocyclers tested so far, will also be invaluable for transferring LQT gene analysis from a research to a diagnostic setting.

\section{Materials and methods}

POLYMERASE CHAIN REACTION

The same PCR protocol was initially used in order to amplify all PCR products. Red Hot Taq DNA polymerase and buffers were supplied by Advanced Biotechnologies, dNTPs were purchased from Pharmacia, and primers were made by Genosys-Sigma. PCR was performed using $50 \mathrm{ng}$ of DNA in a volume of $25 \mu \mathrm{l}$ and the final concentration of reagents was $1 \times$ buffer $\left(20 \mathrm{mmol} / 1\left(\mathrm{NH}_{4}\right)_{2} \mathrm{SO}_{4}, 75\right.$ $\mathrm{mmol} / 1$ Tris- $\mathrm{HCl}, \mathrm{pH} 8.8$, at $25^{\circ} \mathrm{C}, 0.01 \%$ (v/v) Tween 20, $\left.1.5 \mathrm{mmol} / 1 \mathrm{MgCl}_{2}\right)$, dNTPs (0.2 $\mathrm{mmol} / 1$ each), $0.2 \mu \mathrm{mol} / 1$ of each primer, and 1.25 units Red Hot Taq polymerase. Amplification was carried out with the use of a Touchdown thermal cycler (Hybaid). Conditions for each PCR product were optimised by varying the annealing temperature and the $\mathrm{Mg}^{2+}$ concentration in the PCR reaction. A typical PCR programme (a) comprised the following steps: $94^{\circ} \mathrm{C}$ for three minutes (one cycle), $94^{\circ} \mathrm{C}$ for one minute, variable annealing temperature for one minute, $72^{\circ} \mathrm{C}$ for one minute ( 35 cycles), $72^{\circ} \mathrm{C}$ for 10 minutes (one cycle). For several amplifications, a touchdown PCR programme with variable annealing temperatures was used. In that case, the annealing temperature ranged between 70 $60^{\circ} \mathrm{C}$ (b), $70-58^{\circ} \mathrm{C}$ (c), $65-53^{\circ} \mathrm{C}$ (d), or $60-50^{\circ} \mathrm{C}$ (e) depending on the melting properties of the primers. A typical touchdown PCR programme consisted of the following steps: $94^{\circ} \mathrm{C}$ for three minutes. $94^{\circ} \mathrm{C}$ for one minute, annealing started at $70^{\circ} \mathrm{C}$ and decreased by $1^{\circ}$ per cycle, $72^{\circ} \mathrm{C}$ for one minute (11 cycles), $94^{\circ} \mathrm{C}$ for one minute, $60^{\circ} \mathrm{C}$ for one minute, $72^{\circ} \mathrm{C}$ for one minute ( 30 cycles), $72^{\circ} \mathrm{C}$ for 10 minutes (one cycle). Finally, in some cases, amplification conditions given by Splawski et $a l^{19}$ were chosen in order to amplify certain KCNQ1 and KCNE1 fragments. These were (f) $94^{\circ} \mathrm{C}$ for three minutes (one cycle), $94^{\circ} \mathrm{C}$ for 10 seconds, $58^{\circ} \mathrm{C}$ for 20 seconds, $72^{\circ} \mathrm{C}$ for 20 seconds ( 30 cycles), $72^{\circ} \mathrm{C}$ for five minutes (one cycle) and (g) $94^{\circ} \mathrm{C}$ for three minutes (one cycle), $94^{\circ} \mathrm{C}$ for 10 seconds, $64^{\circ} \mathrm{C}$ for 20 seconds, $72^{\circ} \mathrm{C}$ for 20 seconds (five cycles), $94^{\circ} \mathrm{C}$ for 10 seconds, $62^{\circ} \mathrm{C}$ for 20 seconds, $72^{\circ} \mathrm{C}$ for 20 seconds ( 30 cycles), and $72^{\circ} \mathrm{C}$ for five minutes (one cycle).

Products that did not amplify satisfactorily were subjected to a different PCR method using HotStarTaq DNA polymerase and following the manufacturer's protocol (Qiagen). In some cases, a PCR additive, Q solution (also supplied by Qiagen), was included in PCR reactions to facilitate the amplification of difficult templates by modifying the melting behaviour of DNA. Amplification conditions, primer sequences, and sizes of amplified products are given in tables $1-4$.

\section{KCNQ1}

All primers were taken from Splawski et $a l^{19}$ except 9R (5' GAC ACA GGC TGT ACC AAG CCA 3'), 13F (5' CAC TGC CTG CAC

Table 1 Amplification conditions, primers, and sizes of PCR products for KCNQ1 coding region. PCR programmes (a-g) are given in Methods. The value following programme (a) indicates the annealing temperature for each PCR amplicon. Primers were taken from Splawski et al, ${ }^{19}$ except those with an asterisk which were redesigned

\begin{tabular}{|c|c|c|c|c|c|}
\hline Exon & Size $(b p)$ & Primers & $\begin{array}{l}\text { PCR fragment } \\
(b p)\end{array}$ & $\begin{array}{l}\text { PCR } \\
\text { programme }\end{array}$ & $\begin{array}{l}\text { Special } \\
\text { conditions }\end{array}$ \\
\hline \multirow[t]{4}{*}{1} & \multirow[t]{4}{*}{$386+$} & F:CTCGCCTTCGCTGCAGCTC & 334 & (b) & \multirow{8}{*}{$\begin{array}{l}\text { HotStarTaq } \\
\text { Q solution } \\
\text { HotStarTaq } \\
\text { Q solution }\end{array}$} \\
\hline & & R:GCGCGGGTCTAGGCTCACC & & & \\
\hline & & F:CGCCGCGCCCCCAGTTGC & 224 & (b) & \\
\hline & & R:CAGAGCTCCCCCACACCAG & & & \\
\hline \multirow[t]{2}{*}{2} & \multirow[t]{2}{*}{91} & F:ATGGGCAGAGGCCGTGATGCTGAC & 165 & (g) & \\
\hline & & R:ATCCAGCCATGCCCTCAGATGC & & & \\
\hline \multirow[t]{2}{*}{3} & \multirow[t]{2}{*}{127} & F:GTTCAAACAGGTTGCAGGGTCTGA & 256 & (g) & \\
\hline & & R:CTTCCTGGTCTGGAAACCTGG & & & \\
\hline \multirow[t]{2}{*}{4} & \multirow[t]{2}{*}{79} & F:CTCTTCCCTGGGGCCCTGGC & 170 & (b) & \multirow{6}{*}{$\begin{array}{l}\text { HotStarTaq } \\
\mathrm{Q} \text { solution } \\
\text { HotStarTaq }\end{array}$} \\
\hline & & R:TGCGGGGGAGCTTGTGGCACAG & & & \\
\hline \multirow[t]{2}{*}{5} & \multirow[t]{2}{*}{97} & F:TCAGCCCCACACCATCTCCTTC & 154 & (b) & \\
\hline & & R:CTGGGCCCCTACCCTAACCC & & & \\
\hline \multirow[t]{2}{*}{6} & \multirow[t]{2}{*}{141} & F:TCCTGGAGCCCGACACTGTGTGT & 238 & \multirow{2}{*}{ (a) $58^{\circ} \mathrm{C}$} & \\
\hline & & R:TGTCCTGCCCACTCCTCAGCCT & & & \\
\hline \multirow{2}{*}{7} & \multirow[t]{2}{*}{111} & F:TGGCTGACCACTGTCCCTCT & 195 & (b) & \multirow{14}{*}{ HotStarTaq } \\
\hline & & R:CCCCAGGACCCCAGCTGTCCAA & & & \\
\hline \multirow[t]{2}{*}{8} & \multirow[t]{2}{*}{96} & F:GCTGGCAGTGGCCTGTGTGGA & 191 & (g) & \\
\hline & & R:AACAGTGACCAAAATGACAGTGAC & & & \\
\hline \multirow[t]{2}{*}{9} & \multirow[t]{2}{*}{123} & F: TGGCTCAGCAGGTGACAGC & 280 & (a) $64^{\circ} \mathrm{C}$ & \\
\hline & & R:GACACAGGCTGTACCAAGCCAA* & & & \\
\hline \multirow[t]{2}{*}{10} & \multirow[t]{2}{*}{142} & F:GCCTGGCAGACGATGTCCA & 216 & (f) & \\
\hline & & R:CAACTGCCTGAGGGGTTCT & & & \\
\hline \multirow[t]{2}{*}{11} & \multirow[t]{2}{*}{121} & F:CTGTCCCCACACTTTCTCCT & 195 & (f) & \\
\hline & & R:TGAGCTCCAGTCCCCTCCAG & & & \\
\hline \multirow[t]{2}{*}{12} & \multirow[t]{2}{*}{76} & F:TGGCCACTCACAATCTCCT & 222 & (f) & \\
\hline & & R:GCCTTGACACCCTCCACTA & & & \\
\hline \multirow[t]{2}{*}{13} & 95 & F:CACTGCCTGCACTTTGAGCC ^ & 304 & (b) & \\
\hline & & R:GTGAGGAGAAGGGGGTGGTT* & & & \\
\hline 14 & 47 & F:CCAGGGCCAGGTGTGACTG & 119 & (b) & HotStarTaq \\
\hline & & R:TGGGCCCAGAGTAACTGACA & & & \\
\hline 15 & 62 & F: GGCCCTGATTTGGGTGTTTTA & 186 & (b) & \\
\hline & & R:GCAGGAGCTTCACGTTCACA* & & & \\
\hline 16 & $237+$ & F:CACCACTGACTCTCTCGTCT & 297 & (f) & \\
\hline & & R:CCATCCCCCAGCCCCATC & & & \\
\hline
\end{tabular}


Table 2 Amplification conditions, primers, and sizes of PCR products for HERG coding region. PCR programmes (a-g) are given in Methods. The value following programme (a) indicates the annealing temperature for each PCR amplicon. Primers have been reported previously ${ }^{19} 23$

\begin{tabular}{|c|c|c|c|c|c|}
\hline Exon & Size $(b p)$ & Primers & $\begin{array}{l}\text { PCR fragment } \\
(b p)\end{array}$ & $\begin{array}{l}\text { PCR } \\
\text { programme }\end{array}$ & $\begin{array}{l}\text { Special } \\
\text { conditions }\end{array}$ \\
\hline \multirow[t]{2}{*}{1} & $76+$ & F:GGGCCACCCGAAGCCTAGT ${ }^{19}$ & 298 & (c) & $1.0 \mathrm{mmol} / 1$ \\
\hline & & R:CCGTCCCCTCGCCAAAGC ${ }^{19}$ & & & $\mathrm{MgCl}_{2}$ \\
\hline \multirow[t]{2}{*}{2} & 231 & F:GGTCCCGTCACGCGCACTCT ${ }^{23}$ & 312 & (d) & \\
\hline & & R:TTGACCCCGCCCCTGGTCGT ${ }^{23}$ & & & \\
\hline \multirow[t]{2}{*}{3} & 165 & F:TGCCCACTGAGTGGGTGC ${ }^{23}$ & 288 & (c) & \\
\hline & & R:TGACCTTGGACAGCTCACAG ${ }^{23}$ & & & \\
\hline \multirow[t]{4}{*}{4} & 444 & F:CTCCGGGGCTGCTCGGGAT ${ }^{19}$ & 284 & (d) & HotStarTaq \\
\hline & & R:CACCAGCGCACGCCGCTCCT ${ }^{19}$ & & & $\mathrm{Q}$ solution \\
\hline & & F:CCCTGGACGAAGTGACAGCCAT ${ }^{23}$ & 318 & (d) & HotStarTaq \\
\hline & & R:GGCTGGGGCGGAACGGGTCC ${ }^{23}$ & & & $\mathrm{Q}$ solution \\
\hline \multirow[t]{2}{*}{5} & 212 & F:GCCTGACCACGCTGCCTCT ${ }^{23}$ & 279 & (c) & \\
\hline & & R:CCTCCAAGGTGAGAGGAGA ${ }^{23}$ & & & \\
\hline \multirow[t]{4}{*}{6} & 429 & F:CAGAGATGTCATCGCTCCTG ${ }^{19}$ & 295 & (e) & \\
\hline & & R:CAGGCGTAGCCACACTCGGTAG ${ }^{19}$ & & & \\
\hline & & F:TTCCTGCTGAAGGAGACGGAAG ${ }^{19}$ & 296 & (e) & \\
\hline & & R:TACACCACCTGCCTCCTTGCTGA ${ }^{19}$ & & & \\
\hline \multirow[t]{4}{*}{7} & 388 & F:TGCCCCATCAACGGATGTGC ${ }^{23}$ & 240 & (c) & HotStarTaq \\
\hline & & R:CAGCCAGCCGATGCGTGAGTCCA ${ }^{23}$ & & & \\
\hline & & F:TAGCCTGCATCTGGTACGC ${ }^{23}$ & 276 & (a) $58^{\circ} \mathrm{C}$ & HotStarTaq \\
\hline & & R:GCCCGCCCCTGGGCACACTCA ${ }^{23}$ & & & \\
\hline \multirow[t]{2}{*}{8} & 200 & F:CTGTGGGTGGGTGGGGTCC ${ }^{23}$ & 300 & (c) & \\
\hline & & R:TTTCCCAGCCTGCCACCCACT ${ }^{23}$ & & & \\
\hline \multirow[t]{2}{*}{9} & 253 & F:CCAAGGGAGGGTGTGCTGAG ${ }^{23}$ & 331 & (c) & \\
\hline & & R:GGCATTTCCAGTCCAGTGC ${ }^{23}$ & & & \\
\hline \multirow[t]{2}{*}{10} & 194 & F:AGAAGGTGCCTGCTGCCTG ${ }^{23}$ & 286 & (c) & HotStarTaq \\
\hline & & R:TCCAGCTCAGGGCAGCCAA ${ }^{23}$ & & & \\
\hline \multirow[t]{2}{*}{11} & 100 & F:AAGGGCCCTGATACTGATTTT ${ }^{23}$ & 189 & (c) & \\
\hline & & R:TTCCAGCTCCCAGCCTCA ${ }^{23}$ & & & \\
\hline \multirow[t]{4}{*}{12} & 273 & F:CCCCTCTTTGAGGCCCATT ${ }^{23}$ & 279 & (a) $55^{\circ} \mathrm{C}$ & \\
\hline & & R:CTTCTCGCAGTCCTCCATCA ${ }^{23}$ & & & \\
\hline & & F:TGAGAGCAGTGAGGATGA ${ }^{23}$ & 205 & (a) $58^{\circ} \mathrm{C}$ & HotStarTaq \\
\hline & & R:TAGACGCACCACCGCTGCC ${ }^{23}$ & & & Q solution \\
\hline \multirow[t]{2}{*}{13} & 187 & F:CTCACCCAGCTCTGCTCTCTG ${ }^{19}$ & 273 & (d) & HotStarTaq \\
\hline & & R:CACCAGGACCTGGACCAGACT ${ }^{19}$ & & & $\mathrm{Q}$ solution \\
\hline \multirow[t]{2}{*}{14} & 178 & F:GTGGAGGCTGTCACTGGTGT ${ }^{19}$ & 258 & (d) & \\
\hline & & R:GAGGAAGCAGGGCTGGAGCTT ${ }^{19}$ & & & \\
\hline \multirow[t]{2}{*}{15} & $150+$ & F:TGCCCATGCTCTGTGTGTATTG ${ }^{19}$ & 232 & (e) & \\
\hline & & R:CGGCCCAGCAGCGCCTTGATC ${ }^{19}$ & & & \\
\hline
\end{tabular}

TTT GAG CC 3'), 13R (5' GTG AGG AGA AGG GGG TGG TT 3') and 15R (5' GCA GGA GCT TCA CGT TCA CA 3'). PCR conditions are given in table 1.

HERG

Primers were taken from Splawski et $a l^{19}$ and Itoh et al. ${ }^{23}$ The details and PCR conditions are shown in table 2 .

SCN5A

Primers first published by Wang et $a^{22}$ were initially used to amplify all 28 exons of the SCN5A gene. All PCR products were then purified and sequenced. New primers were designed for PCR products with lengths unsuitable for SSCP analysis (approximately $>350 \mathrm{bp}$ ). Primers and PCR conditions for the amplification of the SCN5A gene are given in table 3.

KCNE1 AND KCNE2

Primers for amplification of the coding region (single exon) of the KCNE1 and KCNE2 genes were taken from Splawski et $a l^{19}$ and Abbott et $a l,{ }^{16}$ respectively (table 4 ).

SINGLE STRAND CONFORMATIONAL

POLYMORPHISM ANALYSIS

SSCP analysis was performed with the use of a Protean Cell system (Biorad) at two different temperatures (room temperature and $4^{\circ} \mathrm{C}$ ). Polyacrylamide gels $(20 \mathrm{~cm})$ were made using $2 \times$ stock SequaGel MD solution (National Diagnostics) following the manufacturer's protocol. PCR products $(2 \mu \mathrm{l})$ were resolved overnight on SequaGel $\mathrm{MD}$ gels at different concentrations $(0.4-0.8 \times)$ depending on their size. Wherever possible more than one PCR fragment were multiplexed in the same lane. After each run gels were silver stained using standard methods.

SEQUENCING

PCR products were sequenced using BigDye Terminator chemistry on a 377 ABI PRISM DNA sequencer (PE Biosystems) according to standard protocols.

\section{Results}

Using the PCR conditions detailed in tables 1-4, PCR consistently yielded clean products for all LQT fragments. For KCNQ1, 17 PCR fragments were produced as exon 1 was divided into two separate amplicons. For HERG, 19 PCR fragments were amplified as exons 4, 6, 7, and 12 were split into smaller amplicons. Four new primers were designed for $K C N Q 1$, and existing sequences were used for $H E R G$. However, in the former case, 10 primer sets needed changes to suggested PCR protocols, while for $H E R G$ this was necessary for all amplicons, and primers from two sources ${ }^{19}{ }^{23}$ had to be used to obtain optimal results. In the case of SCN5A, the whole coding region was amplified with the use of 34 PCR fragments. Exon 1 was excluded as it corresponds to the 5' UTR part of the gene and similarly part of exon 28 was not amplified as it is the 3' UTR. Initially, all PCR fragments amplified using the existing SCN5A primers ${ }^{22}$ were sequenced in order to determine their 
Table 3 Amplification conditions, primers, and sizes of PCR products for SCN5A coding region. PCR programmes (a-g) are given in Methods. The value following programme (a) indicates the annealing temperature for each PCR amplicon. Primers were taken from Wang et al, ${ }^{22}$ except those with an asterisk which were redesigned

\begin{tabular}{|c|c|c|c|c|c|}
\hline Exon & Size $(b p)$ & Primers & $\begin{array}{l}\text { PCR fragment } \\
(b p)\end{array}$ & $\begin{array}{l}\text { PCR } \\
\text { programme }\end{array}$ & $\begin{array}{l}\text { Special } \\
\text { conditions }\end{array}$ \\
\hline 2 & 324 & $\begin{array}{l}\text { F:CCAGAAGCAGGATGAGAA* } \\
\text { R:AGAAGGGTAGGCAGGGCT* }\end{array}$ & 329 & (b) & \\
\hline 3 & 117 & $\begin{array}{l}\text { F:AGTCCAAGGGCTCTGAGCCAA } \\
\text { R:GGTACTCAGCAGGTATTAACTGCAA }\end{array}$ & 227 & (b) & \\
\hline 4 & 89 & $\begin{array}{l}\text { F:GGTAGCACTGTCCTGGCAGTGAT } \\
\text { R:CCTGGACTCAAGTCCCCCTTC }\end{array}$ & 294 & (b) & \\
\hline 5 & 128 & $\begin{array}{l}\text { F:TCACTCCACGTAAGGAACCTG } \\
\text { R:ATGTGGACTGCAGGGAGGAAGC }\end{array}$ & 324 & (c) & \\
\hline 6 & 91 & $\begin{array}{l}\text { F:CCTTTCCTCCTCTCACTGTCTGT } \\
\text { R:GGTATTCTGGTGACAGGCACATTC }\end{array}$ & 281 & (c) & \\
\hline 7 & 230 & $\begin{array}{l}\text { F:TGACCCCGTGCTTGTTCTTGCCT* } \\
\text { R:GTCTGCGGTCTCACAAAGTCTTC }\end{array}$ & 307 & (a) $64^{\circ} \mathrm{C}$ & \\
\hline 8 & 63 & $\begin{array}{l}\text { F:CCTGGATGCAAGGCGGAAACT* } \\
\text { R:GGAGACTCCCCTGGCAGGACAA }\end{array}$ & 180 & (b) & \\
\hline 9 & 141 & $\begin{array}{l}\text { F:GGGAGACAAGTCCAGCCCAGCAA } \\
\text { R:AGCCCACACTTGCTGTCCCTTG }\end{array}$ & 262 & (b) & \\
\hline 10 & 198 & $\begin{array}{l}\text { F:ACTTGGAAATGCCCTCACCCAGA } \\
\text { R:CACCTATAGGCACCATCAGTCAG }\end{array}$ & 327 & (c) & $\begin{array}{l}2.0 \mathrm{mmol}^{\prime} 1 \\
\mathrm{MgCl}_{2}\end{array}$ \\
\hline 11 & 178 & $\begin{array}{l}\text { F:AAACGTCCGTTCCTCCACTCT } \\
\text { R:AACCCACAGCTGGGATTACCATT }\end{array}$ & 227 & (b) & \\
\hline 12 & 371 & $\begin{array}{l}\text { F:GCCAGTGGCTCAAAAGACAGGCT } \\
\text { R:CCTGGGCACTGGTCCGGCGCA } \\
\text { F:CACCACACATCACTGCTGGTGC } \\
\text { R:GGAACTGCTGATCAGTTTGGGAGA }\end{array}$ & $\begin{array}{l}280 \\
286\end{array}$ & $\begin{array}{l}\text { (b) } \\
\text { (b) }\end{array}$ & \\
\hline 13 & 132 & $\begin{array}{l}\text { F:CCCTTTTCCCCAGCTGACGCAAA } \\
\text { R:GTCTAAAGCAGGCCAAGACAAATG }\end{array}$ & 282 & (b) & \\
\hline 14 & 238 & $\begin{array}{l}\text { F:AACTAACTCATTGGCTGTCC }{ }^{\star} \\
\text { R:CATTTGAGAGCCAGCTGCAG* }\end{array}$ & 295 & (d) & $\begin{array}{l}2.5 \mathrm{mmol}^{\prime} 1 \\
\mathrm{MgCl}_{2}\end{array}$ \\
\hline 15 & 173 & $\begin{array}{l}\text { F:CTTTCCTATCCCAAACAATACCT } \\
\text { R:CCCCACCATCCCCCATGCAGT }\end{array}$ & 247 & (c) & \\
\hline 16 & 350 & $\begin{array}{l}\text { F:GAGCCAGAGACCTTCACAAGGTCCCCT } \\
\text { R:TGAAAGAAGTCCATCATGTGCCAGCGA } \\
\text { F:AACTACTCGGAGCTGAGGGA } \\
\text { R:CCCTTGCCACTTACCACAAG }\end{array}$ & $\begin{array}{l}267 \\
211\end{array}$ & $\begin{array}{l}\text { (a) } 64^{\circ} \mathrm{C} \\
\text { (e) }\end{array}$ & \\
\hline 17 & 440 & $\begin{array}{l}\text { F:GGGACTGGATGGCTTGGCATGGT } \\
\text { R:CGGGGAGTAGGGGGTGGCAATG } \\
\text { F:GCCCAGGGCCAGCTGCCCAGCT } \\
\text { R:CTGTATATGTAGGTGCCTTATACATG }\end{array}$ & $\begin{array}{l}306 \\
283\end{array}$ & $\begin{array}{l}\text { (b) } \\
\text { (c) }\end{array}$ & \\
\hline 18 & 161 & $\begin{array}{l}\text { F: AGGGTCTAAACCCCCAGGGTCA } \\
\text { R:CCCAGCTGGCTTCAGGGACAAA }\end{array}$ & 280 & (b) & \\
\hline 19 & 120 & $\begin{array}{l}\text { F:GAGGCCAAAGGCTGCTACTCAG } \\
\text { R:CCTGTCCCCTCTGGGTGGAACT }\end{array}$ & 245 & (b) & \\
\hline 20 & 154 & $\begin{array}{l}\text { F:ACAGGCCCTGAGGTGGGCCTGA } \\
\text { R:TGACCTGACTTTCCAGCTGGAGA }\end{array}$ & 287 & (b) & \\
\hline 21 & 173 & $\begin{array}{l}\text { F:TCCAGGCTTCATGTCCACCTGTCT } \\
\text { R:TCTCCCGCACCGGCAATGGT }\end{array}$ & 268 & (b) & \\
\hline 22 & 121 & $\begin{array}{l}\text { F:AGTGGGGAGCTGTTCCCATCCT } \\
\text { R:GGACCGCCTCCCACTCC }\end{array}$ & 216 & (b) & \\
\hline 23 & 282 & $\begin{array}{l}\text { F:AGGAACTGAGCCACTTCTCT }{ }^{\star} \\
\text { R:AGGAAGGAAGTCCСТTCTCT }{ }^{\star}\end{array}$ & 343 & (e) & \\
\hline 24 & 53 & $\begin{array}{l}\text { F:CTCAAGCGAGGTACAGAATTAAATGA } \\
\text { R:GGGCTTTCAGATGCAGACACTGAT }\end{array}$ & 202 & (b) & \\
\hline 25 & 137 & $\begin{array}{l}\text { F:GCCTGTCTGATCTCCCTGTGTGA } \\
\text { R:AGATGGGACCTGGAGCCTGAGTG* }\end{array}$ & 265 & (b) & \\
\hline 26 & 104 & $\begin{array}{l}\text { F:CCATGCTGGGGCCTCTGAGAAC } \\
\text { R:GGCTCTGATGGCTGGCCATGTG }\end{array}$ & 249 & (b) & \\
\hline 27 & 270 & $\begin{array}{l}\text { F:CCCAGCGAGCACTTTCCATTTG } \\
\text { R:GCTTCTCCGTCCAGCTGACTTGTA }\end{array}$ & 337 & (b) & \\
\hline 28 & 3257 & $\begin{array}{l}\text { F:ACCAGTAGCCACAGTCTCTGTTG^ } \\
\text { R:GAAGAGGCACAGCATGCTGTTGG } \\
\text { F:AAGTGGGAGGCTGGCATCGAC } \\
\text { R:GTGCTCTCCTCCGTGGCCACGC } \\
\text { F:GAGCCCAGCCGTGGGCATCCT } \\
\text { R:GTCCCCACTCACCATGGGCAG } \\
\text { F:CCAACCAGATAAGCCTCATCAACA } \\
\text { R:CCGCCTGCTGACGGAAGAGGA } \\
\text { F:TGCTGCAACGCTCTTTGAAGCAT } \\
\text { R:AAAGGCTGCTTTTCAGTGTGTCCT }\end{array}$ & $\begin{array}{l}334 \\
301 \\
309 \\
308 \\
346\end{array}$ & $\begin{array}{l}\text { (a) } 64^{\circ} \mathrm{C} \\
\text { (b) } \\
\text { (b) } \\
\text { (b) } \\
\text { (b) }\end{array}$ & \\
\hline
\end{tabular}

base composition. This was considered necessary as (1) many fragments were of unsuitable size for SSCP analysis and (2) the intronic sequence surrounding all $S C N 5 A$ exons was completely unknown with the exception of the splice junctions which were determined previously. ${ }^{22}$ Twelve new primers yielding smaller PCR amplicons were designed for exons 2,7 , $8,14,16,23,25$, and 28 while exons $12,16,17$, and 28 were subdivided into several PCR products because of their large size. For $K C N E 1$ and $K C N E 2$, existing primer sets were used for the amplification of the whole coding region of these genes which is contained in a single exon. ${ }^{16}{ }^{19}$ However, we reduced the number of PCR fragments needed from three to two. For KCNE1, the two amplified fragments correspond to fragments 1 and 2 (264 and $231 \mathrm{bp}$ respectively) reported by Splawski et al. ${ }^{19}$ These completely cover the coding region of this gene and therefore there was no need for a third fragment. With regard to $K C N E 2$, we combined the forward primer from fragment 1 and the reverse primer from fragment 2 quoted by Abbott et $a l^{16}$ to create a new PCR amplicon of 293 bp. A second PCR 
Table 4 Amplification conditions, primers and sizes of PCR products for KCNE1 (a) and KCNE2 (b) coding region. $P C R$ programmes (a-g) are given in Methods. The value following programme (a) indicates the annealing temperature for each PCR amplicon. Primers for KCNE1 and KCNE2 have been reported previously ${ }^{16} 19$

\begin{tabular}{|c|c|c|c|c|c|}
\hline A Exon & Size (bp) & Primers & $\begin{array}{l}\text { PCR fragment } \\
(b p)\end{array}$ & $\begin{array}{l}\text { PCR } \\
\text { programme }\end{array}$ & $\begin{array}{l}\text { Special } \\
\text { conditions }\end{array}$ \\
\hline 3 & $437+$ & $\begin{array}{l}\text { F: CTGCAGCAGTGGAACCTTAATG } \\
\text { R: GTTCGAGTGCTCCAGCTTCTTG } \\
\text { F: GGGCATCATGCTGAGCTACAT } \\
\text { R: TTAGCCAGTGGTGGGGTTCA }\end{array}$ & $\begin{array}{l}264 \\
231\end{array}$ & $\begin{array}{l}\text { (f) } \\
\text { (f) }\end{array}$ & \\
\hline \multirow[t]{2}{*}{$\begin{array}{l}\text { B Coding region } \\
\text { (single exon) }\end{array}$} & Size $(b p)$ & Primers & $\begin{array}{l}\text { PCR fragment } \\
(b p)\end{array}$ & $\begin{array}{l}\text { PCR } \\
\text { programme }\end{array}$ & $\begin{array}{l}\text { Special } \\
\text { conditions }\end{array}$ \\
\hline & 371 & $\begin{array}{l}\text { F: CCGTTTTCCTAACCTTGTTCG } \\
\text { R: GTTCCCGTCTCTTGGATTTCA } \\
\text { F: AATGTTCTCTTTCATCATCGTG } \\
\text { R: TGTCTGGACGTCAGATGTTAG }\end{array}$ & $\begin{array}{l}291 \\
239\end{array}$ & $\begin{array}{l}\text { (a) } 55^{\circ} \mathrm{C} \\
\text { (a) } 55^{\circ} \mathrm{C}\end{array}$ & \\
\hline
\end{tabular}

amplicon was produced with the primers which Abbott $e t a l^{16}$ used for fragment 3 in their study (213 bp).

SSCP analysis using the methods described earlier produced clear bands for all PCR amplicons. In many cases, depending on their size, PCR products of two or more exons were loaded onto the same lane and resolved simultaneously on an SSCP gel, for example, $K C N Q 1$ exons 2,11 , and 15 or $S C N 5 A$ exons 11,12 , and 15 .

A number of samples from sudden death cases and controls (healthy unrelated subjects) were used to evaluate the efficiency of our methods. SSCP analysis of over 60 samples for KCNQ1, KCNE1, and KCNE2 identified six polymorphisms in the first two genes. These were $1086 \mathrm{C}>\mathrm{A}$ V308V, $1638 \mathrm{G}>\mathrm{A}$ S546S, and $1986 \mathrm{C}>\mathrm{T}$ Y642Y in $\mathrm{KCNQ} 1$ and $84 \mathrm{G}>\mathrm{A}$ S29S, $112 \mathrm{G}>\mathrm{A}$ S38G, and $253 \mathrm{G}>\mathrm{A}$ D $85 \mathrm{~N}$ in $K C N E 1$. No base changes were identified in KCNE2.

\section{Discussion}

In this study we produced a robust and reproducible set of primers for PCR/SSCP analysis of all five genes involved in the long QT syndrome. We also defined the exact PCR conditions for a successful amplification of every PCR fragment, which allows effective mutational analysis of the five known LQT genes. In particular, for $K C N Q 1$ and $H E R G$ we based our analysis on primers published in two previous studies, Splawski et $a l^{19}$ and Itoh et $a l^{23}$ respectively. However, PCR conditions for a number of fragments had to be optimised, as in our experience some PCR products amplified poorly under the original conditions. In addition, new primers were needed for $K C N Q 1$ exons 9, 13, and 15 . Based on the details given in table 1 , all $K C N Q 1$ exons can now be amplified without the use of formamide. Using our PCR methods, mutation screening of HERG can be achieved by amplifying only 19 fragments compared to $20^{19}$ and $24 .{ }^{23}$ This was made possible by recombining existing primers in a more effective way and then optimising PCR conditions for each fragment. For example, HERG exon 6 can be amplified in two fragments instead of three as used by Itoh $e t a l^{23}$ and there is no need for nested primers for exons 1 and 11 of the same gene. ${ }^{19}$
Genomic organisation and sequence of the $S C N 5 A$ gene were first reported by Wang et $a l^{22}$ In that study a total of 41 primer pairs were used to determine the sequence of 28 exons by direct sequencing. Several studies have since used those primers for mutational analysis of some SCN5A exons by SSCP. ${ }^{25-27}$ However, a number of PCR fragments are too large for effective SSCP analysis and contain long intronic sequences of unknown composition. Using the original set of primers, we sequenced all SCN5A exons and then produced several new PCR fragments suitable for SSCP analysis. For amplifying KCNE1 and KCNE2 fragments, no changes were made to the published PCR methods as they were found to work well. However, we recombined the existing primers in a way that permits amplification of the entire coding region of these genes in two fragments instead of the three used in previous studies. ${ }^{16} 19$

PCR products were analysed on SSCP gels by combining more than one fragment in each lane. In that way a large number of fragments can be screened on the same gel in various combinations depending on their electrophoretic mobility, thus reducing the number of gels needed for mutational screening. Evaluation of our system using DNA samples from sudden death cases and controls detected four known polymorphisms and two novel changes in KCNQ1 and KCNE1. In the first gene we found two SNPs at amino acid positions 546 and $642^{28}$ and a novel one at position 308. On the other hand, in KCNE1 we report a novel SNP (84 G>A S29S) and two known polymorphisms at positions 38 and $85 .{ }^{29}{ }^{30}$ Owing to the nature of these two novel changes, we speculate that they may be benign polymorphisms even though they were not observed in 40 controls analysed. These findings provide good evidence that the methods described in this study, considering their limitations, can be effective for screening the known LQT genes for mutations.

This work was supported by grant No PG/99067 from the British Heart Foundation (BHF). P Syrris and W M McKenna are funded by the British Heart Foundation and A Murray is supported by the Conor Power Foundation.

\footnotetext{
1 Schwartz PJ, Moss AJ, Vincent GM, Crampton RS. Diagnostic criteria for the long QT syndrome. An update.
Dito Diagnostic criteria for the
Circulation 1993;88:782-4.

2 Romano C. Congenital cardiac arrhythmias. Lancet 1965;i: Roma.
} 
3 Ward OC. A new familial cardiac syndrome in children. $f$ Irish Med Assoc 1964;54:103-6.

4 Jervell A, Lange-Nielsen F. Congenital deaf mutism, functional heart disease with prolongation of the QT interval, and sudden death. Am Heart 7 1957;54:59-78.

5 Schulze-Bahr E, Wedekind H, Haverkamp W, Borggrefe M, Assmann G, Breithardt G, Funke H. The LQT syndrome - current status of molecular mechanisms. Z Kardiol 1999; 88:245-54.

6 Wang Q, Curran ME, Splawski I, Burn TC, Millholland JM, VanRaay TJ, Shen J, Timothy KW, Vincent GM, de Jager T, Schwartz PJ, Toubin JA, Moss AJ, Atkinson DL, Landes GM, Connors TD, Keating MT. Positional cloning of a novel potassium channel gene: KVLQT1 mutations cause cardiac arrhythmias. Nat Genet 1996;12:17-23.

7 Splawski I, Timothy KW, Vincent GM, Atkinson DL, Keating MT. Molecular basis of the long QT syndrome associated with deafness. N Engl f Med 1997;336:1562-7.

8 Neyroud N, Tesson F, Denjoy I, Leibovici M, Donger C, Barhanin J, Faure S, Gary F, Coumel P, Petit C, Schwartz Barhanin J, Faure S, Gary F, Coumel P, Petit C, Schwartz
K, Guicheney P. A novel mutation on the potassium channel gene KVLQT1 causes the Jervell and LangeNielsen cardioauditory syndrome. Nat Genet 1997;15:

9 Chouabe C, Neyroud N, Guicheney P, Lazdunski M, Romey G, Barhanin J. Properties of KVLQT1 K+ channel mutations in Romano-Ward and Jervell and LangeNielsen inherited cardiac arrhythmias. EMBO f 1997;16: 5472-9.

10 Murray A, Donger C, Fenske C, Spillman I, Richard P, Dong YB, Neyroud N, Chevalier P, Denjoy I, Carter N, Syrris P, Afzal AR, Patton MA, Guicheney P, Jeffery S. Splicing mutations in KCNQ1. A mutation hotspot at codon 344 that produces in frame transcripts. Circulation 1999;100:1077-84.

11 Tyson J, Tranebjaerg L, Bellman S, Wren C, Taylor JF, Bathen J, Aslaksen B, Sorland SJ, Lund O, Malcolm S, Pembrey M, Bhattacharya S, Bitner-Glindzicz M. IsK and KVLQT1: mutation in either of the two subunits of the KVLQT1: mutation in either of the two subunits of the
slow component of the delayed rectifier potassium channel slow component of the delayed rectifier potassium channel Genet 1997;6:2179-85.

12 Donger C, Denjoy I, Berthet M, Neyroud N, Cruaud C, Bennaceur M, Chivoret G, Schwartz K, Coumel P, Guicheney P. KVLQT1 C-terminal missense mutation causes a forme fruste long-QT syndrome. Circulation 1997; 96:2778-81.

13 Curran ME, Splawski I, Timothy KW, Vincent GM, Green ED, Keating MT. A molecular basis for cardiac arrhythmia: HERG mutations cause long QT syndrome. Cell 1995;80: 795-803.

14 Wang Q, Shen J, Splawski I, Atkinson D, Li Z, Robinson JL, Moss AJ, Towbin JA, Keating MT. SCN5A mutations associated with an inherited cardiac arrhythmia, long QT syndrome. Cell 1995;80:805-11.

15 Schulze-Bahr E, Wang Q, Wedekind H, Haverkamp W, Chen Q, Sun Y. KCNE1 mutations cause Jervell and Lange-Nielsen syndrome. Nat Genet 1997;17:267-8.

f Med Genet

2001;38:710-719

University of Oxford,

Department of

Psychiatry, Warneford

Hospital, Headington,

Oxford OX3 7JX, UK

N L J Ross

J Yang

R Wadekar

N A Williams

T J Crow

Human Molecular

Genetics Group,

University of

Cambridge,

Department of

Pathology, Tennis

Court Road,

Cambridge CB2 1QP,

UK

C A Sargent

C A Boucher

N A Affara

Department of

Psychiatry, Teikyo

University School of

Medicine, 2-11-1,

Kaga, Itabashi, Tokyo,

Japan

S Nanko

Correspondence to:

Dr Ross,

nross@molbiol.ox.ac.uk Timothy KW, Keating MT, Goldstein SA. MiRP1 forms I diac arrhythmia. Cell 1999;97:175-87.

17 Splawski I, Tristani-Firouzi M, Lehmann MH, Sanguinett $\mathrm{MC}$, Keating MT. Mutations in the hminK gene cause long QT syndrome. Nat Genet 1997;17:338-40.
EDITOR - There have been a number of claims for linkage to schizophrenia but none has been reliably established. The findings of genome scans have been inconsistent between studies. $^{12}$ On the basis of an association of and a relationship between sex and diagnosis within families (the "same sex concordance" effect), a gene for psychosis in a region of $\mathrm{X}-\mathrm{Y}$ homology was suggested. ${ }^{3}$ In addition, there psychosis with sex chromosome aneuploidies
18 Priori SG, Schwartz PJ, Napolitano C, Bianchi L, Dennis A, De Fusco M, Brown AM, Casari G. A recessive variant of the Romano-Ward long-QT syndrome? Circulation 1998; 97:2420-5.

19 Splawski I, Shen J, Timothy KW, Vincent GM, Lehmann $\mathrm{MH}$, Keating MT. Genomic structure of three long QT syndrome genes: KVLQT1, HERG, KCNE1. Genomics 1998;51:86-97.

20 Wattanasirichaigoon D, Vesely MR, Duggal P, Levine JC, Blume ED, Wolff GS, Edwards SB, Beggs AH. Sodium channel abnormalities are infrequent in patients with long QT syndrome: identification of two novel SCN5A mutations. Am f Med Genet 1999;86:470-6.

21 Neyroud N, Richard P, Vignier N, Donger C, Denjoy I, Demay L, Shkolnikova M, Pesce R, Chevalier P, Hainque B, Coumel P, Schwartz K, Guicheney P. Genomic organisation of the $K C N Q 1 \mathrm{~K}^{+}$channel gene and identification of C-terminal mutations in the long QT syndrome. Circ Res 1999;84:290-7.

22 Wang $\mathrm{Q}$, Li Z, Shen J, Keating MT. Genomic organization of the human SCN5A gene encoding the cardiac sodium channel. Genomics 1996;34:9-16.

23 Itoh $\mathrm{T}$, Tanaka $\mathrm{T}$, Nagai R, Kamiya $\mathrm{T}$, Sawayama $\mathrm{T}$, Nakayama T, Tomoike $H$, Sakurada $H$, Yazaki $Y$, Nakamura Y. Genomic organization and mutational analysis of HERG, a gene responsible for familial long QT syndrome. Hum Genet 1998;102:435-9.

24 Larsen LA, Christiansen M, Vuust J, Andersen PS. High throughput single strand conformation polymorphism analysis by automated capillary electrophoresis: robust multiplex analysis and pattern based identification of allelic variants. Hum Mutat 1999:13:318-27.

25 Chen Q, Kirsch GE, Zhang D, Brugada R, Brugada J, Brugada P, Potenza D, Moya A, Borggrefe M, Breithardt G, Ortiz-Lopez R, Wang Z, Antzelevitch C, O'Brien RE, Schulze-Bahr E, Keating MT, Towbin JA, Wang Q. Genetic basis and molecular mechanism for idiopathic ventricular fibrillation. Nature 1998;392: 293-6.

26 Bezzina C, Veldkamp MW, van Den Berg MP, Postma AV, Rook MB, Viersma JW, van Langen IM, Tan-Sindhunata G, Bink-Boelkens MT, van Der Hout AH, Mannens MM, Wilde AA. A single $\mathrm{Na}^{+}$channel mutation causing both long QT and Brugada syndromes. Circ Res 1999;85:120613

27 Wei J, Wang DW, Alings M, Fish F, Wathen M, Roden DM, George AL Jr. Congenital long QT syndrome caused by a novel mutation in a conserved acidic domain of the cardiac $\mathrm{Na}^{+}$channel. Circulation 1999;99:3165-71.

28 Lee MP, Hu RJ, Johnson LA, Feinberg AP. Human KVLQT1 gene shows tissue-specific imprinting and encompasses Beckwith-Wiedemann syndrome chromosomal rearrangements. Nat Genet 1997;15:181-5.

29 Lai LP, Deng CL, Moss AJ, Kass RS, Liang CS. Polymorphism of the gene encoding a human minimal potassium ion channel (mink). Gene 1994;151:339-40.

30 Tesson F, Donger C, Denjoy I, Berthet M, Bennaceur M, Petit C, Coumel P, Schwartz K, Guicheney P. Exclusion of KCNE1 (IsK) as a candidate gene for Jervell and LangeNielsen syndrome. $f \mathrm{Mol}$ Cell Cardiol 1996;28:2051-5. is an argument that psychosis is related to cerebral asymmetry, a putative defining feature of the human brain, and that a determinant of asymmetry is in the X-Y homologous class. ${ }^{4}$ Searches for linkage on the $\mathrm{X}$ chromosome have yielded weak evidence for linkage in $\mathrm{Xp} 11^{5}$ and on the proximal long arm, ${ }^{6-8}$ but, arguably, these findings have been no more consistent than those on the autosomes. ${ }^{9}$ 
In the absence of consistent linkage, one approach to finding genes associated with psychosis is through analysis of cytogenetic anomalies. One such anomaly is the case of an XX male with schizophrenia. ${ }^{10} 11$ In general, $\mathrm{XX}$ maleness is the result of the transfer of the testis determining factor $(S R Y)$ to the $\mathrm{X}$ chromosome $^{12}$ as a result of an abnormal X-Y interchange involving the non-recombining region of $\mathrm{Yp}$ and homologous sequences in $\mathrm{Xp} .{ }^{13}{ }^{14}$ We showed previously that the breakpoint on the $\mathrm{Y}$ in this case is within the distal Yp11.2/Xq21.3 region of homology. ${ }^{8}$

In this study we have characterised the $\mathrm{Y}$ breakpoint using a sequencing approach and fluorescence in situ hybridisation (FISH). We have shown that the abnormal X-Y interchange occurred between retroviral long terminal repeats (LTR). This is distinct from previously described translocations, which frequently involve hot spots such as the protein kinase gene $P R K$ that has homologues on both $\mathrm{Yp}$ and $\mathrm{Xp} .{ }^{1516}$ Cloning of the $\mathrm{Yp} / \mathrm{Xp}$ junction fragment allowed the development of an $\mathrm{X}$ specific STS for radiation hybrid mapping, which places the $\mathrm{X}$ chromosome breakpoint within the PAR1. The breakpoint on the X chromosome is unusual in this category of $\mathrm{XX}$ male patients, as most occur proximal to the pseudoautosomal boundary (PABX). Only one breakpoint within PAR1 has previously been reported, ${ }^{17}$ and in this patient the translocation is mediated through an Alu-Alu recombination and the $\mathrm{Y}$ breakpoint is also within the Yp11.2 region of homology with Xq21.3, but is located telomeric to that in the present case. Unfortunately, no details of the psychiatric phenotype in that case are available (D C Page, personal communication).

\section{Materials and methods \\ PATIENT}

The XX male patient investigated in this study is Japanese and has been described previously. ${ }^{10}{ }^{11}$ There was no family history of mental illness. He married but has no children. $\mathrm{He}$ was admitted to hospital with a diagnosis of schizophrenia but showed little response to neuroleptic medication. After a second admission, he remained in hospital for 30 years with chronic delusions. He was of dull normal intelligence (full scale WAIS 72, verbal IQ 68, performance IQ 75) with blunted affect. His symptoms satisfy the DSM-III-R criteria for the diagnosis of schizophrenia. Cytogenetic studies showed a 46,XX karyotype. No family history of psychosis was noted and no material was available from other family members.

\section{CELL LINE}

Lymphocytes from the patient transformed with Epstein Barr virus (EBV) were the source of genomic DNA and of metaphase chromosomes. The transformed cells were cultured in RPM1640 medium supplemented with $10 \%$ fetal calf serum (FCS).

EXTRACTION OF GENOMIC DNA

DNA was extracted from transformed lymphocytes using Genomix kits (Talent/VH Bio,
Newcastle Upon Tyne, UK) according to the manufacturer's instructions. DNA obtained from the blood of normal Japanese males and females served as controls.

PCR AMPLIFICATION OF SEQUENCE TAGGED SITES (STS)

Twenty $\mu \mathrm{l}$ reactions containing $100 \mathrm{ng}$ of genomic DNA, $12 \mathrm{pmol}$ of each primer, 0.2 $\mathrm{mmol} / \mathrm{l}$ of each dNTP, $0.4 \mathrm{U}$ of Taq polymerase (Promega Inc), and $1 \times$ PCR buffer (Promega Inc) were amplified using a thermocycler (Genetic Research Instrument) as follows. After an initial denaturation step at $94^{\circ} \mathrm{C}$ for five minutes, samples were subjected to 35 cycles for 30 seconds at $94^{\circ} \mathrm{C}, 30$ seconds at $55^{\circ} \mathrm{C}$, one minute at $72^{\circ} \mathrm{C}$, followed by a final step for 10 minutes at $72^{\circ} \mathrm{C}$. The annealing temperature varied depending on the $\mathrm{Tm}$ of the primers. Products were analysed by electrophoresis on $1-2 \%$ agarose gels.

DNA SEQUENCING

PCR amplification of STSs were scaled up two to threefold and the products were purified using Qiaquick PCR purification kits (Qiagen Ltd, UK). The purified products were sequenced using dye terminator cycle sequencing (Big Dye sequencing system, Applied Biosystems Inc) and were analysed by an ABI 373 sequencer (Applied Biosystems Inc). Sequencing of the cloned $3 \mathrm{~kb} \mathrm{Yp/Xp}$ junction fragment was carried out in a stepwise manner by primer extension initiated from both $\mathrm{T} 7$ and $\mathrm{Sp} 6$ ends of the cloning vector.

BAC AND PAC CLONES

BAC clones derived from the $\mathrm{Yp}$ region homologous to Xq21.3 were gifts from Dr Gareth Howell (Sanger Centre). PAC clones were isolated from the RPCI-1 library (available through the HGMP resource centre, Hinxton) by screening with $\mathrm{X} / \mathrm{Y}$ homologous STS primer pairs. ${ }^{18-20}$

Transformed bacteria were cultured in L-broth containing chloramphenicol or kanamycin as appropriate and DNA was extracted using an alkaline lysis method. ${ }^{21}$ Clones were tested for the presence of STSs to confirm that they were authentic. DNA from clones selected for in situ hybridisation were purified using Qiagen Midi columns (Qiagen Ltd, UK).

PCR PRIMERS

Primers for amplification of STSs have been described previously. ${ }^{18-20}$ Other primers were as follows: J: 5' CAGCAACATGTATTGAAA ATAC; M: 5' TCTGCTGCCTGCCCCTGA; $\mathrm{N}$ : 5'GGCAGCATTGCCGCAAAC; O: 5'AGTCAGAGTAATGAGGCCTCTC; P: 5' GAGAAGAAAGAATGGGGAGGAT; AC: 5' CTATGACTGGACGTGCACATAG. AP: 5' TCCCTATATCTCCCGTGT; AR 5' ACGTGCGAACTGGTACAT.

Primers J and $M$ are $Y$ specific at their 3' ends. They were designed by comparing the sequence of the relevant part of Yp (from PAC clone dJ145K17 and GenBank entry AC012077) with the Xq21.3 homologous sequence (AL121823 from the Sanger Centre). Primers N, O, and P 
were designed from the Yp sequence. Forward $(\mathrm{F})$ and reverse $(\mathrm{R})$ primers for amplifying the fragment spanning the Tsp509I restriction enzyme sites in Yp were 5'ACTGTCTTCTCCCCAATGAA and 5' GTGATTGGGTCAAAGTGGCT, respectively.

INVERSE PCR

Five $\mu$ amounts of genomic DNA from the $\mathrm{XX}$ male, a normal Japanese male, and a normal Japanese female were digested to completion with $\mathrm{BamHI}$ at $37^{\circ} \mathrm{C}$ overnight. The digested DNA was extracted with phenol/ chloroform, chloroform, precipitated with ethanol in the presence of $0.3 \mathrm{~mol} / 1$ sodium acetate, and resuspended in water. A total of $200 \mathrm{ng}$ of digested DNA were self-ligated overnight at $4^{\circ} \mathrm{C}$ in a $40 \mu \mathrm{l}$ reaction containing $1 \times$ ligase buffer (Promega) and 0.15 U T4 ligase (Gibco). Ligated preparations were denatured at $94^{\circ} \mathrm{C}$ for five minutes and quenched on ice before use in PCR reactions. Approximately 20 ng of ligated DNA were the templates for the first round of inverse PCR using the Extensor High Fidelity PCR kit (Advanced Biotechnologies), according to the manufacturer's instructions. Fifty $\mu \mathrm{l}$ reactions containing $1 \times$ buffer 1 , $350 \mu \mathrm{mol} / 1$ of each dNTP, $1.75 \mathrm{mmol} / 1 \mathrm{MgCl}_{2}$, and $2 \mathrm{U}$ of $T a q$ polymerase were subjected to 35 cycles of amplification. Cycling parameters were as follows: an initial denaturation step at $94^{\circ} \mathrm{C}$ for two minutes, followed by 35 cycles of $94^{\circ} \mathrm{C}$ for 15 seconds, $66^{\circ} \mathrm{C}$ for 30 seconds, $68^{\circ} \mathrm{C}$ for five minutes, and a final extension step at $72^{\circ} \mathrm{C}$ for five minutes.

Primers J and $\mathrm{P}$ were used for the first round of inverse PCR and a secondary PCR was carried out with primers $\mathrm{J}$ and $\mathrm{O}$ essentially as above using $1 / 10$ dilution of the first PCR reaction products as template.

CLONING OF THE Yp/Xp JUNCTION FRAGMENT Inverse PCR products were cloned using the pGEM TA cloning kit (Promega) according to the manufacturer's instructions.

FLUORESCENCE IN SITU HYBRIDISATION (FISH) $\mathrm{BAC}$ and PAC clones containing relevant STS markers were selected for FISH analysis. Total BAC and PAC DNA was labelled with biotin by nick translation (Biotin-nick translation kit, Boehringer Mannheim). Metaphase chromosomes from the patient and normal controls were hybridised to biotin labelled DNA and bound DNA was shown using fluorescently labelled antibiotin antibody according to standard protocols. ${ }^{22}$

ANALYSIS OF MICROSATELLITE MARKERS

To refine the breakpoint in $\mathrm{Xp} 22.3$, the number of alleles of a variety of microsatellite markers mapping in $\mathrm{Xp} 22.3$ was estimated in the XX male and normal Japanese male and female DNA. Genomic DNA was amplified through PCR using the relevant primers as described in the Genbank and Genethon databases. One of each pair of primers was labelled with cy5 and the PCR products were analysed in a denaturing polyacrylamide sequencing gel using the Alf Express sequencer (Pharmacia).
RADIATION HYBRID MAPPING

The STS BPX, developed from the X specific region of the breakpoint junction fragment (primers AP and AR), was mapped using the Genebridge 4 radiation hybrid panel (HGMP Resource Centre, Hinxton). The pattern of positive and negative hybrids was converted to a data vector and submitted to http://www. sanger.ac.uk/Software/RHserver//RHserver. shtml for two point RHMAP analysis with framework markers. The Genemap99 at the Genbank web page http://www.ncbi.nlm.nih. gov/genemap99/map.cgi?CHR=X was consulted to identify the map location of these markers. Vectors for the highest scoring framework markers and their neighbours were retrieved from EBI at http://corba.ebi.ac.uk/ RHdb/species/HUMAN/gm98.html and reanalysed with the BPX vector to position BPX within the radiation hybrid map.

\section{Results}

MAPPING THE BREAKPOINT ON THE Y

CHROMOSOME

Since previous studies had indicated that the breakpoint mapped in the region of Yp11.2 homologous to Xq21.3 (fig 1), further mapping of its location required an approach that could discriminate between homologous sequences derived from $\mathrm{X}$ and $\mathrm{Y}$ chromosomes. Initial PCR analysis confirmed that the SRY marker was present in the XX male, the marker DXYS156 showed the Y specific polymorphism, and the Y specific STSs sY58 and sY78 which map outside the $\mathrm{X}-\mathrm{Y}$ homology region were not present (not shown). Further experiments involved sequencing STSs in the genomes of the XX male patient and normal Japanese males and females. The method depends on the capacity to detect heterozygosity and assumes that the PCR conditions can amplify both $\mathrm{X}$ and $\mathrm{Y}$ derived STSs efficiently. In the case of GMGXY6, Y specific primers gave amplification with only the normal male and the XX male (not shown).

The results of analysis of 22 STSs within the $\mathrm{X}-\mathrm{Y}$ homology region are summarised in table 1 and fig 1. A number of cases were uninformative because there were no differences between males and females. The most proximal Y marker present was GMGXY6Y, and the first confirmed deleted marker was the $\mathrm{Y}$ homologue of $13 \mathrm{~d}$. The distance between GMGXY6Y and 13d is approximately $500 \mathrm{~kb}$. To localise the breakpoint within this region further, PAC and BAC clones selected for the intervening non-informative STSs were used in FISH.

FLUORESCENCE IN SITU HYBRIDISATION (FISH) The results of in situ hybridisation obtained with the XX male chromosomes are shown in fig 2. The BAC clone BA32K15 (fig 1) containing sY41 and sY42 hybridised to the Xq region of both $\mathrm{X}$ chromosomes (arrows 1 and 2 in fig 2A) but also to a second site at the telomeric end of the abnormal $\mathrm{X}$ chromosome (arrow 1). Similar results were obtained using the PAC clone dJ145K17, which spans the sY42, 13d, and 2450L markers. However, in 
A

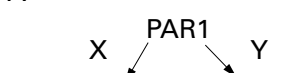

$X{ }^{P A R 1} Y$

SR22.33

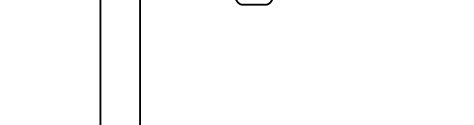

Xq21.3

$\longleftarrow \mathrm{sY} 20$
$-\mathrm{GXY} 5$

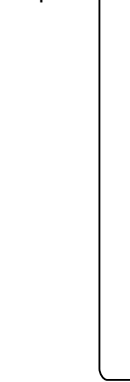

Figure 1 (A) Schematic transposition. The 3.5 Mb Xq21.3/Yp11.2 region of homology comprising STS markers $s Y 20$ to GXY5 is indicated (black box). Grey box represents the pseudoautosomal regions (PAR1) of X and Y. Dark grey box indicates the male specific gene SRY. (B) Map of Yp showing selected STS markers within the 3.5 Mb region homologous to Xq21.3. ${ }^{23}$ Arrow indicates the location of the breakpoint (Bkpt) between $13 d$ and sY42 markers in the abnormal paternal X chromosome of the XX male with psychosis. GMGXY4, GMGXY5, GMGXY6, GMGXY9, and GMGXY12 have been abbreviated. (C) Enlargement of part of YP11.2 showing the location of BAC and PAC clones used for FISH.

this case, the signal in the abnormal Xp (arrow 1 , fig 2B) was fainter than in $\mathrm{Xq}$ indicating that only part of this sequence was present on the telomere of the abnormal $\mathrm{X}$ chromosome. Finally, the BAC clone BA240N18, which is centromeric to $13 \mathrm{~d}$ and contains STS $2450 \mathrm{~L}$, hybridised to Xq of both chromosomes but not to Xp (fig 2C). These results, together with the STS analysis discussed above, confirm that the

Table 1 Analysis of STSs in genomic DNA of the XX male patient

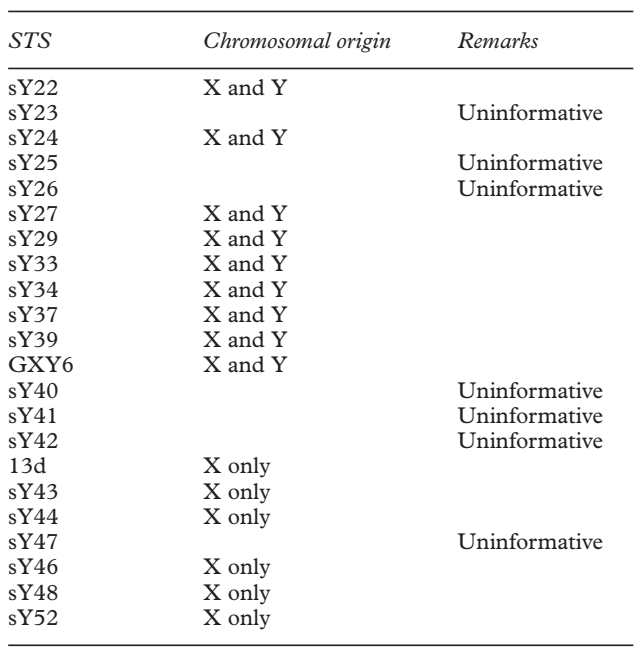

breakpoint on $\mathrm{Yp}$ lies between the markers sY42 and $13 \mathrm{~d}$.

FINE MAPPING OF THE BREAKPOINT BY RESTRICTION ENZYME ANALYSIS AND Y SPECIFIC PCR

To map the breakpoint further, we exploited differences between the sequences of Xq21.3 and Yp11.2 in the region spanning $13 \mathrm{~d}$ and sY42 to design Y specific primers and primers that amplify fragments containing restriction enzyme (RE) sites which differentiate between $\mathrm{X}$ and $\mathrm{Y}$. Primers F/R (fig 3B) were designed to amplify a region containing an $\mathrm{RE}$ site difference between the $\mathrm{X}$ and $\mathrm{Y}$ chromosomes. Digestion of PCR product from $\mathrm{X}$ derived DNA with $T s p 509$ I is expected to produce two fragments of $161 \mathrm{bp}$ and $23 \mathrm{bp}$, respectively, whereas only one $184 \mathrm{bp}$ fragment is expected from Y derived DNA. Fig 4A shows the results of a $T s p 509$ I digestion of PCR products from the patient and controls indicating that the XX male had $\mathrm{Y}$ derived sequence in this region. We further showed that the $\mathrm{Y}$ specific primer M (1940 bp from 13d) (fig 3) and primer $\mathrm{N}$ (1816 bp from 13d) amplified a product of expected size (124 bp) using normal Japanese male DNA as template, but failed to amplify products using normal Japanese female DNA or the XX male DNA as templates (fig 4B). We concluded therefore that the breakpoint 

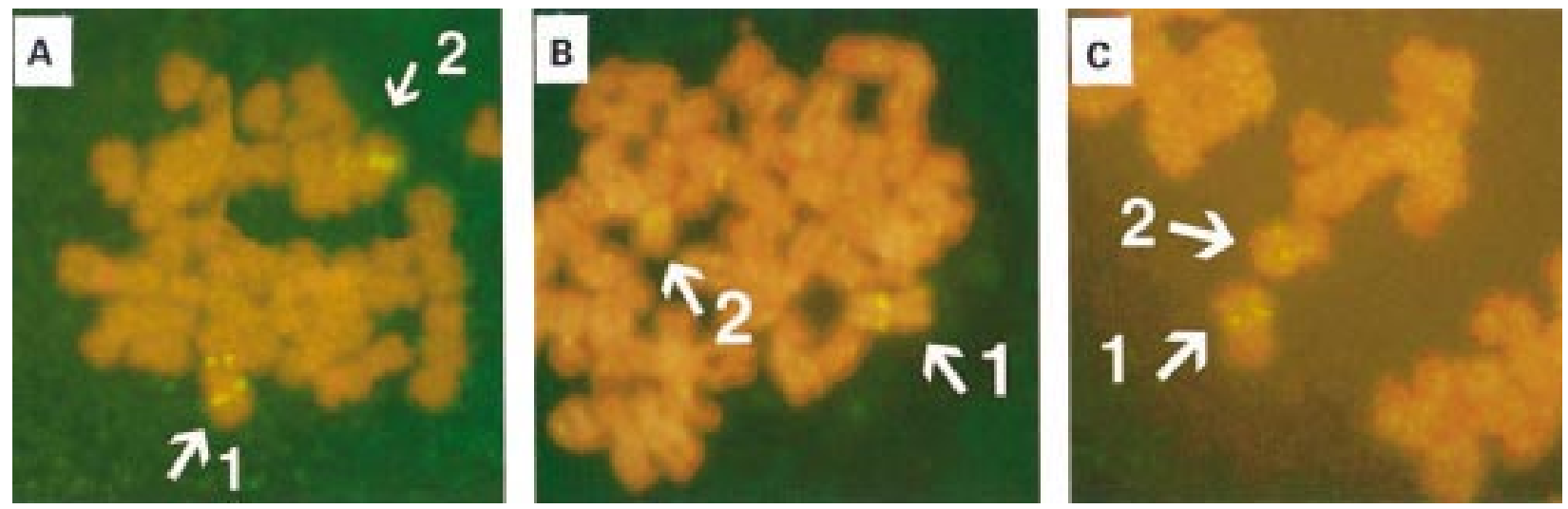

Figure 2 Results of FISH with clones BA32K15 (A), df145K17 (B), and BA240N18 (C) on metaphase chromosomes of the XX male. Arrows 1 and 2 indicate abnormal paternal $X$ chromosome and normal maternal chromosome respectively. Four yellow dots on the abnormal chromosome in (A, arrow 1) show that sY41-sY42 sequences are present in the terminal part of $X p$ as well as $X q$, whereas the normal chromosome ( $A$, arrow 2) shows only two dots in Xq. Fainter dots in Xp compared to $X q$ in (B, arrow 1) indicate that only part of the sequence between markers $s Y 42$ and $2450 L$ was translocated to $X p$. Absence of dots in Xp in (C) indicate that the sequence translocated to Xp did not include the marker $2450 L$.

mapped within the region defined by the $\mathrm{X}$ specific Tsp509I RE site and primer M.

THE JUNCTION FRAGMENT

Inverse $P C R$ and cloning of the $Y_{P}-X p$ junction fragment

To isolate the junction between $\mathrm{Yp}$ and $\mathrm{Xp}$, nested inverse PCR was performed. Genomic DNA was digested with $B a m \mathrm{HI}$, religated at low concentration, and used as template for inverse PCR. Primer locations are indicated in fig 3. Primers J (designed to be $\mathrm{Y}$ specific at its $3^{\prime}$ end) and primer $P$ were used for the first round of PCR and primers $\mathrm{J}$ and $\mathrm{O}$ for the secondary PCR. The results of the secondary PCR with primers $\mathrm{J}$ and $\mathrm{O}$ are shown in fig $4 \mathrm{C}$. A major unique fragment (approximately $3 \mathrm{~kb}$ ) was obtained from the XX male DNA but not from normal Japanese male and female DNA. This fragment was gel purified and cloned. Ten recombinant clones with an insert of expected size were sequenced from both ends. Three clones contained the expected ends as shown by the presence of primers $\mathrm{J}$ and $\mathrm{O}$ in the sequence and a $B a m \mathrm{HI}$ site at the expected distance from primer $\mathrm{O}$.

A

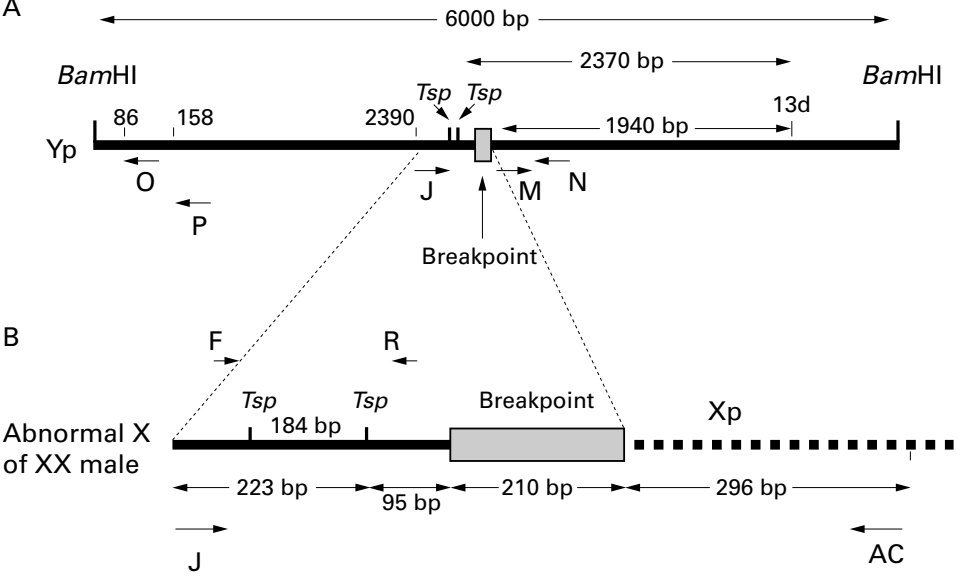

Figure 3 (A) Sketch of part of Yp showing the location of primers and the relevant restriction enzyme Tsp509I (Tsp) sites (not to scale). (B) Sketch of the Yp/Xp junction showing the location of the breakpoint, relevant Tsp509I (Tsp) sites, and primers $\mathcal{F}$ and AC which were used to amplify a unique fragment in the XX male. Note presence of two $T s p 509 I R E$ sites 184 bp apart in $Y p$ within the sequence flanked by $F$ and $R$ primers.
The complete sequence of the junction fragment from one of the clones (clone 10) is shown in fig 5. The sequence 3' of the J primer contains nucleotides (position 23-339 inclusive) present in $\mathrm{Yp} 11.2$ but not in $\mathrm{Xq} 21.3$, that is, the sequence is $100 \% \mathrm{Y}$ derived. From position 551 onward, there are a number of single or double nucleotides which are neither Xq21.3 nor Yp11.2 derived. We believe that this indicates the presence of $\mathrm{Xp}$ derived sequences. Consequently, the breakpoint on the $\mathrm{Y}$ chromosome has occurred within the region $340-550 \mathrm{bp}$. This is consistent with and extends our independent data (fig 4A) which indicated a difference in a RE site for $T s p 509 \mathrm{I}$ in the XX male that also occurred in the Yp sequence, but not the sequence from Xq21.3. Thus, fig 5 shows the sequence GATT at position 223 in the XX male, also found in Yp11.2, whereas the Xq21.3 derived sequence has the Tsp509I RE site AATT at this point. This is also consistent with results shown in fig $4 \mathrm{~B}$ which showed the absence of $\mathrm{Y}$ specific sequence at the primer $\mathrm{M}$ site in the $\mathrm{XX}$ male. Thus, at position 665, the $\mathrm{XX}$ male sequence has a $G$ instead of $A$ at the 3' end of the primer and a $C$ instead of $G$ at the fourth nucleotide from its 5 ' end. Primer $\mathrm{O}$ is at the expected distance from the BamHI site (deduced from the sequence of $\mathrm{Yp}$ ).

To confirm that the cloned fragment indeed spanned the Yp-Xp junction, a PCR was carried out using primer $\mathrm{J}$ and primer $\mathrm{AC}$ which is located within the putative $\mathrm{Xp}$ region. Fig 4D1 shows that a product of expected size (800 bp) was amplified using the $\mathrm{XX}$ male genomic DNA as template but not normal Japanese male and female DNA controls. The results show that the fragment is a unique sequence present only in the $\mathrm{XX}$ male. A second set of primers confirmed this result (not shown). A control for the DNA template amplification is shown in fig 4D2.

Analysis of the sequence of the junction fragment Most of the $2975 \mathrm{bp}$ sequence consists of LTR and LINE repeats. Clearly these must have been involved in the abnormal recombination between $\mathrm{Yp}$ and $\mathrm{Xp}$ during meiosis, forming the abnormal paternal $\mathrm{X}$ of the $\mathrm{XX}$ male 
patient. Since these repeats share extensive sequence identity, it is difficult to map the breakpoint exactly. However, it was possible to identify LTR sequences which contained nucleotides present in Yp but not Xq21.3 and nucleotides that were neither Yp nor Xq21.3 derived. Part of the sequence (which did not consist entirely of repeat elements) contained $14 \mathrm{CpG}$ dinucleotides in a $270 \mathrm{bp}$ region which showed $97 \%$ identity with a CpG island sequence (Genbank Accession Z57539). This is of interest since it suggests that there could be genes in $\mathrm{Xp}$ downstream of the breakpoint that might be affected by the Yp translocation.

To date we have not found convincing identity between the sequence 3' of the breakpoint and sequences in $\mathrm{Xp}$ as a whole or Xp22.3 in particular. However, sequencing of this region by the Human Genome Project is not yet complete. Database searches for identity are further complicated because of the presence of LTR repeat sequences in many chromosomes.

MAPPING THE BREAKPOINT ON THE X

CHROMOSOME

Microsatellite markers

In an attempt to map the breakpoint on

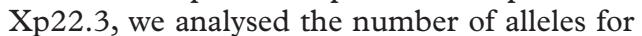
microsatellite markers in the genome of the patient. The results showed that the patient has two alleles for DXS6807 indicating that the breakpoint is distal to this marker. Analysis of markers DXS1233, DXS7100, DXS1060, DXS987, and the PAR1 markers DXYS228 and DXYS233 were uninformative. Fig 6 shows the chromosome rearrangement and the
A

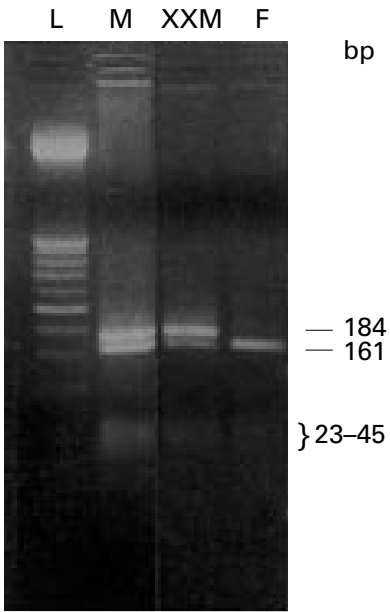

C
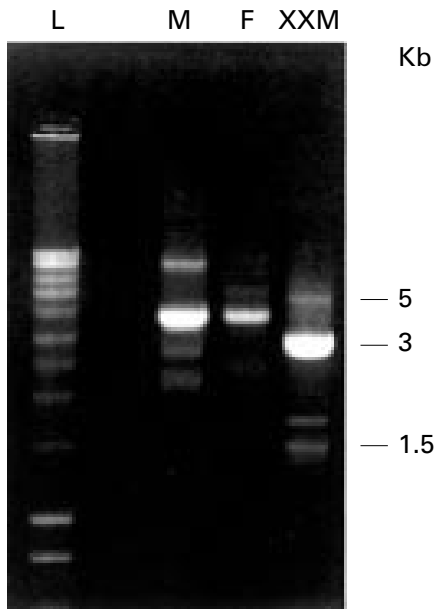

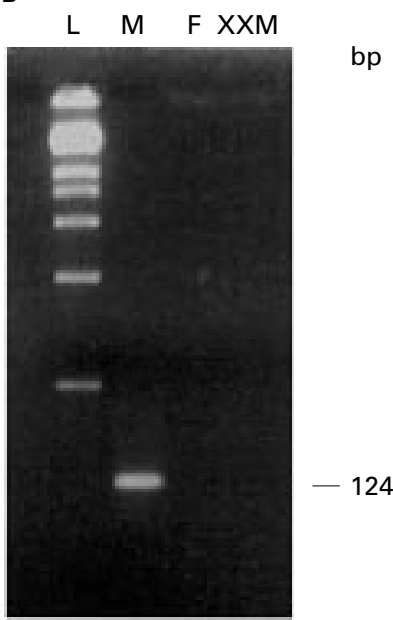

D
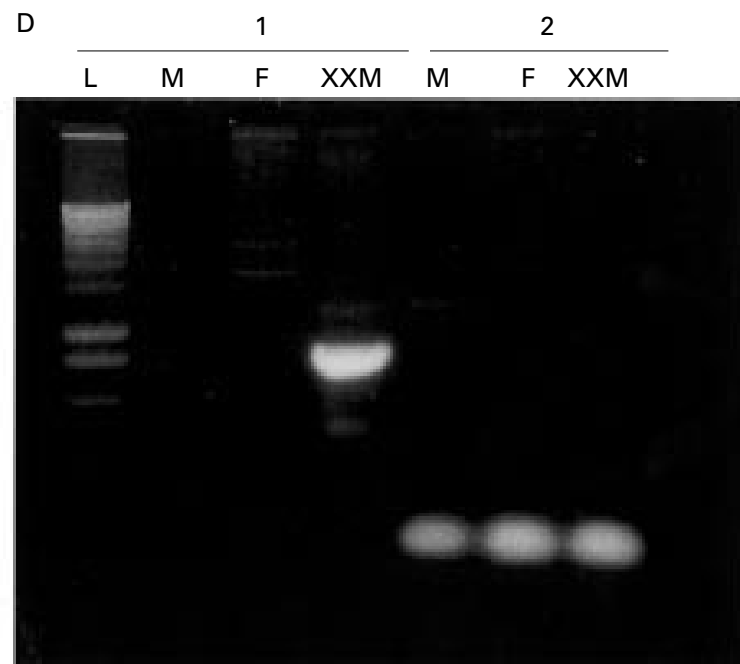

Figure 4 (A) Results of Tsp509I digestion of PCR product obtained with primers $F$ and $R$ (see fig 3) showing that the $X X$ male patient has a male genotype at this point. (B) Results of a PCR with primers $M$ and $N$ (see fig 3) showing amplification of the expected size product (124 bp) from a normal fapanese male but not from a normal fapanese female or the XX male. Since primer $M$ is Y specific at its 3' end, the results indicate that the XX male does not have Yp derived sequence at this point. (C) Results of a PCR with primers $\mathcal{F}$ and $O$ (see fig 3) showing amplification of a unique major 3 $k b$ band in the XX male. This is the secondary PCR subsequent to inverse PCR with primers 7 and $P$. (D1). Results of a $P C R$ showing that primers $\mathcal{F}$ and AC amplify a fragment of expected size ( $800 \mathrm{bp}$ ) in the XX male but not in normal fapanese males and females. This confirms that the fragment is unique and spans the Yp/Xp junction in the XX male. (D2) Results of a PCR using sY46 primers as a control confirmed that all three genomic DNAs could be amplified and generated the expected 200 bp product. 
XX male: CAGCAACATGTATTGAAAATACTGTCTTCTCCCCAATGAATATTCTTAGTGCCTTTGTCAAAAATIAGTTCACTGTAGGTCTGTGGATtTGTATATGGGT $\mathrm{Yp} 11.2$
$\mathrm{Xq} 21.3$

XX male:

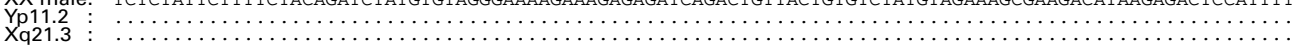

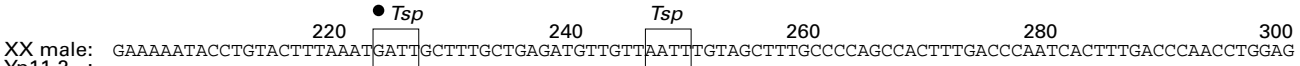

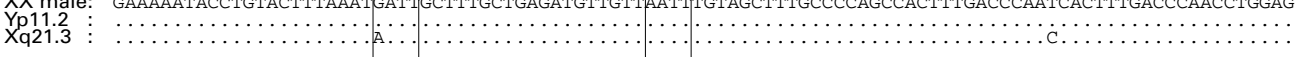

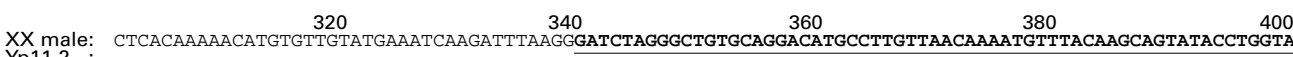
Yp11.2 XX male: $\begin{array}{ccc}420 & 440 & 460\end{array}$

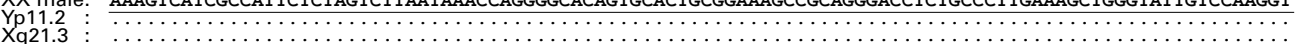
$\begin{array}{cccc}520 & 540 & 560 & 580\end{array}$ XX male:
Yp1 1.2
$\mathbf{X} 21.3$ XX male: GGTAAAAGAGGAAAGCCTCTTGCACTTGAGATAGAGGAAAGCCACTGTCTCCTGCCTGCCCCTGGGAACTGAACGTCTCGGTATAAAACCCGATTGTACA

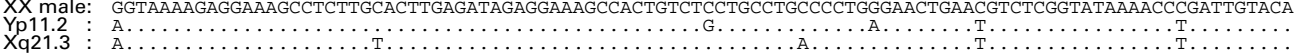
XX male: $\begin{array}{cccc}720 & 740 & 760 & 780\end{array}$

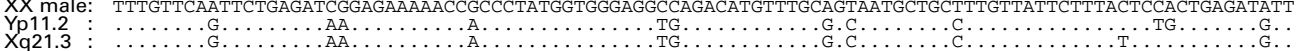
Primer AC

XX male: $820 \quad 860 \quad 860 \quad 880 \quad 900$

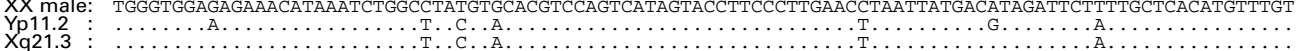

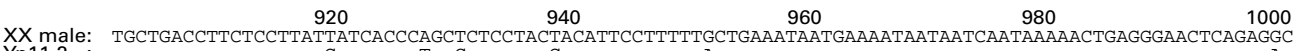

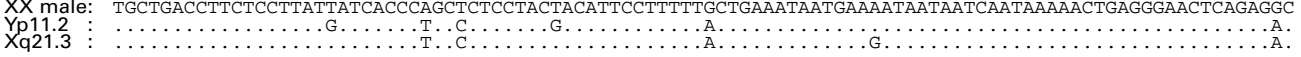
XX male: (Continued): TCAGTCTCTCGTCCCACCCGACTGGAAATACCCACAGGTGTGGAGGGGCAGGCCACCCCTTCACTGAGGGAAGAGAGAGACCCTCTCATAtTGTtTTATG 1194 TTGTTTTATACTCATTACCTGTTTTAAGAAAAACAGCAGGAAGTGAGATCAAAGACAGGCAGCCCGGCGCCAGGCCCGATACCAGGTCTGTGTCTGCCGG 1294 CCCTAAACCCAGTAGTTAAAACTCAACTCATAACTTAGAAACCGATGTTATTCATAGATTCCAGACGTCGTATAGAAGAACACTGCGAAACTCCCTGCCC 1394 CGTTCTGTTTCTCTCTGACACAGGTGCACGCAGCCCCTGTCACGTACCCCTTGCCCGCTCAAATCAATCACGACCCTTTCATGTAAAATCTTTAGTGTTG 1494 TGAGCCCTTAAAAAGGGACAGAAATTGTGCATTTGGAGAGCCGGGATTTTAAGGCAGTAGCTTCCCGATGCTCCCAGCTGAATAAAGCCCTTCCTTCTAC 1594 AGCTTGGTGTCTGAGAGGTTTTGTCTGAGGCTCGTCCTGCTACATTACTTTTGTGGGTTTTTTTTGTTTTTTTTCCAACTTCTTGCTTTTTCTCTCCTCC 1694 TGTCTTGTGAACTAGGCAAGGTGAGGGGACGATGGCAGCAGGAGGAGTACTGGTCTCCTTCCTTAAGAATATCCCTGGAAACTCTCTTTCCCATCTTGCA 1794 CGATGGCAGGTGAAAAAGTTGAGAAGGCAGATACTAAAGAGAAGAAACCTGAAGCCAAGAAGGCTGATGCTGGTGGCGAGGTGAAAAACCGTCACCTCAA 1894

Primer AP

GGCTAAAAGGCCCGAGAAGAGGAAGCCCCATTGCAGCCACAACCGTGTCCTTGTCAGAGGAATTGGCAGGCAATCCCTATATCTCCCGTGTATTCCGGGA 1994 AGGCCGTGTACAAGAGGAAGTACTCAGCCACTAAATCCAACGTTGAAAAGAAGAAGAAGGAGAAGGTTCTTGCGACCGTTACACAACCAGTTGGCGGTGA 2094 CAAGGACGGAGGTACCCGCGTGGTTAAACTTCGCAAAATGCCTAGGTATTATCCTGAAATGCCTACCCTTGTTTTTACTTTAACTTGTTACTTTGAATAT 2194 TGTTCTGCTTGTCTCTTTAATCACCTAGACCTGCTTCTCATGTAAATGAGACTCTCTCTAGGTGGGAAAGCCGGACAAACTCCAATTGACCACTTAATtT 2294 TCAAGACTCTAAGGGCTCCTCACCCAACCCCCTTTCCTAAGGAGTTGGCCTGGGTAAACAGATCCTCAGCATTTCAAACGAGCCCAATTAACTAATAAGG 2394 TACTGGCACCCACAATGTATGAAGTTCCCCAGGAATTTTCCTCCAAGAGATAACAACATAAAACCTTCAGTTTGTGTCCTGCATAGACCGTATATCTAAT 2494 TATAATGAAAGATTTAGAACCTTGCACCTGCTACCGTTGCTCTTCTTGTCACCATTTGTCTTTTAAGTTGTTTATCACTCTGTAACCCTTTTGATtTtTT 2594 TCATTCTTGCATGTTTTTACTTCTCTAGAATTATTACATTTGAGTCCCCCTCCCCTTCCTAAACCTAGGTATAAAAGTTAATGGAGCCCCTTCCACGTGG 2694 CCAAGAGAATTTTGAGCGTTAGCCGTCTCTTTGGCCGCCGGCTTAATAAAGGACTCTTAATTCGTCTCAAAGTGTGGCGTTCTCACTAACTCGCCTGGGT 2794 Primer AR
BamHI
ACGACAATCCTACTGAAGATGTACCAGTTCGCACGTGAGAAAACGGCGAGCCAGCATTATGCCCGGGACCATTCGGATCCTTTTCTTCTGGGACAGAAGT 2894

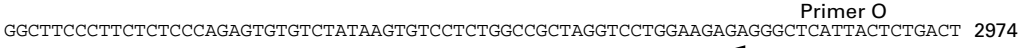

Figure 5 Multiple alignment of part of the sequence of the $3 \mathrm{~kb} Y \mathrm{P} / \mathrm{Xp}$ junction fragment and homologous sequences in $Y p 11.2$ and $X q 21.3$ showing that the XX male has $100 \% Y$ specific sequences for the first 339 bases but the sequence differs from $X q 21.3$ and $Y p$ sequences from position 551. We expect the sequences from position 551 onwards to be Xp22.3 derived. The breakpoint is estimated to be within the region 340-550 (bold and underlined). The sequence of the rest of the junction fragment extending from 1001 to 2974 is shown in the lower part of the figure. A CpG island consisting of 13 Cp $G$ (bold) is underlined. Sequences which do not contain LTR repeats (underlined and italics) were used to design primers $A P / A R$ for radiation hybrid mapping. PCR primers, the BamHI RE site, and relevant Tsp509I RE sites are indicated. The filled circle indicates loss of a Tsp509I RE site in Yp11.2 and in the XX male DNA. The sequence of the junction fragment extending from primer $\mathcal{F}$ to the BamHI RE site has been submitted to EMBL (Accession number AF309278).

position of the breakpoints in this patient relative to markers, genes, and previously described structural abnormalities of Xp22.3.

\section{Radiation hybrid mapping}

The STS BPX was used to amplify the Genebridge 4 radiation hybrid panel. The expected 


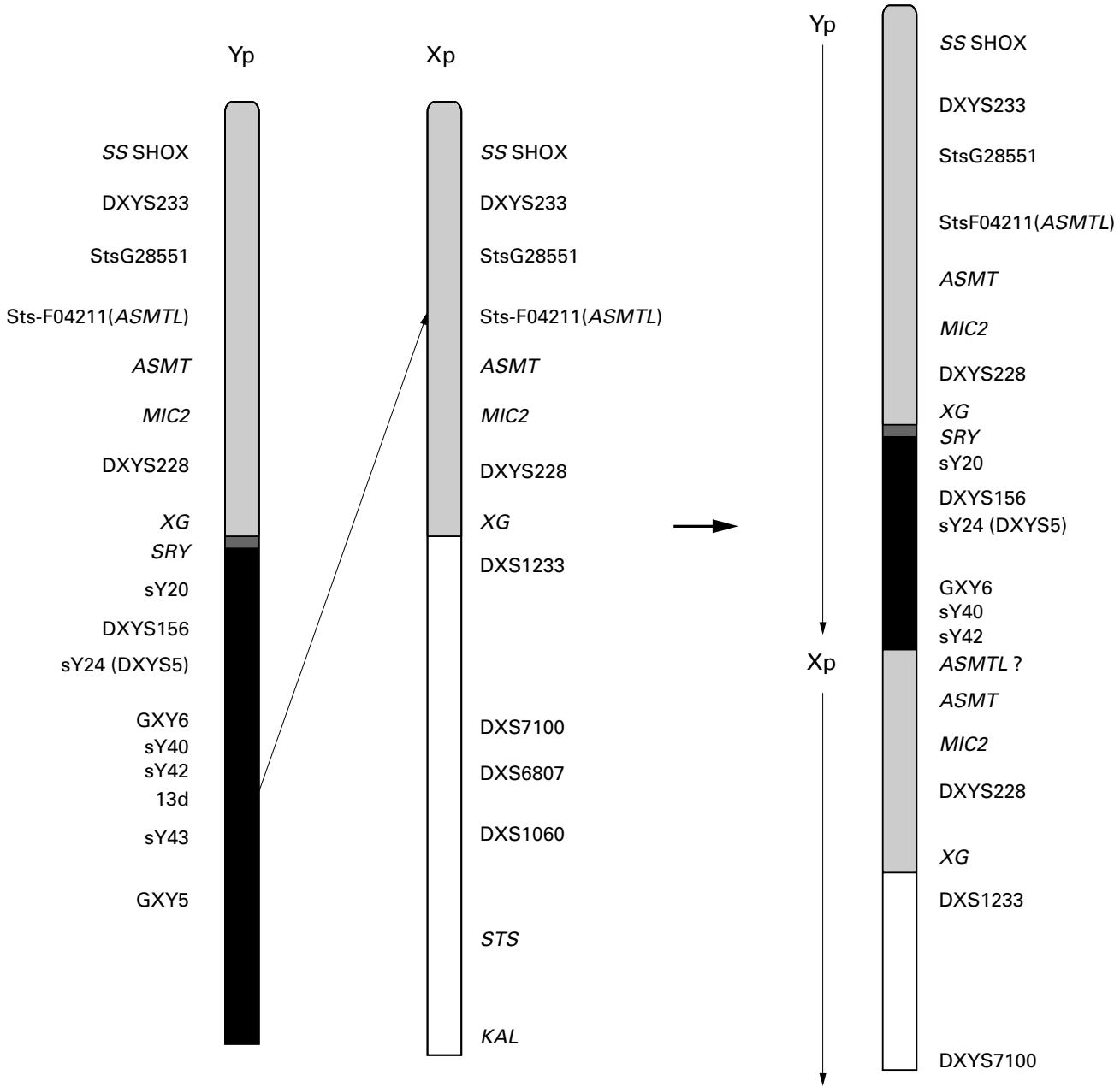

Figure 6 Ideogram showing illegitimate recombination between Yp11.2 (black box) and Xp22.33 (grey box) during paternal meiosis resulting in an abnormal paternal $X$ in the XX male patient. The breakpoint is between sY42 and $13 d$ markers in Yp11.2 and distal to ASMT in Xp22.33. The region comprising the genes XG to ASMT and probably also ASMTL is duplicated in the abnormal paternal $X$ and therefore triplicated in diploid cells of the patient. Grey box

represents the pseudoautosomal regions (PAR1) of $X$ and Y. Dark grey box indicates the male specific SRY gene. Black box indicates Xq21.3/Yp11.2 homology region. Unfilled box shows part of Xp22.3 proximal to PAR1. Relevant markers and genes are indicated. ASMT: acetylserotonin N-methyltransferase. ASMTL: acetylserotonin N-methyltransferase-like. STS: steroid sulphatase deficiency. SS: SHOX short stature gene. KAL: Kallmann syndrome gene. Other genes MIC2 and XG are indicated.

product size (862 bp) was amplified from the human control DNA but not from the mouse and hamster DNA. The positive and negative results of the hybrid amplifications were converted to a vector and submitted to the Sanger Centre web site for two point RHMAP analysis. Lod scores of 20.9 and 16.5 were obtained for the framework markers AFMa284xc9 and AFMb290xg5, respectively. Based on the Genebridge 4 radiation hybrid map, Genemap99, both framework markers are located in PAR1 with AFMa284xc9 being more distal. The Genebridge 4 vectors for these framework markers and their neighbouring markers (stSG28551, sts-F04211, stSG38742, stSG3076, stSG15779, stSG25747, stSG21520) were extracted from the EBI database. Analysis of these vectors positioned BPX between AFMa284xc9 (DXYS233) and AFMb290xg5 (DXYS228), with an identical vector to the markers stSG28551 and sts-F04211 acetylserotonin $\mathrm{N}$-methyltransferase-like ( $A S M T L)$ but distal to acetylserotonin $\mathrm{N}$-methyltransferase (ASMT) (fig 6).

\section{Discussion}

The paternal $\mathrm{X}$ of our patient was the result of abnormal recombination between $\mathrm{Xp}$ and $\mathrm{Yp}$ during male meiosis in an extensive region of retroviral LTR repeats. These particular repeats are in low abundance in the genome and at least $95 \%$ identical between loci on Xp and Yp. Approximately $4 \mathrm{Mb}$ of $\mathrm{Yp}$, including $S R Y$, were translocated to Xp22.33 on the abnormal $\mathrm{X}$ chromosome. Single/double nucleotide differences between the $\mathrm{X}$ and $\mathrm{Y}$ in the region of $\mathrm{X}-\mathrm{Y}$ homology were exploited to determine the origin of STS markers in the XX male by sequencing and restriction enzyme analysis. These differences also allowed the design of primers for Y specific PCR and inverse PCR, leading to the cloning and sequencing of the translocation junction fragment. We were thus able to map the breakpoint on Yp to within a $210 \mathrm{bp}$ interval (between sY42 and 13d) and develop a new STS (BPX) from the putative Xp22.33 derived sequence. The Yp breakpoint lies within $180 \mathrm{~kb}$ of repeats comprising various LTR and LINE elements, with no genes yet described within the immediate 
vicinity. The Xp22.33 STS BPX was mapped to PAR1 between framework markers DXYS233 and DXYS228 using the Genebridge 4 radiation hybrid mapping panel. Fine mapping positioned BPX close to ASMTL and distal to $A S M T$.

This is the second patient to be characterised with a translocation between Yp sequences in the Xq21.3/Yp homology block and the Xp PAR1. In the case described previously, ${ }^{17}$ the Yp breakpoint was defined just telomeric to DXYS5 within the Xq21.3/Yp homology block, and the $\mathrm{Xp}$ breakpoint distal to DXYS28. Thus, this patient ${ }^{17}$ has a smaller contribution from $\mathrm{Yp}$, but an additional $1 \mathrm{Mb}$ from the $\mathrm{X}$ chromosome. Both cases are atypical of $(\mathrm{Y}+) \mathrm{XX}$ males, as they have triplication of PAR1 genes, and in this respect are similar to people with sex chromosome aneuploidies (XXX and XXY). In contrast to Klinefelter (XXY) syndrome, our patient, like other XX males, has stature within the normal female range. Triplication including PAR1 was also found in one subject bearing an isodicentric chromosome derived from $\mathrm{Yp}^{24}$ with mental retardation and in a male patient with a duplication of distal $\mathrm{Xp}^{25}$ with autism who also had severe mental retardation. In contrast, an atypical XXY subject has been described with a partial deletion of the short arm of one X chromosome ${ }^{26}$ without cognitive impairment. These case reports are consistent with the hypothesis that triplication of genes in the proximal part of PAR1 (ASMT, MIC2R, $M I C 2, X G$, possibly $A S M T L$, and any as yet unknown genes) increases the risk of cognitive impairment. However, the cognitive impairment in our patient is somewhat more severe than is generally seen in Klinefelter syndrome in which it is mild and selective to verbal ability. ${ }^{4}$ The relationship of cognitive function to genes in PAR1 therefore remains unclear.

An increased prevalence (two to threefold) of schizophrenia in Klinefelter syndrome (47, $\mathrm{XXY}), 47, \mathrm{XXX}$, and $47, \mathrm{XYY}^{327}$ and an increased incidence of sex chromosome aneuploidies in some populations with psychosis would support the involvement of gene dosage from regions of homology between the sex chromosomes in psychosis. ${ }^{28}$ The patient reported in this study has two regions of the sex chromosome homology triplicated, the proximal part of the PAR1 and the distal part of the Yp11.2/Xq21.3 homology block. The largest class of $\mathrm{Y}(+) \mathrm{XX}$ males is the result of illegitimate recombination in hot spots involving the PRKX/PRKY genes. ${ }^{15} 16$ The breakpoints in these patients involve the transfer of material from the short arm of the $\mathrm{Y}$ chromosome including the $\mathrm{Yp}$ block of $\mathrm{Xq} 21.3 / \mathrm{Yp} 11.2$ homology to the abnormal $\mathrm{X}$ chromosome. There is no evidence of an increased incidence of psychosis in such patients. Therefore, it is unlikely that additional copies of genes normally found in the Xq21.3/Yp11.2 homology block contribute directly to a psychotic phenotype. Although it is possible that triplication of proximal PAR1 gene(s) contributes to psychosis in this patient, the fact that most subjects with supernumerary sex chromosomes do not suffer from psychosis reflects a more complex pathogenesis.

The chromosomal rearrangement in the XX male may affect gene expression in a number of ways. First, increased gene dosage may lead to an abnormally high level of the triplicated gene products, for example, in PAR1 as noted. Second, the rearrangement may disrupt genes or affect expression through a position effect caused by the juxtapositioning of $\mathrm{X}$ and $\mathrm{Y}$ chromosome material. This could lead to either an up or downregulation of PAR1 or transferred Yp genes. Third, the rearrangement may alter any established imprint or X inactivation status of PAR1 or Yp genes. Investigation of these possibilities in this patient may indicate which of the triplicated loci are most likely to be involved in the phenotype.

We are grateful to the UK Medical Research Council, the Stanley Foundation, SANE, and the Denise Callahan Research Fellowship for support and to Dr Mark Ross and Dr Gareth Howell (The Sanger Centre) for advice and for supplying PAC and BAC clones. We are also grateful to Drs B Gao, M Sun, W and BAC clones. We are also grateful to Drs B Gao, M Sun, W $\mathrm{R}$ A Brown, and M H Shen (Biochemistry Department, Oxford
University) for access to their facilities and advice on FISH and University) for access to their facilities and advice on FISH and
to the MRC funded DNA sequencing facility in the Department to the MRC funded DNA sequencing facility in the Department
of Biochemistry, Oxford University. We are grateful to Dr L E of Biochemistry, Oxford University. We are grateful to Dr L E
DeLisi for help in preserving the cell line. CAS and CAB wish to acknowledge the support of PIC (the Pig Improvement Company).

1 Crow TJ, DeLisi LE. The chromosome workshops at the 5th International Congress of Psychiatric Genetics - the weight of the evidence from genome scans. Psychiatr Genet of the evidence

2 DeLisi LE, Craddock NJ, Detera-Wadleigh S, Foroud T, Gejman P, Kennedy JL, Lendon C, Macciardi F, McKeon , Mynett-Johnson L, Nurnberger JI, Paterson A, Schwab S, Van Broeckhoven C, Wildenauer D, Crow TJ. Update on chromosomal locations for psychiatric disorders. Report of the Interim meeting of chromosome Workshop Chairpersons from the VIIth World Congress of Psychiatric Genetics, Monterey, California, 14-18 October 1999. Am F Med Genet (Neuropsychiatr Genet) 2000;96:434-49.

3 Crow TJ. Sex chromosomes and psychosis. The case for a pseudoautosomal locus. Br f Psychiatry 1988;153:675-83.

Crow TJ. Sexual selection, Machiavellian intelligence, and the origins of psychosis. Lancet 1993;342:594-8.

5 Dann J, DeLisi LE, Devoto M, Laval S, Nancarrow DJ, Shields G, Smith A, Loftus J, Peterson P, Vita A, Comazzi M, Invernizzi G, Levinson DF, Wildenauer D, Mowry BJ, Collier D, Powell J, Crowe RR, Andreasen NC, Silverman Collier D, Powell J, Crowe RR, Andreasen NC, Silverman
JM, Mohs RC, Murray RM, Walters MK, Lennon DP, JM, Mohs RC, Murray RM, Walters MK, Lennon DP,
Hayward NK, Albus M, Lerer B, Maier W, Crow TJ. A Hayward NK, Albus M, Lerer B, Maier W, Crow TJ. A linkage study of schizophrenia to markers within
near the $M A O B$ gene. Psychiatr Res 1997;70:131-43.

6 Crow TJ, Poulter M, Lofthouse R, Chen G, Shah T, Bass N, Morganti C, Vita A, Smith C, Boccio-Smith A, Shields G, DeLisi LE. Male siblings with schizophrenia share alleles at the androgen receptor above chance expectation. Am $\mathcal{F} M e d$ Genet (Neuropsychiatr Genet) 1993;48:159-60.

7 DeLisi LE, Devoto M, Lofthouse R, Poulter M, Smith A, Shields G, Bass N, Chen G, Vita A, Morganti C, Ott J, Crow TJ. Search for linkage to schizophrenia on the X and
$\mathrm{Y}$ chromosomes. Am $\mathcal{7}$ Med Genet (Neuropsychiatr Genet) 1994;54:113-21.

8 Laval SH, Dann JC, Butler RJ, Loftus J, Rue J, Leask SJ, Bass N, Comazzi M, Vita A, Nanko S, Shaw S, Peterson P, Shields G, Smith AB, Stewart J, DeLisi LE, Crow TJ. Evidence for linkage to psychosis and cerebral asymmetry (relative hand skill) on the X chromosome. Am f Med Genet (Neuropsychiatr Genet) 1998;81:420-7.

9 DeLisi LE, Shaw S, Sherrington R, Nanthakumar B, Shields GeLisi LE, Shaw S, Sherrington R, Nanthakumar B, Shields S, Smith AB, Wellman N, Larach VW, Loftus J, Razi K, Stewart J, Comazzi M, Vita A, De Hert M, Crow TJ. Fail-
ure to establish linkage on the X chromosome in 301 famiure to establish linkage on the $\mathrm{X}$ chromosome in 301 fami-
lies with schizophrenia or schizoaffective disorder. $A m ~ f$ lies with schizophrenia or schizoaffective disorder.

10 Nanko S. Schizophrenia-like psychosis in a 46,XX male. Folia Psychiatr Neurol fpn 1981;35:461-3.

1 Nanko S. XX males and psychosis. In: Racagni G, Brunello $\mathrm{N}$, Fukuda T, eds. Biological psychiatry. Amsterdam: Elsevier, 1991:485-7

12 Sinclair AH, Berta P, Palmer MS, Hawkins JR, Griffiths BL, Smith MJ, Foster JW, Frischauf AM, Lovell-Badge R, Goodfellow PN. A gene from the human sex-determining region encodes a protein with homology to a conserved DNA-binding motif. Nature 1990;346:240-4

13 Ferguson-Smith MA. X-Y interchange in the etiology of true hermaphroditism and of XX Klinefelter's syndrome. Lancet 1966;ii:475-6.

14 Page DC, Brown LG, de la Chapelle A. Exchange of terminal portions of X- and Y-chromosomal short arms in human XX males. Nature 1987;328:437-40. 
f Med Genet 2001;38:719-723

Division of

Reproductive

Genetics, Albert

Einstein College of

Medicine, Bronx, New

York, USA

P Dar

A A Javed

$M$ Ben-Yishay

J C Ferreira

S J Gross

H M Nitowsky

The Centre for Applied

Genomics,

Department of

Genetics and Genomic

Biology, The Hospital

for Sick Children,

Toronto, Ontario,

Canada

A D Paterson

The Prenatal

Diagnosis Program,

Toronto General

Hospital, Toronto,

Ontario, Canada

D Chitayat

Department of

Molecular Genetics,

Albert Einstein

College of Medicine,

Bronx, New York, USA

B E Morrow

Correspondence to: Dr Dar, 3 Barazani Street No 12, Tel Aviv 69121, Israel, peerdar@yahoo.com

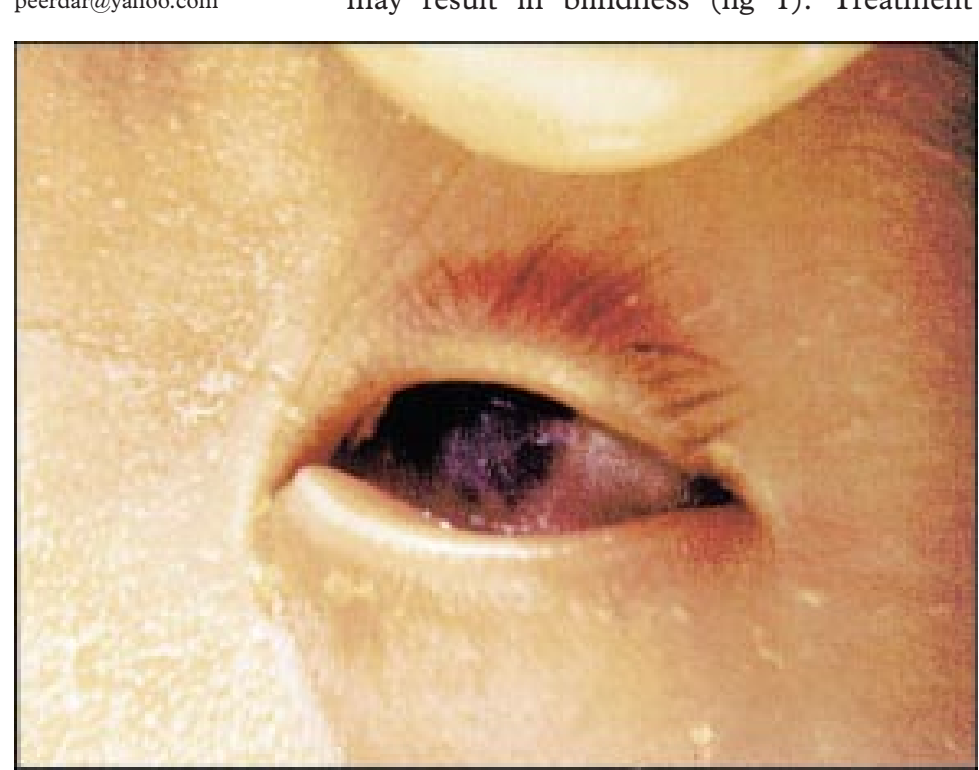

Figure 1 Corneal dermoids as seen immediately after birth in subject IV.8. 43-interva map based on naturally occurring deletions.

21 Sambrook J, Fritsch EF, Maniatis T. Molecular cloning: a
15 Weil D, Wang I, Dietrich A, Poustka A, Weissenbach J, Petit $\mathrm{C}$. Highly homologous loci on the $\mathrm{X}$ and $\mathrm{Y}$ chromosomes are hot-spots for ectopic recombinations leading to XX maleness. Nat Genet 1994;7:414-19.

16 Schiebel K, Winkelmann M, Mertz A, Xu X, Page DC, Weil D, Petit C, Rappold GA. Abnormal XY interchange between a novel isolated protein kinase gene, PRKY, and its homologue, PRKX, accounts for one third of all (Y+) XX males and (Y-)XY females. Hum Mol Genet 1997;6:1985-9.

17 Rouyer F, Simmler MC, Page DC, Weissenbach J. A sex chromosome rearrangement in a human XX male caused by Alu-Alu recombination. Cell 1987;51:417-25.

18 Vollrath D, Foote S, Hilton A, Brown LA, Beer-Romero P, Bogan JS, Page DC. The human Y chromosome: Science 1992;258:52-9.

19 Jones MH, Khwaja OSA, Briggs H, Lambson B, Davey PM, Chalmers J, Zhou CY, Walker EM, Zhang Y, Todd C, Chalmers J, Zhou CY, Walker EM, Zhang Y, Todd C, overlapping yeast artificial chromosome clones spanning the human Y chromosome euchromatin. Genomics 1994; 24:266-75

20 Mumm S, Molini B, Terrell J, Srivastava A, Schlessinger D. Evolutionary features of the 4-Mb Xq21.3 XY homology region revealed by a map at $60-\mathrm{kb}$ resolution. Genome Res 1997;7:307-14 laboratory manual. Cold Spring Harbor, New York: Cold Spring Harbor Laboratory Press, 1989.
22 Zheng YL, Ferguson-Smith MA, Warner JP, FergusonSmith ME, Sargent CA, Carter NP. Analysis of chromosome 21 copy number in cultured amniocytes by fluorescence in situ hybridization using a cosmid contig. Prenat Diagn 1992;12:931-43.

23 Sargent CA, Briggs H, Chalmers IJ, Lambson B, Walker E, Affara NA. The sequence organization of Yp/proximal Xq homologous regions of the human sex chromosomes is highly conserved. Genomics 1996;32:200-9.

24 Chalmers IJ. Molecular analysis of functional variation in the $Y$ chromosome. PhD Thesis, University of Leeds, 1996.

25 Rao PN, Klinepete K, Stewart W, Hayworth R, Grubs R, Pettenati MJ. Molecular cytogenetic analysis of a duplication $\mathrm{Xp}$ in a male: further delineation of a possible sex influencing region on the $\mathrm{X}$ chromosome. Hum Genet 1994;94:149-53.

26 Mark HF, Feldman D, Sigman M. Conventional and molecular cytogenetic identification of a variant Klinefelter syndrome patient with a deleted X chromosome. Pathobiology 1999;67:55-8.

27 DeLisi LE, Friedrich U, Wahlstrom J, Crow TJ. Schizophrenia and sex chromosome anomalies. Schizophrenia Bull 994;20:495-505.

28 Kumra S, Wiggs E, Krasnewich D, Meck J, Smith ACM, Bedwell J, Fernandez T, Jacobsen LK, Lenane M, Rapoport JL. Brief report: association of sex chromosome anomalies with childhood-onset psychotic disorders. $7 \mathrm{Am}$ Acad Child Adolesc Psychiatry 1998;37:292-6.

\section{Potential mapping of corneal dermoids to Xq24-qter}

Peer Dar, Ali A Javed, Myrna Ben-Yishay, Jose C Ferreira, Andrew D Paterson,
Susan J Gross, David Chitayat, Bernice E Morrow, Harold M Nitowsky

EDITOR-Corneal dermoids (CND) (MIM 304730) are rare, congenital, benign tumours involving the cornea. Histologically, the dermoids consist of a combination of ectodermal elements including keratinised epithelium, hair, and sebaceous glands and mesodermal elements including fibrous tissue, fat, and blood vessels in different proportions The tumour is by definition a choristoma since it is histologically a normal tissue in an abnormal site. Clinically, these tumours appear as opacification of the cornea at birth and if untreated may result in blindness (fig 1). Treatment

d limbus, and rarely affect the centre of the cornea. Although most cases are sporadic, familial cases with an autosomal dominant mode of inheritance have been reported. The second form with hereditary dermoids of the cornea is ring dermoids (MIM 180550), an autosomal dominant condition with isolated dermoids at the periphery of the cornea at the limbus. ${ }^{2}$

A third form of congenital dermoids involving the cornea was initially described by our institution in a family of Puerto-Rican ancestry. ${ }^{3}$ The three affected males had congenital, bilateral, and central corneal opacification at birth and no additional abnormalities. ${ }^{4}$ The described pattern of transmission was suggestive of $\mathrm{X}$ linked recessive inheritance. To date, this is the only family described with this inherited form of CND. Previous efforts to localise the gene on the $\mathrm{X}$ chromosome using RFLPs for linkage analysis ${ }^{5}$ gave a lod score of 2.4 at $\theta=0$ with the $\mathrm{DXS} 43 \mathrm{pD} 2$ probe at 
$\mathrm{Xp22.2.} \mathrm{Here,} \mathrm{we} \mathrm{report} \mathrm{the} \mathrm{analysis} \mathrm{of} \mathrm{the}$ extended family to establish linkage.

\section{Case reports}

Twenty three members of a four generation family were ascertained in our centre. Clinical data from the 15 subjects who participated in the previous linkage study ${ }^{5}$ were available to us but blood samples were available for only 10 out of the 15. II. 2 and II.10 declined participation in the current study. In addition, we studied seven family members, including three affected males, not previously described (IV.2, IV.3, IV.5-IV.9). This study was approved by the Albert Einstein College of Medicine Institutional Review Board, in accordance with the guidelines of the Office for the Protection from Research Risks, and informed consent was obtained before participation (CCI 91-157).

All family members including carriers and unaffected members underwent full ophthalmic examination in our centre and ophthalmic records and histopathology slides of affected males were reviewed. We identified six males out of 23 family members who were affected with congenital corneal dermoids. The 17 unaffected family members did not exhibit any medical or ophthalmic condition that could be attributed to or associated with CND. The pattern of transmission is consistent with an $\mathrm{X}$ linked recessive mode of inheritance as indicated by the presence of only affected men, an absence of male to male transmission, and unaffected obligate carrier females (fig 2). In all cases the dermoids appeared as a bilateral, superficial, greyish layer with irregular, raised, whitish plaques and fine blood vessels that covered the centre of the cornea. The peripheral border of the cornea was intact in all cases. The ophthalmic examination of affected males was consistent with the previously described examination of subjects III.8, III.9, and IV.1. ${ }^{34}$ Briefly, ocular examinations showed normal adnexal structures, eyes were orthophoric to Hirschberg testing, and eye movements were conjugate and normal. Schiotz tonometry
II

DXS458 DXS1220 DXS1001 DXS8057 DXS1047 DXS1062 DXS102 DXS102 DXS1232 DXS1205 DXS8028 DXS297

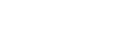

III

DXS458
DXS1220

DXS1001

DXS8057

DXS1047

DXS8094

DXS1062

DXS102

DXS1232

DXS1205

DXS8028

DXS297

DXS8377

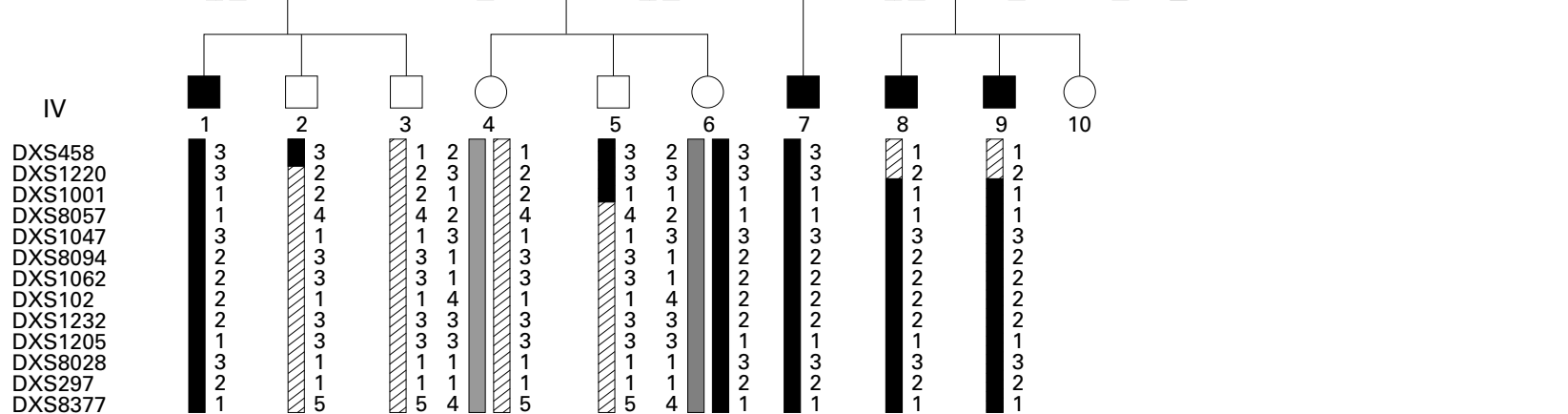

Figure 2 Haplotype analysis of the four generation family segregating X linked CD. The at risk haplotype is blackened to show recombinations. Carrier females are indicated by a black dot within a circle and affected males are indicated by blackened squares. Unblackened squares and circles without a black dot denote unaffected males and females not known to be carriers, respectively. Asterisks show subjects who were analysed in the previous report but for whom blood samples were not available for current linkage analysis. 
Table 1 Two point lod scores between XLCD and markers flanking DXS43pD2 on Xp22.2

\begin{tabular}{|c|c|c|c|c|c|c|c|c|c|c|c|}
\hline \multirow[b]{2}{*}{ Marker } & \multirow[b]{2}{*}{ Band $^{*}$} & \multirow{2}{*}{$\begin{array}{l}\text { Position } \\
(M b)^{\star}\end{array}$} & \multirow{2}{*}{$\begin{array}{l}\text { Female genetic } \\
\text { map }(c M) \dagger\end{array}$} & \multicolumn{7}{|c|}{ Lod score at $\theta=$} & \multirow[b]{2}{*}{$Z \max (\theta)$} \\
\hline & & & & 0.00 & 0.01 & 0.05 & 0.10 & 0.20 & 0.30 & 0.40 & \\
\hline DXS996 & $\mathrm{p} 22.3$ & 5.2 & 8.8 & $-\propto$ & -4.60 & -1.96 & -0.96 & -0.17 & 0.11 & 0.14 & $0.14(0.40)$ \\
\hline DXS237 & $\mathrm{p} 22.3$ & 8.5 & - & $-\propto$ & -5.62 & -2.90 & -1.79 & -0.80 & -0.34 & -0.11 & $-0.11(0.40)$ \\
\hline$K A L 1$ & p22.32 & 9.0 & - & $-\propto$ & -5.13 & -2.44 & -1.38 & -0.49 & -0.13 & 0.00 & $0.00(0.00)$ \\
\hline DXS8036 & - & 9.1 & 23.1 & $-\propto$ & -2.68 & -1.30 & -0.74 & -0.24 & -0.03 & 0.04 & $0.04(0.40)$ \\
\hline DXS987 & $\mathrm{p} 22$ & 16.3 & 22.0 & $-\propto$ & -2.91 & -0.99 & -0.32 & 0.10 & 0.14 & 0.07 & $0.14(0.30)$ \\
\hline DXS207 & $\mathrm{p} 22.2$ & 16.6 & - & $-\propto$ & -7.24 & -3.85 & -2.47 & -1.22 & -0.59 & -0.22 & $-0.22(0.40)$ \\
\hline DXS43 & $\mathrm{p} 22.2$ & 17.5 & - & $-\propto$ & -7.30 & -3.96 & -2.64 & -1.51 & -0.93 & -0.44 & $-0.44(0.40)$ \\
\hline DXS43pD2 & $\mathrm{p} 22.2$ & 17.5 & - & $-\propto$ & -1.31 & -0.08 & 0.30 & 0.44 & 0.31 & 0.12 & $0.44(0.20)$ \\
\hline DXS418 & pter-p21 & 19.6 & - & $-\propto$ & -7.48 & -4.04 & -2.61 & -1.27 & -0.59 & -0.20 & $-0.22(0.40)$ \\
\hline DXS1052 & p22.1 & 24.7 & 32.9 & $-\propto$ & -6.31 & -3.55 & -2.40 & -1.28 & -0.67 & -0.27 & $-0.27(0.40)$ \\
\hline
\end{tabular}

*Obtained from The Genetic Location Database (Collins et al, 1996, http://cedar.genetics.soton.ac.uk/public_html/ldb.html).

†Obtained from Centre for Medical Genetics, Marshfield (Broman et al, 1998, http://www.marshmed.org/genetics/).

$\ddagger$ Lod scores calculated for 22 family members.

ranged from 20 to $22 \mathrm{mmHg}$ bilaterally. Anterior chambers and fundi could not be seen because of the opacification, but intraoperatively were described as normal and clear. The severity of the disease corresponded with the length of time from birth to surgical intervention. All affected subjects had had at least one corneal transplant. Subjects IV.7 and III. 8 had had four and five operations, respectively, and both are considered legally blind.

Microscopic examination of affected corneas was consistent with a dermis-like tissue. It showed a highly vascularised, dense, and irregular collagenous connective tissue in all cases with sparing of the corneal periphery. Hair follicles and hair shafts were present in two cases and sebaceous glands were present in three. The outer layer of stratified squamous epithelium was found to be keratinised in three cases and Bowman's membrane was absent in these cases and in one additional case. The two inner layers, Descemet's membrane and the endothelium, were intact in all cases.

A total of 17 subjects were subjected to genotype analysis. We initially studied the previously reported Xp22.2 locus with the DXS43pD2 probe which detects two PvuII alleles of sizes 6.2 and $5.6 \mathrm{~kb}$ on a genomic Southern blot ${ }^{6}$ and with nine additional microsatellite markers flanking DXS43pD2 at Xp22.1-p22.3. Briefly, polymorphic markers and genetic distances were obtained from the Centre for Medical Genetics, Marshfield ${ }^{7}$ and the Genome Database (http:\|gdbwww.gdb.org). For genotyping, the reverse primers were radiolabelled with $\left[{ }^{32} \mathrm{P}\right]-\mathrm{ATP}$, and the $\mathrm{PCR}$ product was amplified under standard reaction conditions. ${ }^{8}$ The PCR product was denatured by adding $20 \mu \mathrm{l}$ of stop solution containing 5:1 phosphamide:EDTA and then heating for 10 minutes at $65^{\circ} \mathrm{C}$. The radiolabelled PCR products were separated on $6 \%$ acrylamide denaturing sequencing gels, and alleles were assigned according to their molecular weight.

Linkage analysis was performed assuming an $\mathrm{X}$ linked recessive mode of inheritance with complete penetrance and without phenocopies. The frequency of the disease predisposing allele was set to 0.0001 . Marker allele frequencies were estimated from the founders. Disease marker pairwise linkage analysis was performed using MLINK from LINKAGE $v$ $5.2^{9-11}$ using a range of recombination fractions. Linkage analysis for the DXS43pD2 marker included the results of the five additional subjects previously studied with this probe, as the genotyping results and slides were available to us and could be reviewed and confirmed. Multipoint linkage analysis was performed using only markers which are of known order and intermarker recombination fractions using data from the Marshfield genetic map ${ }^{7}$ (http:// www.marshmed.org/genetics/) using LINKMAP from LINKAGE $v$ 5.2..$^{9-11}$ Because of computational limitations, a "shifting" three point analysis was performed. ${ }^{12}$ Analysis of the previously suggested DXS43pD2 probe showed two obligatory meiotic recombination events between the disease locus and the marker in subjects IV.3 and IV.8 not previously tested. Analysis of the additional nine markers flanking DXS43pD2 showed significantly negative lod scores at $\theta=0.00$ and a negative pattern for linkage at Xp22.1-p22.3 (table 1). As disclosed from the new haplotypes, the two point linkage analysis excludes the postulated XLCD locus on Xp22 as the site for the XLCD gene in this family. Thereafter, a systematic genotype analysis was undertaken with 22 microsatellite markers, separated by $5-20 \mathrm{cM}$, spanning the $\mathrm{X}$ chromosome. The disease status in the $\mathrm{X}$ linked CND family came into phase as markers from the $\mathrm{Xq} 24$-qter region were examined (fig 2). A two point linkage analysis gave positive lod scores of 2.9 for DXS102, DXS1232, and DXS8377 at a recombination fraction of $\theta=0.00$ (table 2). The centromeric boundary was defined by the marker DXS1001 on Xq24 (approximately 45 $\mathrm{cM}$ from the telomere). No meiotic crossovers were observed with the 10 markers in the region DXS8057-DXS8377, a 38 cM interval. In agreement with the two point linkage results, multipoint analysis gave a very flat lod score curve with a maximum of 2.92 over the non-recombinant interval between DXS1062/ DXS8094 and DXS8028, a 25 cM interval (fig 3).

\section{Discussion}

In conclusion, we mapped the gene for CND to chromosome Xq24-qter, within a $\sim 45 \mathrm{cM}$ region, by using haplotype and linkage analyses. Although $C N D$ was mapped to a large interval with six markers with lod scores of more than 2.8 at $\theta=0.00$, our findings reemphasise the caution that is required in interpreting linkage results in a single family. The 
Table 2 Two point lod scores between XLCD and markers on Xq21-qter

\begin{tabular}{|c|c|c|c|c|c|c|c|c|c|c|c|}
\hline \multirow[b]{2}{*}{ Marker } & \multirow[b]{2}{*}{ Band $^{\star}$} & \multirow{2}{*}{$\begin{array}{l}\text { Position } \\
(M b) t\end{array}$} & \multirow{2}{*}{$\begin{array}{l}\text { Female genetic } \\
\text { map }(c M) \ddagger\end{array}$} & \multicolumn{7}{|c|}{ Lod score at $\theta=$} & \multirow[b]{2}{*}{$Z \max (\theta)$} \\
\hline & & & & 0.00 & 0.01 & 0.05 & 0.10 & 0.20 & 0.30 & 0.40 & \\
\hline DXS458 & $\mathrm{q} 21.2-23$ & 137.7 & - & $-\propto$ & -5.32 & -2.63 & -1.56 & -0.64 & -0.23 & -0.05 & $-0.05(0.40)$ \\
\hline DXS1220 & q23 & 148.8 & 120.5 & $-\propto$ & -2.87 & -0.95 & -0.27 & 0.16 & 0.19 & 0.09 & $0.19(0.00)$ \\
\hline DXS1001 & $\mathrm{q} 24$ & 150.6 & 130.4 & $-\propto$ & 1.14 & 1.63 & 1.65 & 1.37 & 0.93 & 0.44 & $1.63(0.10)$ \\
\hline DXS8057 & $\mathrm{q} 24$ & 151.0 & 137.4 & 1.89 & 1.84 & 1.62 & 1.33 & 0.73 & 0.15 & -0.16 & $1.89(0.00)$ \\
\hline DXS1047 & $\mathrm{q} 25$ & 151.6 & 143.2 & 2.83 & 2.78 & 2.57 & 2.29 & 1.72 & 1.11 & 0.52 & $2.83(0.00)$ \\
\hline DXS8094 & - & 154.1 & 144.8 & 2.89 & 2.84 & 2.62 & 2.33 & 1.73 & 1.11 & 0.51 & $2.89(0.00)$ \\
\hline DXS1062 & q26 & 154.1 & 144.8 & 2.13 & 2.08 & 1.86 & 1.58 & 0.99 & 0.39 & -0.03 & $2.13(0.00)$ \\
\hline DXS102 & q26.3-27.1 & 154.7 & - & 2.90 & 2.85 & 2.63 & 2.34 & 1.73 & 1.10 & 0.50 & $2.90(0.00)$ \\
\hline DXS1232 & - & 155.2 & 150.2 & 2.90 & 2.85 & 2.63 & 2.34 & 1.73 & 1.10 & 0.50 & $2.90(0.00)$ \\
\hline DXS1205 & - & 155.6 & 154.3 & 2.89 & 2.84 & 2.62 & 2.33 & 1.73 & 1.10 & 0.51 & $2.89(0.00)$ \\
\hline DXS8028 & - & 157.8 & 169.7 & 1.87 & 1.82 & 1.60 & 1.32 & 0.73 & 0.15 & -0.15 & $1.87(0.00)$ \\
\hline DXS297 & q27.3 & 158.1 & - & 2.13 & 2.08 & 1.86 & 1.58 & 0.99 & 0.39 & -0.03 & $2.13(0.00)$ \\
\hline DXS8377 & $\mathrm{q} 28 \dagger$ & 159.2 & - & 2.90 & 2.85 & 2.63 & 2.34 & 1.73 & 1.10 & 0.50 & $2.90(0.00)$ \\
\hline
\end{tabular}

*Obtained from The Genetic Location Database (Collins et al, 1996, http://cedar.genetics.soton.ac.uk/public_html/ldb.html). †Obtained from the Genome Data Base (http://gdbwww.gdb.org).

‡Obtained from Centre for Medical Genetics, Marshfield (Broman et al, 1998, http://www.marshmed.org/genetics/).

addition of new members to this family and their inclusion in the study showed two new recombinations in a locus previously suggested to be linked to the disorder.

The unique features of the corneal dermoids in this family were the bilaterality of the tumours and their localisation in the central matrix of the cornea while sparing the periphery of the cornea, Descemet's membrane, and the endothelial membrane. Since corneal dermoids are considered to be an aberrant development of ectopic tissue in the cornea, it can be speculated that it results from a mutation in a gene that has a role in the normal differentiation of the matrix component of the cornea. The interval found to be linked to CND is currently known to contain 119 genes of which 38 have protein products with

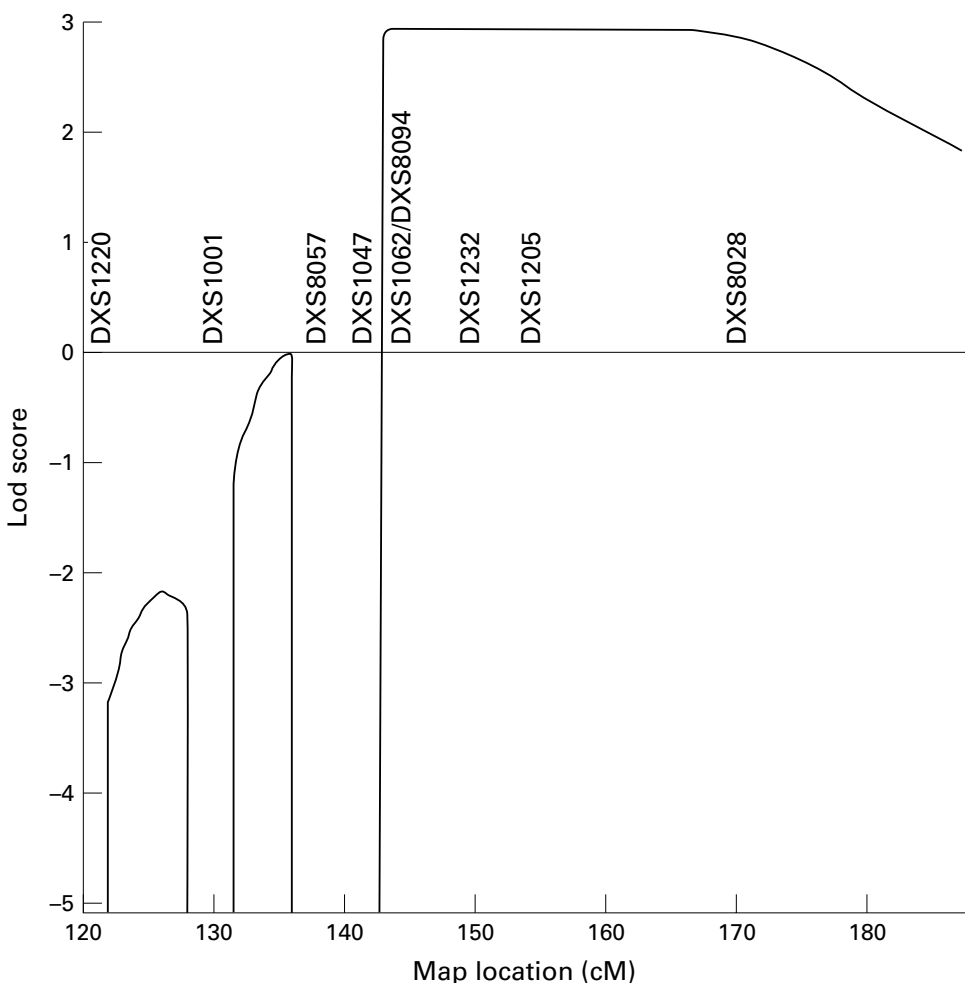

Figure 3 Multipoint analysis of a $70 \mathrm{cM}$ region encompassing the $X$ linked $C D$ locus on Xq24-Xqter. The multipoint Zmax 2.92 was obtained with an interval between DXS1062 and DXS8028, a $25 \mathrm{cM}$ interval. The physical distance of this interval is $3.7 \mathrm{Mb}$ (The Genome Data Base http://gdbwww.gdb.org). unknown function or an abnormal function which has not been implicated in any known disorder. Examination of the known data regarding these genes failed to pinpoint any target gene that may have a role in corneal development. Since there are no additional informative recombinations in this interval, the candidate region cannot be further narrowed and only additional families with XLCD can assist in advancing mapping and identification of the XLCD gene.

- A four generation family with congenital corneal dermoids segregating as an $\mathrm{X}$ linked trait was studied.

- Of 23 family members, bilateral and central dermoid tumours of the cornea were identified at birth in six males.

- Linkage analysis performed for 17 subjects localised the gene for the disease to a $45 \mathrm{cM}$ interval distal to DXS1001.

Electronic database information. Online Mendelian Inheritance in Man, OMIM (TM). McKusick-Nathans Institute for Genetic Medicine, Johns Hopkins University (Baltimore, MD) and National Center for Biotechnology Information, National Library of Medicine (Bethesda, MD), 2000. http:// www.ncbi.nlm.nih.gov/omim/. Center for Medical Genetics, Marshfield, Wisconsin, http://www.marshmed.org/genetics. Genome database, http://gdbwww.gdb.org The Genetic Location Database, Collins et al, 1996, http://cedar genetics.soton ac.ul/ public_html/1db.html A D Paterson is sup

A D Paterson is supported by an MRC (Canada) Program Arant "The Centre for Applied Genomics".

1 Goldenhar M. Associations malformatives de l'oeil et de l'oreille: en particulier, le syndrome: dermoide epibulbaireappendices auriculaires-fistula auris congenita et ses relations avec la dysostose mandibulo-faciale. F Genet Hum 1952;1:243-82.

2 Mattos J, Contreras F, O’Donnell FE Jr. Ring dermoid syndrome. A new syndrome of autosomal dominantly nherited, bilateral, annular limbal dermoids with corneal and conjunctival extension. Arch Ophthalmol 1980;98: 1059-61

3 Henkind P, Marinoff G, Manas A, Friedman A. Bilateral corneal dermoids. Am f Ophthalmol 1973;76:972-7.

4 Topilow HW, Cykiert RC, Goldman K, Palmer E, Henkind P. Bilateral corneal dermis-like choristomas; an $\mathrm{X}$ chromosome-linked disorder. Arch Ophthalmol 1981;99: 1387-91.

5 Igbal MA, Chitayat D, Hahm SYE, Nitowsky HM. Linkage of gene for corneal dermoids with the DXS43 (Xp22.2p22.1) locus. Am f Hum Genet 1987;41:A171.

6 Norby S, Schwartz M. Assignment of the locus order DXS28-DXS67-DMD as a spin-off from diagnostic DNA marker analysis in a family with Duchenne muscular marker analysis in a family with

7 Broman KW, Murray JC, Sheffield VC, White RL, Weber JL. Comprehensive human genetic maps: individual and JL. Comprehensive human genetic maps: individual and
sex-specific variation in recombination. Am $\mathcal{f}$ Hum Genet sex-specific variati
1998;63:861-9. 
8 Morrow B, Goldberg R, Carlson C, Das Gupta R, Sirotkin H, Collins J, Dunham I, O'Donnell H, Scambler P, 22q11 deletions in velo-cardio-facial syndrome. Am f Hum $22 \mathrm{q} 11$ deletions in velo-card

9 Lathrop GM, Lalouel JM, Julier C, Ott J. Strategies for multilocus linkage analysis in humans. Proc Natl Acad Sci USA 1984;81:3443- 6

10 Lathrop GM, Lalouel JM, Julier C, Ott J. Multilocus linkage analysis in humans: detection of linkage and estimation of recombination. Am f Hum Genet 1985;37:482-98.
11 Terwilliger JD, Ott J. Handbook of human linkage analysis. Baltimore: Johns Hopkins University Press, 1994.

$12 \mathrm{Xu}$ J, Meyers D, Freije D, Isaacs S, Wiley K, Nusskern D, Ewing C, Wilkens E, Bujnovszky P, Bova GS, Walsh P, Isaacs W, Schleutker J, Matikainen M, Tammela T, Visakorpi T, Kallioniemi OP, Berry R, Schaid D, French A, McDonnell S, Schroeder I, Blute M, Thibodeau S, Trent J. Evidence for a prostate cancer susceptibility locus on the X chromosome. Nat Genet 1998;20:175-9.

\title{
Satellites on the terminal short arm of chromosome $12(12 \mathrm{ps})$, inherited through several generations in three families: a new variant without phenotypic effect
}

\author{
Lionel Willatt, Andrew J Green, Dorothy Trump
}

EDITOR-Five of the human autosomes are acrocentric, chromosomes 13, 14, 15, 21, and 22 , and are identified by the presence of satellited short arms. These short arms contain three bands, p11, p12, and p13, ${ }^{1}$ and are composed of repetitive DNA containing satellite repeats and copies of ribosomal RNA genes. Band $\mathrm{p} 11$, the pericentromeric region, is composed of several types of tandemly repeated DNA including satellites I, II, III, and IV, and $\beta$ satellite DNA. ${ }^{2-4}$ Band $\mathrm{p} 12$, the satellite stalks, contains multiple copies of genes coding for ribosomal $\mathrm{RNA}^{5}$ and is known as the nucleolar organiser region (NOR) as the nucleolus is formed by an aggregation of ribosomal RNA. This can be recognised by staining with silver nitrate (AgNOR staining) ${ }^{6}$ Band p13 contains $\beta$ satellite DNA and terminal telomeric sequences. ${ }^{27}$

Loss or gain of the short arm of acrocentric chromosomes occurs without apparent phenotypic effect. For example, Robertsonian translocations occur when two acrocentric chromosomes are joined by centric fusion with the resulting loss of the short arm material and have no associated phenotype in this euchromatically balanced form. ${ }^{8}$ Chromosomal rearrangements involving the short arms of acrocentric chromosomes are a well known form of chromosomal variation. The most common variation results from rearrangements between the short arms of acrocentric chromosomes. Thus, the satellites of acrocentric chromosomes range in size from no satellites to double or treble satellites as shown by AgNOR staining. ${ }^{8}$ Translocations between the short arm of an acrocentric chromosome and the heterochromatic region of the long arm of the Y chromosome, resulting in acrocentric chromosomes with $\mathrm{Y}$ chromosome heterochromatin in place of satellites and satellited Y chromosomes, are also observed..$^{9}$ More rarely, non-acrocentric chromosomes with terminal satellites have been described which arise from a translocation between the short arm of an acrocentric and the terminal region of another chromosome. ${ }^{11-19}$ Interstitial insertion of NORs from an acrocentric chromosome into another chromosome, giving rise to non-acrocentric chromosomes with interstitial satellites, is a rare form of chromosomal rearrangement without phenotypic effect. ${ }^{19-24}$ In contrast to these variant chromosomes, satellited non-acrocentric chromosomes resulting from an insertion or translocation between an acrocentric chromosome and another chromosome, in which there is loss of material from the non-acrocentric chromosome, are associated with an abnormal phenotype..$^{25}$ When a satellited non-acrocentric chromosome is observed it is essential to distinguish between these two possibilities.

We describe three pedigrees in which multiple family members have NORs at the telomeric region of the short arm of one chromosome 12 (12ps).

\section{Case reports}

In family 1 , parental chromosome studies were undertaken following a stillbirth at 38 weeks. These studies showed a chromosome 12 with positively NOR staining satellite stalks at the end of the short arm (12ps) in the mother, who had an otherwise normal female chromosome complement. The paternal karyotype was normal. Family studies showed that this satellited chromosome had been inherited from her mother. Each of these women was well with no associated phenotype. There was no other significant family history (fig 1 ).

In family 2, chromosome analysis of an amniotic fluid sample received for maternal age showed a male karyotype with positively NOR staining satellite stalks at the end of the short arm of one chromosome 12 (12ps). Parental chromosome analysis showed that the $12 \mathrm{ps}$ chromosome was paternal in origin with no associated phenotype. The family history was unremarkable. The pregnancy proceeded to term and the child at the age of 3 years has no developmental problems (fig 1).

In family 3, a chromosome 22 (tuple 1) microdeletion was identified in a 3 month old child with tetralogy of Fallot and dysmorphic facies, consistent with DiGeorge/VCF syndrome. Parental chromosome studies showed that the microdeletion was de novo. However, the father was found to have one chromosome 12 with positively NOR staining satellite stalks at the end of the short arm (12ps) with no 
Family 1

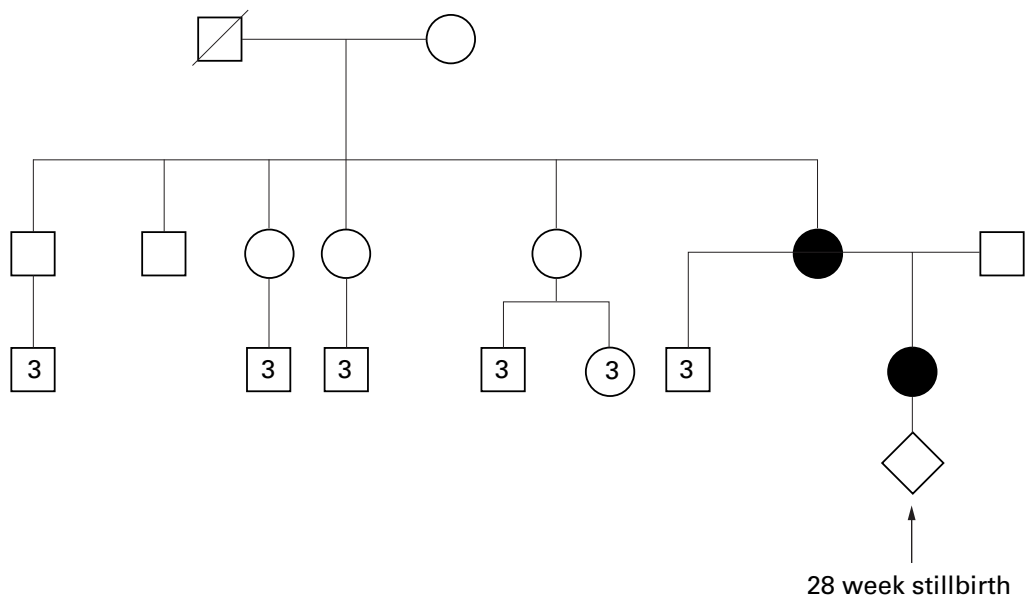

Family 2

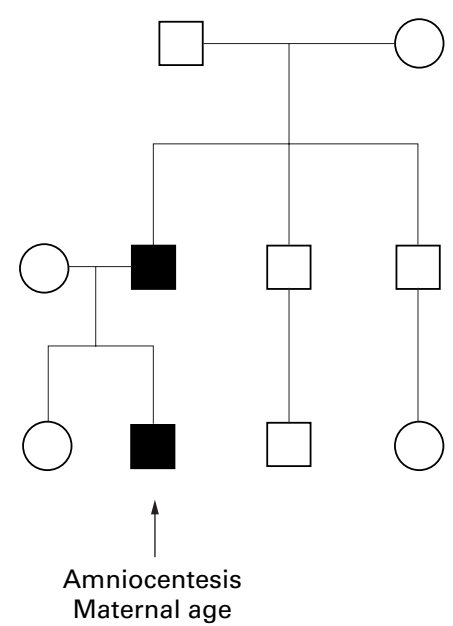

Family 3

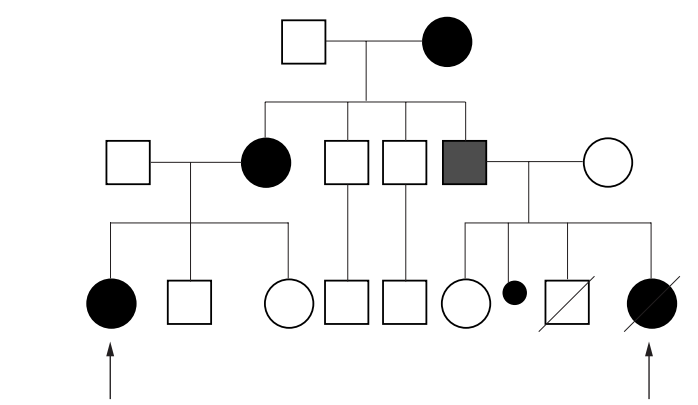

Short stature

$\operatorname{Del}(22)(q 11.2 q 11.2)$

Figure 1 Pedigrees of families 1, 2, and 3. Subjects who carry the satellited chromosome 12 (12ps) are shown by filled symbols.

associated phenotype. The $12 \mathrm{ps}$ chromosome was not present in the index case (fig 1).

In a fourth family, a 13 year old girl was referred with short stature. Blood chromosome analysis showed the presence of positively NOR staining satellite stalks at the end of the short arm of one chromosome 12 (12ps). The remainder of the karyotype was normal and there was no evidence of mosaicism for $45, \mathrm{X}$ in
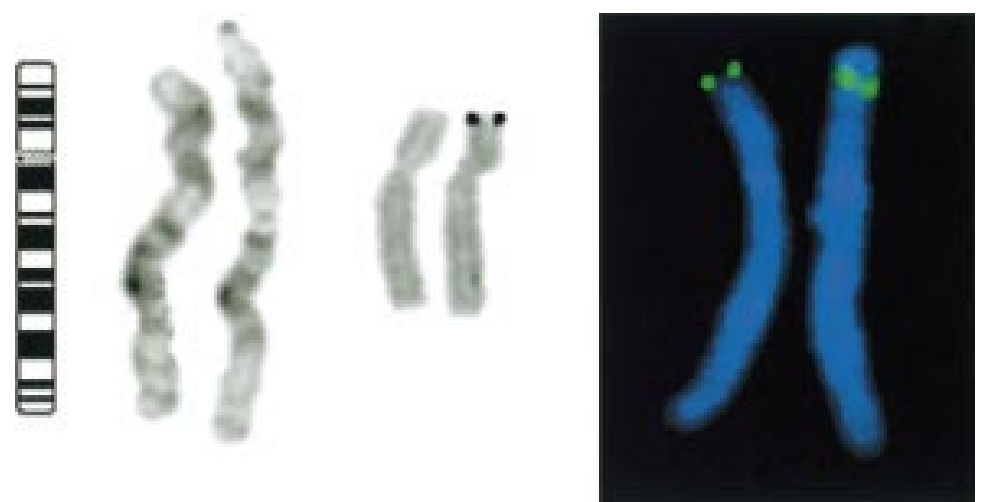

Figure 2 (Left) GTL banding. (Middle) AgNOR staining. (Right) Subtelomeric probe $V I \mathcal{F}^{2}$.
30 cells examined. Parental karyotyping indicated that the chromosome 12 with positively NOR staining satellite stalks was maternally derived. The mother was of normal height and there was no family history of short stature. This family was subsequently identified as part of family 3 (fig 1).

Chromosome studies including GTL banding, silver staining (AgNOR), and fluorescence in situ hybridisation (FISH) studies were performed by standard techniques. ${ }^{6}$

\section{Results}

GTL banding showed no detectable loss of material from the satellited chromosome 12 in any of the families, with band p13 still present (fig 2, left). Silver (AgNOR) staining confirmed the presence of NOR positive material (fig 2, middle). The NOR bearing satellited chromosome took part in NOR associations with acrocentric chromosomes. The alpha satellite (centromeric) probes for the acrocentric chromosomes 13/21 (D13Z1), 14/22, and 15 did not hybridise to the satellited chromosome 12 , thus confirming it was monocentric. FISH studies with the chromosome 12 short arm 
subtelomeric probe $\mathrm{VIJ}^{227}$ showed no detectable loss of material from the 12 ps chromosome (fig 2, right).

\section{Discussion}

We have described three families in which a satellited chromosome 12 (12ps) is inherited. There was no evidence for loss or gain of genetically significant material. The clinical indication for chromosome analysis of the proband was different in each case and both maternal and paternal transmission of the satellited chromosome was evident. In view of the lack of a consistent phenotype in the probands and the normal phenotype in the heterozygous parents, this satellited chromosome 12 appears to be a previously undescribed heritable variant chromosome, without phenotypic effect. Our detection of this rare variant in these three families makes it probable that they are related, especially as they all share a travelling, semi-nomadic lifestyle.

It is notable that the majority of reported cases of familial satellited non-acrocentric autosomes have been identified at prenatal diagnosis for maternal age, as was the case for family 2 in the present study. ${ }^{11-19}$ When a satellited non-acrocentric chromosome is identified at prenatal diagnosis, it is essential to distinguish between significant loss or gain of material and variant chromosomes. In some cases, satellited non-acrocentric chromosomes identified at prenatal diagnosis have been shown to be unbalanced products of a parental balanced translocation ${ }^{25} 26$ and the satellited chromosome in the proband has been associated with an abnormal phenotype. Gene density is high in the subtelomeric regions of chromosomes so particular care has to be taken before deciding that the integrity of this region has been maintained. In particular, cases of WolfHirschhorn and cri du chat syndromes involving a satellited short arm of chromosomes 4 or 5 respectively have been frequently reported. ${ }^{27-29}$ In the family with a satellited 4 (qs) variant, described by Babu et al ${ }^{30}$ the index case had an interstitial deletion of chromosome 4 in the region adjacent to the satellites (q35), thus explaining his developmental problems. Careful conventional banding analysis, exclusion of loss of subtelomeric regions by using commercially available subtelomeric FISH probes, and the demonstration of inheritance of the identical rearrangement from a phenotypically normal parent should provide reassurance. In the family described by Mihelick et al, ${ }^{31}$ the proband had craniorachischisis whereas other family members who carried the satellited chromosome 4 (qs) had a normal phenotype. This family was studied before the advent of FISH and it is probable that the craniorachischisis was a coincidental finding. The satellited chromosome 10 (qs) described by Storto et $a l^{18}$ was unusual in being present in mosaic form in the father. This chromosome 10 with satellites must presumably have occurred for the first time in the father. Interestingly, as far as we are aware, there are no other published reports of de novo satellited non-acrocentric variant chromosomes. The lack of a clinical phenotype, and the normal hybridisation analysis with the chromosome $12 p$ subtelomeric probe would indicate that there has been no loss of the subtelomeric region of $12 p$ in these families. However, it is impossible to exclude the possibility that this rearrangement is an interstitial insertion of a NOR into the most subtelomeric part of $12 \mathrm{p}$, rather than a terminal attachment to $12 \mathrm{p}$. The satellited chromosome 12 reported in the present study is different from the familial dicentric satellited chromosome 12 variant described by Watt et al. ${ }^{20}$ In their family, satellite material and a centromere from an acrocentric chromosome had been interstitially inserted into the proximal short arm of chromosome 12 .

The case described by Miller et $a l^{14}$ was unusual in that the satellited chromosome 4 (qs) did not stain with AgNOR staining in the proband, but was NOR positive in other family members including the father of the fetus. As judged by silver (AgNOR) staining, not all NORs are active in every cell. Of the 10 NORs present on the acrocentric chromosomes, most people have between four and seven that are active per cell. ${ }^{32}$ The satellited 4 (qs) in the proband appeared morphologically the same as in the other family members. It is possible that examination of more cells in the proband would have shown AgNOR staining in some cells. The possibility that the satellited chromosome 4 (qs) in the proband had lost its NOR activity cannot be excluded.

When a chromosome anomaly appears to be an apparently harmless variant, then there may be a dilemma regarding further family follow up. Taking blood samples for chromosome analysis may raise anxiety in the family needlessly and might also be a time consuming exercise. This has to be balanced against the problems associated with the unexpected finding of a satellited chromosome at prenatal diagnosis.

The satellites on acrocentric chromosomes show a considerable variation in size in the population. This is considered to arise from unequal recombination between acrocentric short arms at meiosis occurring in these regions of sequence homology. The close proximity of the repetitive sequences of the acrocentric chromosomes in a common nucleolus is also likely to favour recombination, even in mitosis. ${ }^{33}$ It is likely, for example, that the case of mosaic satellited chromosome 10 (qs) described by Storto et $a l^{18}$ arose mitotically. Rearrangements resulting in nonacrocentric chromosomes may also arise because of sequence homology at the breakpoints and scattered within the genome are repeat sequences with homology to the acrocentric repetitive DNA. ${ }^{34}$ Furthermore, there is strong homology between the satellite sequences of acrocentric chromosomes and the subtelomeric repetitive sequences on some autosomes. ${ }^{35}$ It is possible that these variants arise from abnormal pairing and subsequent crossing over at meiosis between the satellites of acrocentric chromosomes and complementary subtelomeric sequences. Sequences similar to the D4Z4 complex repeat associated with FSHD, which maps to $4 \mathrm{q} 35$, are found on the 
short arm of acrocentric chromosomes ${ }^{36}$ and it is of interest that chromosome 4 (4qs) is the most frequently described satellited variant chromosome.

Description and proper evaluation of these rare variants is vital when counselling subjects and families in whom a satellited chromosome is found, particularly when detected prenatally.

- We describe three apparently unrelated families in whom a translocation of a nucleolar organiser region (NOR) onto the short arm of chromosome 12 has been inherited through several generations.

- Conventional banding and FISH studies showed no detectable loss of material from this satellited chromosome 12 (12ps).

- There was no evidence of reproductive problems or phenotypic effects in the carriers of this satellited chromosome 12 , indicating that it is a previously unreported variant chromosome.

1 ISCN (1995). Basel: Karger, 1995.

2 Greig GM, Willard HF. $\beta$ satellite DNA: characterization and localization of two subfamilies from the distal and proximal short arms of the human acrocentric chromosomes. Hum Genet 1992;12:573-80.

3 Tagarro I, Wiegant J, Raap AK, Gonzalez-Aguilera JJ, Fernandez-Perlatt AM Assignment of human satellite Fernandez-Perlatta AM. Assignment of human satellite DNA as revealed by fluorescent in situ hyb

4 Tagarro I, Fernandez-Perlatta AM, Gonzalez-Aguilera JJ. Chromosomal localisation of human satellites 2 and 3 by a FISH method using oligonucleotides as probes. Hum Gene 1994;93:383-8.

5 Evans HG, Buckland RA, Pardue ML. Localisation of the genes coding for $18 \mathrm{~S}$ and $28 \mathrm{~S}$ ribosomal RNA in the human genome. Chromosoma 1974;48:405-26.

6 Rooney DE, Czepulkowski BH. Human cytogenetics, a practical approach. Vol 1. New York: IRL Press, 1992.

7 Moyzis RK, Buckingham JM, Scott Cram L, Dani M, Deaven LL, Jones MD, Meyne J, Ratliff RL, Wu JR. A highly conserved repetitive DNA sequence, (TTAGGG)n, present at the telomeres of human chromosomes. Proc Natl present at the telomeres of hum

8 Gardner RJM, Sutherland GR. Chromosome abnormalities and genetic counselling. 2nd ed. Oxford: Oxford University Press, 1996.

9 Cohen MM, Fredrick RW, Balkin NE, Simpson NJ. The identification of $\mathrm{Y}$ chromosome translocations following distamycin A treatment. Clin Genet 1981;19:335-42.

10 Neumann AA, Robson LG, Smith A. A 15p+ variant shown to be a $\mathrm{t}(\mathrm{Y} ; 15)$ with fluorescence in situ hybridisation. Ann Genet 1992;35:227-30.

11 Elliot J, Barnes ICS. A satellited chromosome 2 detected at prenatal diagnosis. 7 Med Genet 1992;29:203.

12 Habibian R., Hajianpour MJ, Shaffer LG, Niedenard L, Hajianpour AK. Genotype-phenotype correlation in satellited $1 \mathrm{p}$ chromosome: importance of fluorescence in situ hybridization (

13 Arn PH, Younie L, Russo S, Zackowski JL, Mankinen C, Estabrooks L. Reproductive outcome in 3 families with a satellited chromosome 4 with review of the literature. Am $\mathcal{F}$ Med Genet 1995;57:420-4.

14 Miller I, Songster G, Fontana S, Hsieh CL. Satellited 4q identified in amniotic fluid cells. Am f Med Genet 1995;55 237-9.
15 Lamb AN, Pettanati M, Hanna J, Krasikov N, Neu R, Rao $\mathrm{N}$, Weinstein M, Weiser J, Estabrooks L. Six cases of satel-
lited long arm of chromosome 2 detected during prenatal chromosome diagnosis. Am ₹ Hum Genet Suppl 1995;57: chrom

16 Shah HO, Verma RS, Conte RA, Chester M, Shklovskaya TV, Kleyman SM, Diaz-Barrios V, Feldman B, Lin JH, Sherman J. Fishing for the origin of satellite on the long arm of chromosome 4. Am F Hum Genet Suppl 1997;61: A375.

17 Killos LD, Lese CM, Mills PL, Precht KS, Stanley WS, Ledbetter DH. A satellited $17 \mathrm{p}$ with telomere deleted and no apparent clinical consequence. Am f Hum Genet Suppl 1997;61:A130.

18 Storto PD, Diehn TN, O'Malley DP, Bullard BA, Netzloff ML, VanDyke DL, Feldman GL, Precht KS, Ledbetter DH, Lese CM. Satellited chromosome 10 detected prenatally in a fetus and confirmed as mosaic in a parent. Prenat Diagn 1999;19:1088-9.

19 Guttenbach M, Haaf T, Steinlein C, Caesar, Schinzel A, Schmid M. Ectopic NORs on human chromosomes 4 qter and 8q11: rare chromosomal variants detected in two famiand 8q11: rare chromosomal variants

20 Watt JL, Couzin DA, Lloyd DJ, Stephen GS, McKay E. A familial insertion involving an active nucleolar organise within chromosome 12. F Med Genet 1984;21:379-84

21 Prieto F, Badia L, Beneyto M, Palau F. Nucleolus organiser regions (NORs) inserted in 6q15. Hum Genet 1989;81:289(90.

22 Park VM, Gustashaw KM, Wathen TM. The presence of interstitial telomeric sequences in constitutional chromosome abnormalities. Am f Hum Genet 1992;50:914-23.

23 Norris FM, Mercer B, Pertile MD. Interstitial insertion of NORs into Yq and 22q: two case studies. Bull Hum Genet Soc Australasia 1995;8:48.

24 Guttenbach M, Nassar N, Feichtinger W, Steinlein C, Nanda I, Wanner G, Kerem B, Schmid M. An interstitial nucleolus organiser region in the long arm of chromosome 7: cytogenetic characterisation and familial segregation. 7: cytogenetic characterisation and

25 Faivre L, Morichon-Delvallez, Viot G, Larger-Piet A, Narcy F, Turleau C, Pinson MP, Dumez Y, Munnich A, Vekemans M. Prenatal diagnosis of a satellited nonacrocentric chromosome derived from a maternal translocation $(10 ; 13)(\mathrm{p} 13 ; \mathrm{p} 12)$ and review of literature. Prenat Diagn 1999;19:282-6.

26 Chen CP, Devriendt K, Chern SR, Lee CC, Wang W, Lin SP. Prenatal diagnosis of inherited satellited nonacrocentric chromosomes. Prenat Diagn 2000;20:384-9.

27 Vocero-Akbani A, Helms C, Wang JC, Sanjurjo FJ, Korte-Sarfarty J, Veile RA, Liu L, Jauch A, Burgess AK, Ahrent L, Chen M, Gavin MR, Iannantuoni K, Morton SM, Pandit SD, Read CM, Steinbrueck T, Warlick C, Smoller DA, Donis-Keller $H$. Mapping human telomere Smoller DA, Donis-Keller H. Mapping human telomere rens specific morphisms for 14 proterminal regions. Genomics 1996;36: 492-506.

28 Niebuhr E. The cri du chat syndrome. Epidemiology, cytogenetics and clinical features. Hum Genet 1978;44:22775 .

29 Dev VG, Byrne J, Bunch G. Partial translocation of NOR and its activity in a balanced carrier and her cri-du-chat fetus. Hum Genet 1979;51:121-36.

30 Babu VR, Roberson JR, Van Dyke DL, Weiss L. Interstitial deletion of $4 \mathrm{q} 35$ in a familial satellited $4 \mathrm{q}$ in a child with developmental delay. Am f Hum Genet Suppl 1984;41:A13

31 Mihelick K, Jackson-Cook C, Hays P, Flannery DB, Brown A. Craniorachischisis in a fetus with familial satellited 4q. Am f Hum Genet Suppl 1984;36:105S.

32 Varley JM. Patterns of silver staining of human chromosomes. Chromosoma 1977;61:207-14.

33 Giussani U, Facchinetti B, Cassina G, Zuffardi O. Mitotic recombination among acrocentric chromosomes short arms. Ann Hum Genet 1996;60:91-7.

34 Sylvester JE, Gonzalez IL. Sequence analysis of $8.3 \mathrm{~kb}$ of DNA adjacent to the distal side of the human ribosomal gene. Am 7 Hum Genet 1996;59(suppl 14):A313.

35 Thoraval D, Asakawa J, Kodaira M, Chang C, Radany E, Kuick R, Lamb B, Richardson B, Neel JV, Glover T, Hanash S. A methylated human 9 -kb repetitive sequence on acrocentric chromosomes is homologous to a subtelomeric repeat in chimpanzees. Proc Natl Acad Sci USA 1996;93:4442-7.

36 Lyle R, Wright TJ, Clark LN, Hewitt JE. The FSHDassociated repeat $\mathrm{D} 4 \mathrm{Z} 4$, is a member of a dispersed family of homeobox-containing repeats, subsets of which are clustered on the short arms of the acrocentric chromosomes. Genomics 1995;28:389-97. 